Portland State University

PDXScholar

Summer 9-18-2014

\title{
Bicycle Level of Service: Where are the Gaps in Bicycle Flow Measures?
}

Pamela Christine Johnson

Portland State University

Follow this and additional works at: https://pdxscholar.library.pdx.edu/open_access_etds

Part of the Transportation Commons, and the Urban, Community and Regional Planning Commons Let us know how access to this document benefits you.

\section{Recommended Citation}

Johnson, Pamela Christine, "Bicycle Level of Service: Where are the Gaps in Bicycle Flow Measures?" (2014). Dissertations and Theses. Paper 1975.

\subsection{0/etd.1974}

This Thesis is brought to you for free and open access. It has been accepted for inclusion in Dissertations and Theses by an authorized administrator of PDXScholar. For more information, please contact pdxscholar@pdx.edu. 
Bicycle Level of Service:

Where are the Gaps in Bicycle Flow Measures?

by

Pamela Christine Johnson

A thesis submitted in partial fulfillment of the requirements for the degree of

Master of Science

in

Civil and Environmental Engineering

Thesis Committee:

Miguel Figliozzi, Chair

Christopher Monsere

Robert L. Bertini

Krista Nordback

Portland State University

2014 


\begin{abstract}
Bicycle use is increasing in many parts of the U.S. Local and regional governments have set ambitious bicycle mode share goals as part of their strategy to curb greenhouse gas emissions and relieve traffic congestion. In particular, Portland, Oregon has set a $25 \%$ mode share goal for 2030 (PBOT 2010). Currently bicycle mode share in Portland is $6.1 \%$ of all trips. Other cities and regional planning organizations are also setting ambitious bicycle mode share goals and increasing bicycle facilities and programs to encourage bicycling. Increases in bicycle mode share are being encouraged to increase. However, cities with higher-than-average bicycle mode share are beginning to experience locations with bicycle traffic congestion, especially during peak commute hours. Today, there are no established methods are used to describe or measure bicycle traffic flows.
\end{abstract}

In the 1960s, the Highway Capacity Manual (HCM) introduced Level of Service (LOS) measurements to describe traffic flow and capacity of motor vehicles on highways using an A-to-F grading system; "A" describes free flow traffic with no maneuvering constraints for the driver and an " $F$ " grade corresponds to over capacity situations in which traffic flow breaks down or becomes "jammed". LOS metrics were expanded to highway and road facilities, operations and design. In the 1990s, the HCM introduced LOS measurements for transit, pedestrians, and bicycles. Today, there many well established and emerging bicycle level of service (BLOS) methods that measure the stress, comfort and perception of safety of bicycle facilities. However, it was been assumed that bicycle traffic volumes are low and do not warrant the use of a LOS 
measure for bicycle capacity and traffic flow. There are few BLOS methods that take bicycle flow into consideration, except for in the case of separated bicycle and bicyclepedestrian paths.

This thesis investigated the state of BLOS capacity methods that use bicycle volumes as a variable. The existing methods were applied to bicycle facility elements along a corridor that experiences high bicycle volumes in Portland, Oregon. Using data from the study corridor, BLOS was calculated and a sensitivity analysis was applied to each of the methods to determine how sensitive the models are to each of the variables used. An intercept survey was conducted to compare the BLOS capacity scores calculated for the corridor with the users' perception. In addition, 2030 bicycle mode share for the study corridor was estimated and the implications of increased future bicycle congestion were discussed. Gaps in the BLOS methods, limitations of the thesis study and future research were summarized.

In general, the existing methods for BLOS capacity are intended for separated paths; they are not appropriate for existing high traffic flow facilities. Most of the BLOS traffic flow methods that have been developed are most sensitive to bicycle volumes. Some of these models may be a good starting point to improve BLOS capacity and traffic flow measures for high bicycle volume locations. Without the tools to measure and evaluate the patterns of bicycle capacity and traffic flow, it will be difficult to monitor and mitigate bicycle congestion and to plan for efficient bicycle facilities in the future. This report concludes 
that it is now time to develop new BLOS capacity measures that address bicycle traffic flow. 


\section{ACKNOWLEDGEMENTS}

I would like to acknowledge Dr. Miguel Figliozzi and my committee for their support and guidance. I would also like to acknowledge the Oregon Department of Transportation, the Dwight David Eisenhower Graduate Fellowship program and the Oregon Transportation Research and Education Consortium for financial support throughout my education. In addition, I would like to thank my colleagues in the ITS Lab. Your constant hard work and creativity inspired me. I learned so much from all of you. Special thanks to Bryan Blanc and Katherine Bell. 


\section{TABLE OF CONTENTS}

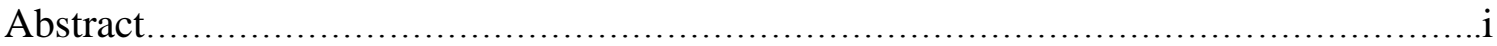

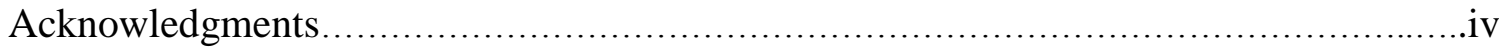

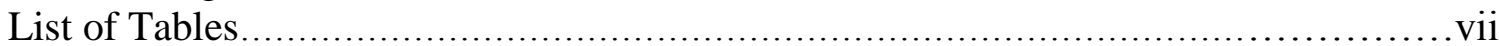

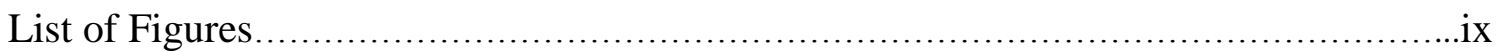

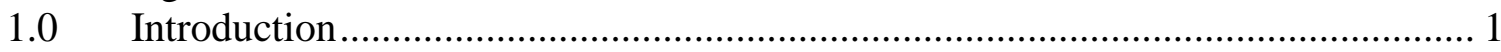

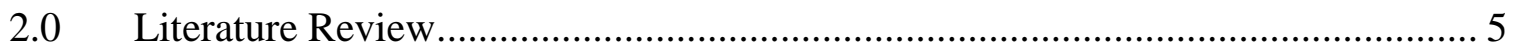

2.1 Highway Capacity Manual and Level of Service ………………………......... 5

2.2 State of BLOS Measures that Include Bicycle Volumes .................................. 11

2.2.1 BLOS methods for Off-Street Paths .......................................................... 11

2.2.2 BLOS for On-Street Bike Lanes ........................................................... 14

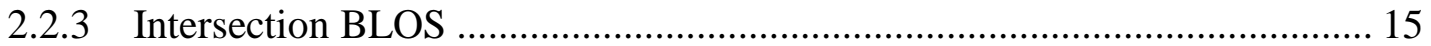

2.3 Bicycle Density and Capacity Studies ...................................................... 19

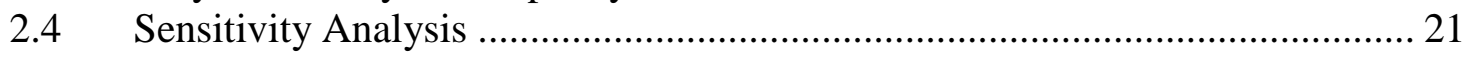

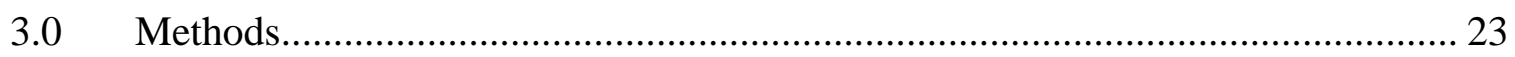

$3.1 \quad$ On-Street Segments ........................................................................... 23

3.1.1 Botma LOS for Bicycle Paths ................................................................ 23

3.1.2 HCM 2000, On-Street Bicycle Lanes ........................................................ 25

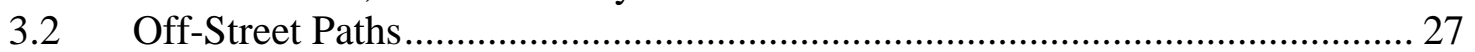

3.2.1 Botma LOS for Pedestrian- Bicycle Paths.................................................... 27

3.2.2 HCM 2000 Shared Off-Street Paths …………...................................... 29

3.2.3 FHWA Shared Use Path Analysis Tool..................................................... 30

3.2.4 HCM 2010 Method for BLOS for Off -Street Paths..................................... 32

$3.3 \quad$ Signalized intersections ........................................................................... 41

3.3.1 HCM 2000 Signalized Intersections ............................................................ 41

4.0 Site Description............................................................................................... 42

4.1 The Hawthorne Bridge Corridor Study Area .................................................. 48

4.2 Segment Descriptions ................................................................................ 49

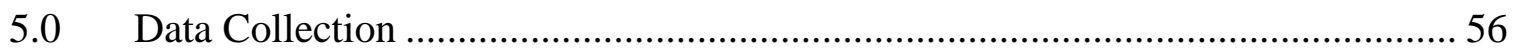

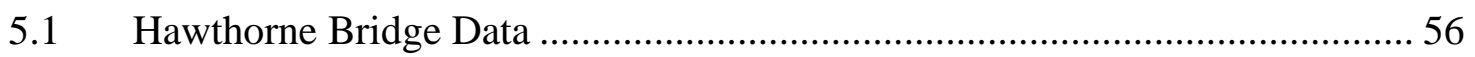

5.1.1 Portland Bureau of Transportation Manual Counts ...................................... 56

5.1.2 Hawthorne Bridge Continuous Bicycle Counts ........................................... 58

5.1.3 Portland Maps and Online Data Collection ……………............................... 64

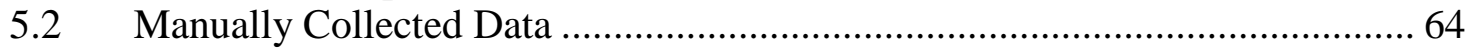

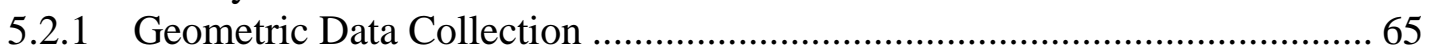

5.2.2 Data Collection for directional and route mode share ……......................... 65

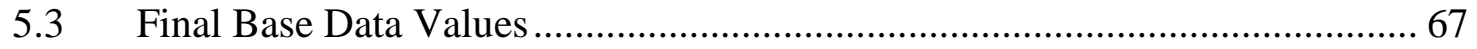

6.0 Data Analysis and Results ........................................................................... 70 


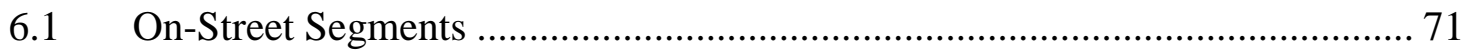

6.1.1 Botma LOS for One-Way Bicycle Paths ..................................................... 73

6.1.2 Botma LOS for One-Way Bicycle Paths with HCM Default Values........... 75

6.1.3 HCM 2000 LOS for One-Way Bicycle Paths.............................................. 76

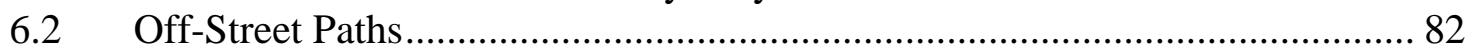

6.2.1 Botma LOS for Pedestrian- Bicycle Paths ................................................... 84

6.2.2 HCM 2000 Shared Off-Street Paths ………….......................................... 90

6.2.3 FHWA Shared Use Path Analysis Tool........................................................ 94

6.2.4 HCM 2010 method for BLOS for off street paths ....................................... 99

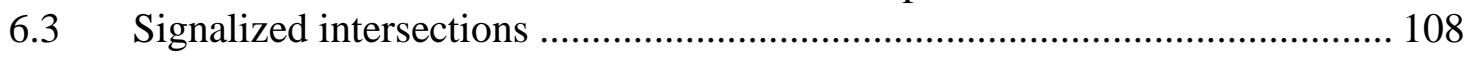

6.3.1 HCM 2000 Signalized Intersections ........................................................ 108

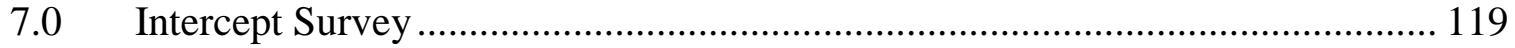

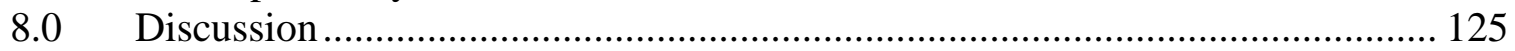

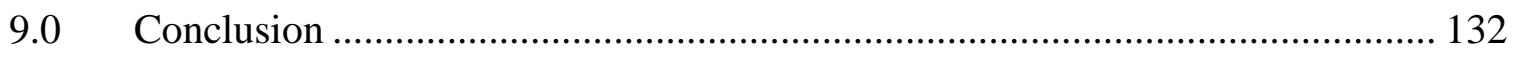

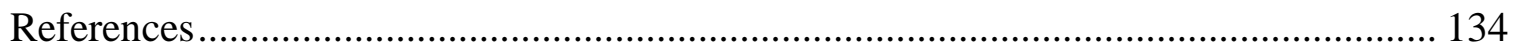

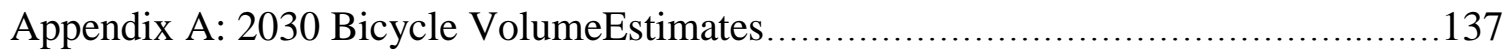

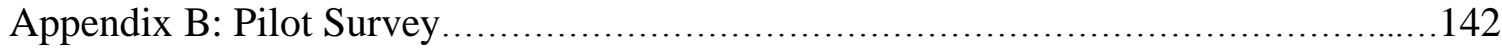

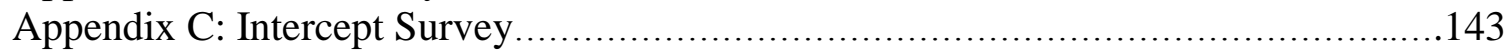




\section{LIST OF TABLES}

Table 1: Service Measures for Different Elements from the HCM 2010 ........................ 10

Table 2: Summary of BLOS Methods that Use Bicycle Traffic Flow as a Variable........ 18

Table 3: Density BLOS for Different Geographic Locations (Hummer et al. 2006) ....... 20

Table 4: Bicycle Saturation Flow Studies and Results (Hummer et al. 2006) .................. 21

Table 5: Botma Definition of Bicycle Lane Widths (Botma 1995).................................. 24

Table 6: Service Volumes and Frequency Of Events for One-Way, Two Lane Bicycle

Paths Using Default Values (Botma 1995) ........................................................... 25

Table 7: HCM 2000 Bike Lane BLOS Thresholds (TRB 2000) ....................................... 26

Table 8: BLOS for Users of a Two-Way, Two Lane Path (Botma 1995) ........................ 29

Table 9: BLOS for HCM 2000 Shared Off-Street Paths (TRB 2000) ............................... 30

Table 10: BLOS for FHWA Shared Use Path Analysis Tool (Patten et al. 2006) ........... 31

Table 11: Number of Operational Path Lanes Based on Path Width (TRB 2010) ........... 39

Table 12: On-Street Segments ................................................................................... 51

Table 13: Off-Street, Shared Path Segments ................................................................. 53

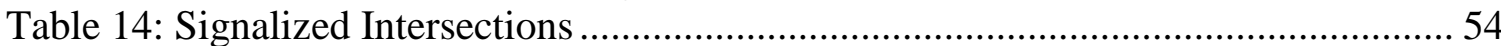

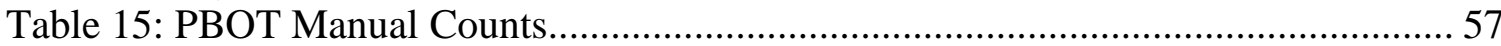

Table 16: Manual Directional Counts of Bicyclists and Pedestrians..................................... 66

Table 17: PBOT Peak Hour Manual Counts Used for Base Values...................................... 68

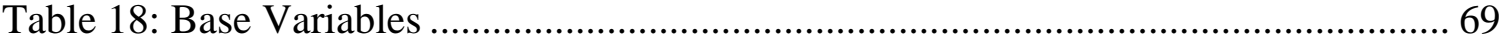

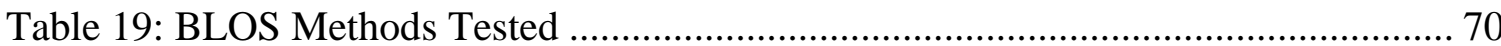

Table 20: Methods and Variables Used for On-Street Bicycle Lanes .............................. 71

Table 21: Variables Used and BLOS Results for On-Street, One-Way Segments........... 74

Table 22: Service Volumes and Frequency of Events for One-Way, Two Lane Bicycle

Paths Using Default Values (Botma 1995)........................................................... 75

Table 23: BLOS Comparison of Frequency Thresholds.................................................... 76

Table 24: Summary of BLOS Scores for On-Street Bicycle Lanes.................................. 79

Table 25: Off-Street Path Segments and Variables ....................................................... 84

Table 26: BLOS Value Comparison Between Botma Default Values versus HCM Default

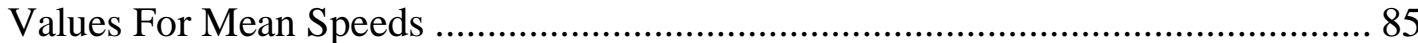

Table 27: BLOS for Users of a Two-Way, Two Lane Path (Botma 1995) ...................... 86

Table 28: BLOS Table for HCM 2000 Shared Paths for a Three Lane Path (HCM 2000)

Table 29: Directional Splits Modeled for Bicycle and Pedestrians ................................. 90

Table 30: Shared Off-Street Path Segments and Base Values............................................. 94

Table 31: BLOS Thresholds for Shared Use Path Flow Analysis Tool (Hummer et al.

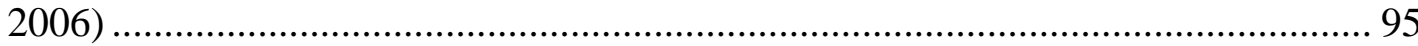

Table 32: Variables Used for HCM 2010 BLOS for off-street paths ............................. 100

Table 33: BLOS Results for Segments 4, 5 and 10 Using HCM BLOS for Shared Off-

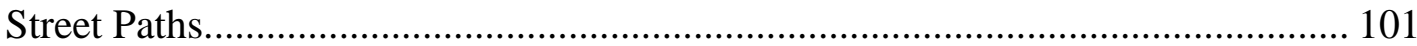

Table 34: Summary of BLOS Scores for Off-Street Segments ....................................... 107

Table 35: Summary of Intersection BLOS Variables and Results .................................. 111 
Table 36: Summary of BLOS Methods and Scores for Each Segment/ Element Using

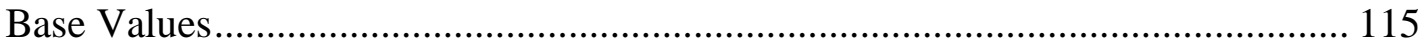

Table 37: Summary of BLOS Methods that Include Bicycle Volumes as an Input ....... 116

Table 38: LOS Grades from Intercept Survey .............................................................. 122

Table 39: Segments that Respondents Would Like to See Improved.............................. 122 


\section{LIST OF FIGURES}

Figure 1: Screenshot of Shared Use Path Flow Analysis Tool, FHWA .......................... 32

Figure 2: Screenshot of Shared Use Path Flow Analysis Tool. Inputs, FHWA .............. 32

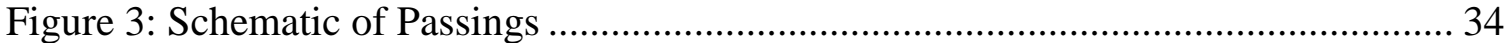

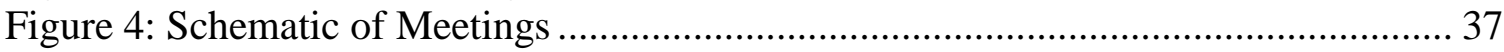

Figure 5: Delay from Cyclist Passing a Meeting of Two Path Users .............................. 38

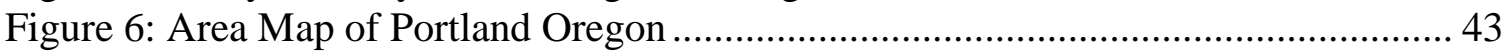

Figure 7: 2012 Estimated Portland Bridge Bicycle AADT (PBOT 2012) ...................... 45

Figure 8: Hawthorne Bridge Corridor Study Area ..................................................... 47

Figure 9: Hawthorne Bridge Study Corridor with Element Numbers ............................. 50

Figure 10: Collected Data from the Hawthorne Bridge ............................................... 56

Figure 11: Vicinity map of Hawthorne Bridge from Eco Counter Website and Hawthorne

Totem Counter Source: EcoVisio ..................................................................... 59

Figure 12: Screenshot of the Eco Counter Website Displaying Available data Format

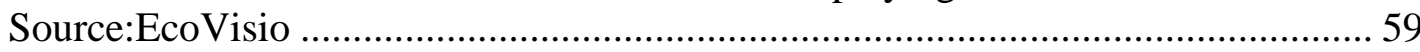

Figure 13: Average 2014 Winter and Summer Hourly Bicycle Volumes ....................... 61

Figure 14: 2013 Hawthorne Bridge North Sidewalk Hourly Bicycle Volumes .............. 62

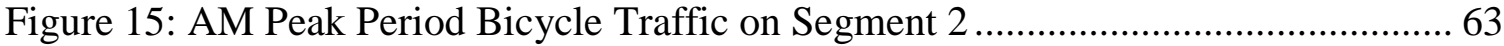

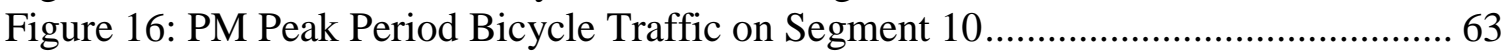

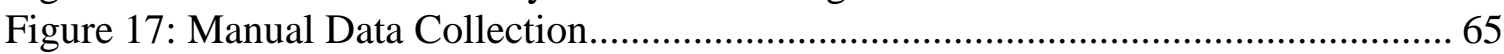

Figure 18: On-Street Bicycle Lanes and Locations ................................................... 72

Figure 19: Sensitivity of Variables in Botma One-Way Path With Botma BLOS

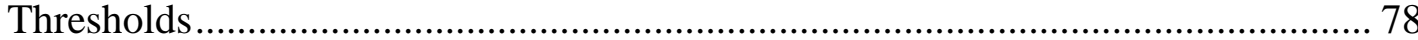

Figure 20: Sensitivity of Variables in Botma One-Way Bicycle Path With HCM 2000

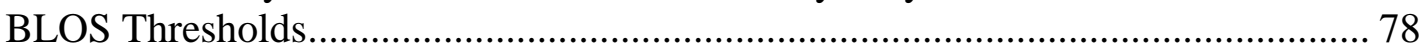

Figure 21: Off-Street Bicycle Lanes .................................................................... 83

Figure 22: Sensitivity Analysis of Bicycle and Pedestrian Volumes and BLOS Thresholds

Figure 23: Sensitivity Analysis of Mean Speeds and BLOS Thresholds ..................... 88

Figure 24: Sensitivity of Bicycle and Pedestrian Volumes and BLOS Thresholds......... 92

Figure 25: Sensitivity of Directional Splits for Bicycles and Pedestrians Volumes......... 93

Figure 26: Percent Change in BLOS Score with Percent Change in Total Volume and

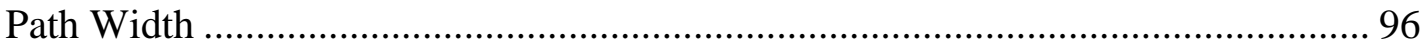

Figure 27: Percent Change in BLOS Score with Percent Changes in Bicycle Proportion

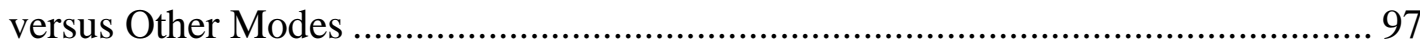

Figure 28: Percent Change in BLOS Score with Change in With or Without Center Line

Figure 29: Sensitivity of Bicycle and Pedestrian Volumes

Figure 30: Sensitivity of Geometric Variables ............................................................ 103 
Figure 31: Sensitivity of Standard Deviation and Mean Speeds of Bicycles and

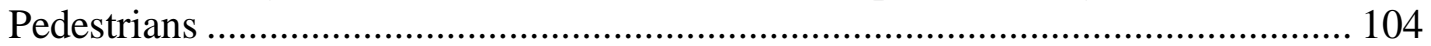

Figure 32: Sensitivity of Peak Hour Factor, Percent Bicycles and Pedestrians in Subject Direction, and the Percentage of Bicycles to Pedestrians ...................................... 106

Figure 33: Signalized Intersection ........................................................................... 109

Figure 34: Sensitivity Analysis and BLOS Thresholds for Saturation Flow Rate and Bicycle Volume for Controlled Intersections ....................................................... 112 Figure 35: Sensitivity Analysis and BLOS Thresholds for Effective Green Time and Cycle Length .. 113 


\subsection{INTRODUCTION}

In the U.S., local transportation agencies and regional planning organizations are promoting bicycle use as a strategy to alleviate transportation congestion, improve greenhouse gas emissions and public health. Many cities and Metropolitan Planning Organizations (MPOs) have set aggressive bicycle mode share goals in their regional plans. In particular, Portland, Oregon has set a 25\% bicycle mode share goal for 2030 (PBOT 2010). Currently, bicycle mode share in Portland is $6.1 \%$ of all trips. As mode share for bicycles has increased, bicycle volumes have also increased. At some locations, periods of bicycle traffic congestion have begun to appear. Similar to motor vehicles, the most common times of day for bicycle congestion are during peak commute hours. For cyclists in Portland, these locations of traffic congestion tend to be near route bottlenecks such as bridges in the central business district or where safe bicycle routes to different areas of the city are limited. Although these areas of bicycle traffic congestion exist, there are currently no methods that can describe these incidences of high bicycle traffic flow and resulting congestion.

Without the tools to measure and evaluate the patterns of bicycle capacity and traffic flow, it will be difficult monitoring and mitigating bicycle congestion and planning efficient bicycle facilities in the future. 
Level of Service (LOS) measurements were first developed in the 1960s in the Highway Capacity Manual (HCM) to describe traffic flow and operations of motor vehicles on highways using an A-to-F grading system; A is free flow traffic with no maneuvering constraints for the driver and an F grading for breakdown flow, or traffic jam conditions. Additional LOS metrics were developed to describe facilities and operations.

In the 1980s, the HCM expanded LOS measures to transit, pedestrians, and bicycles. Bicycle level of service (BLOS) was developed for bicycle facility comfort. BLOS capacity methods has not been established based on the assumption that bicycle traffic volumes are generally low and do not warrant a BLOS capacity measure (HCM 2010; Landis, Vattikuti, and Brannick 1997), with one exception, in the case of an off-street path. This off-street path BLOS method is known as hindrance; the delay experienced due to passing and meeting other bicyclists and pedestrians on a path. Over the past two decades, modifications and expansion of the hindrance method have been attempted. In the late 1990s the Federal Highway Administration (FHWA) recommended that the hindrance method for separated off-street paths could be applied to on-street bike lane and was included in the HCM 2000 manual. However, this method was dropped in the HCM 2010 due to lack of research and evidence that the method is appropriate for applying to on-street facilities (HCM 2010).

This thesis investigated the state of BLOS capacity methods that use bicycle volumes as a variable. The existing methods were then applied to bicycle facility elements along a corridor that experiences high bicycle volumes in Portland, Oregon. Using data from the 
study corridor, BLOS was calculated and a sensitivity analysis was applied to each of the methods to determine how sensitive the models are to each of the variables used. An intercept survey was conducted to compare the BLOS capacity scores calculated for the corridor with the users' perception. 2030 bicycle mode share for the study corridor was estimated for the corridor and the implications of not addressing bicycle congestion were discussed. Gaps in the BLOS methods, limitations of the thesis study and future research were summarized.

The site that was chosen to apply the existing BLOS capacity methods was the Hawthorne Bridge Corridor in Portland, Oregon. The advantages of this corridor are that it is currently experiencing periods of high bicycle traffic volumes, robust bicycle data is available, and the corridor includes a variety of bicycle facility elements such as on-street bicycle lanes of varying widths, off-street paths, and intersections.

The thesis is organized as follows. A literature review of the history of LOS measures is given and the role of the HCM in its development. The state of BLOS measures that consider bicycle volumes is summarized. Research regarding Bicycle capacity and traffic flow are discussed. In addition, the methods used to design a sensitivity test for each of the models in this thesis project are described. Next, each of the methods that calculate BLOS measures using bicycle flow is explained. Following the methods, the Hawthorne Bridge Corridor site and elements are described. The data collection and how the data was used to develop a base set of values to test each of the methods is explained. Following, the BLOS methods are analyzed; BLOS is calculated for the appropriate 
elements along the Hawthorne Corridor and a sensitivity analysis is used to evaluate the sensitivity to each of the variable inputs. The intercept survey results are described and compared with the analysis. A discussion follows that explains the result, discusses the gaps and its implications for future BLOS analysis. Finally, limitations of the methods and study are outlined and future research is recommended. 


\subsection{LITERATURE REVIEW}

\subsection{Highway Capacity Manual and Level of Service}

The Highway Capacity Manual (HCM) was first developed in 1950 to provide capacity guidelines for freeway design for transportation professionals. In the 1965 version of the HCM a performance measurement was introduced, named Level of Service (LOS), and was synonymous with motor vehicle capacity on highways. LOS was developed in order to easily explain the operations of the road network in a way that elected officials and the public can easily understand. LOS performance measures are based on a grading system of "A" to "F"; "A" being the best performance and "F" the worst. During the first two decades, HCM was focused on motor vehicle operations (TRB 2000).

Bicycles and pedestrians first appeared in the HCM in 1985. However, bicycles and pedestrians were only considered obstacles to level of service for motor vehicles. Then, in 1991 a monumental shift occurred in the management of the US highway system. The Intermodal Surface Transportation Efficiency Act (ISTEA) was signed into law. ISTEA shifted the focus of the Federal transportation agencies from encouraging the construction of highways (as the highway system was essentially completed) to improving the existing freeway system and designing a safer and more efficient transportation system for all modes. ISTEA encouraged the development of a more multimodal transportation system integrating more transit, bicycle, and pedestrian facilities (Schweppe 2001) 
This shift in the transportation industry's purpose influenced the HCM`s performance measures. In the HCM 2000 pedestrian traffic became relatively well defined and LOS methodologies were developed for pedestrian flow and facilities. Bicycle level of service (BLOS) measures were mainly focused on cyclist comfort on various bicycle facilities but also included some experimental methods for calculating bicycle delay at intersections and BLOS based on bicycle traffic flow in bike lanes and shoulders.

The most current version, the HCM 2010, has included a multi-modal level of service (MMLOS) method for urban streets. The MMLOS framework takes into consideration the perspectives of motor vehicle drivers, pedestrians, bicycles and transit users on different types of transportation facilities including intersections and urban streets (TRB 2010). One of the key features is that it integrates the effects of motor vehicles on pedestrians and bicyclists. For bicycles this latest edition emphasizes BLOS measures of cycling comfort based on the quality of bicycle facilities and the speed and density of motor vehicle traffic next to the facilities. This latest version of the HCM also includes a detailed BLOS method that measures the delay of bicyclists on off-street paths. However, the 2010 version dropped 2000 version's methods of bicycle delay at intersections and BLOS based on bicycle traffic flow on bike lanes and shoulders. The reasoning for the exclusion of the additional bicycle measures was due to lack of research of the methods used (TRB 2010).

Other transportation organizations have also developed guidelines and measures of LOS. Agencies and organizations adapted the most recent versions of the HCM as the basis for 
their own models, such as the Florida DOT 2013 Quality/Level of Service Handbook (State of Florida Department of Transportation 2013). The American Association of State Highway and Transportation Officials (AASHTO) and the Federal Highway Administration (FHWA) have their own level of service reference guides and methods for BLOS but also borrow from the HCM (AASHTO 2010; FHWA 1998).

In the last 20 years additional performance measures similar to BLOS have been developed by transportation researchers. These methods have aimed to address the unique characteristics of bicycle travel that have not been reflected in the standard BLOS methods, and are in some cases, a reaction to the limitations of the present accepted methods. BLOS type performance metrics are often developed from survey results of respondents perceptions of bicycle facilities (Carter et al. 2013). A common process that is used in the development of a bicycle performance metrics is to instruct research subjects to study photos, watch video taken by someone on a bicycle in different environments or have them ride directly on facilities. The research subjects are then asked to give feedback about their perception of comfort or safety at each scenario. Using the responses from the respondents and the attributes of the facilities in the study area, models of performance metrics are developed. Regression-based methods, order probit models, and fuzzy clustering are common methods for developing BLOS determination method (Landis, Vattikuti, and Brannick 1997; Landis et al. 2003; Petritsch et al. 2007; Jensen 2007; Jensen 2012; Sorton and Walsh 1994). 
Among the performance metrics that have been developed, definitions vary. Types of BLOS performance measures include measures of cyclist perception, level of bicyclist stress, bicycle interaction hazard score, and bicycle suitability (Lowry et al. 2012; AsadiShekari, Moeinaddini, and Zaly Shah 2013). One BLOS method is described as the "perception index for bicycle level of service (Callister and Lowry 2013). The HCM defines BLOS measures as the "perceived comfort and safety of bicycle travel (TRB 2010)." Another method measures "Bicycle Suitability." Most of the methods use road facility characteristics and motor vehicle speeds and volumes to determine how suitable the facility is for cycling (Callister and Lowry 2013)." The HCM and the Florida DOT Quality/Level of service have different definitions of LOS and require different criteria (Dowling et al. 2014).

The HCM 2010 defines three different concepts that overlap in meaning; 1) quality of service, 2) level of service, and 3) service measures. Quality of service is how the traveler perceives the functioning of the roadway facility. Travel surveys, user complaints and observations were used to develop quality of service measures. Level of Service (LOS) is the grading system used to describe certain thresholds of quality of service. Service measures define LOS measures for different elements. Elements of a roadway include segments, points, facilities, corridors, areas, and systems. Service measures interpret user's perceptions and are measureable in the field. Operational analysis is the determination of instantaneous conditions on a road element and then deciding if the existing facilities are adequate or if operational improvements are warranted. Design 
analysis determines LOS based on the attributes of the roadway facilities or the addition or change of roadway facilities. Planning and preliminary analysis uses a number of default values to project future LOS before new facilities or changes to existing facilities are made. The HCM also provides methods for evaluating individual elements of a road system or a combination of elements (TRB 2010).

The main variables used to calculate operational LOS are vehicle volumes and speed. The LOS metrics include traffic density, percent time following, average travel speed, percent free flow speed, and delay. In contrast, BLOS for on-street facilities is determined from geometric variables, motor vehicle traffic and speed, not bicycle volume. Only for offstreet paths are BLOS calculated using bicycle volumes and speed.

Table 1 lists the different system elements. For each of the elements, the type of service measurements available for motor vehicles and bicycles is given. 
Table 1: Service Measures for Different Elements from the HCM 2010

\begin{tabular}{c|cc}
\hline System Element & Motor Vehicles & Bicycles \\
\hline $\begin{array}{c}\text { Freeways and Multi-lane } \\
\text { Highways }\end{array}$ & Density & $\begin{array}{c}\text { Comfort } \\
\text { Perceived exposure }^{1}\end{array}$ \\
Two-Lane-Highway & $\begin{array}{c}\text { Percent time following } \\
\text { Average Travel Speed } \\
\text { Percent free-flow speed }\end{array}$ & $\begin{array}{c}\text { Comfort } \\
\text { Perceived exposure }\end{array}$ \\
\hline $\begin{array}{c}\text { Urban Street Facilities and } \\
\text { Segments }\end{array}$ & Percent free-flow speed & $\begin{array}{c}\text { Comfort }^{2} \\
\text { Perceived exposure }\end{array}$ \\
\hline $\begin{array}{c}\text { Urban Street Intersections } \\
\text { bicycle facilities }\end{array}$ & Control Delay & None \\
\hline
\end{tabular}

A main assumption in BLOS analysis is that bicycle volumes rarely reach a critical mass in which bicycle volumes would affect bicycle traffic flow, delay or have a significant effect on the comfort of cycling. The Florida DOT Q/LOS handbook claims that bicycle volumes do not have an effect on BLOS (State of Florida Department of Transportation 2013). In 1997, Bruce W. Landis, et al. wrote in his report, Real-Time Human Perceptions, Toward a Bicycle Level of Service;

"Thus defined, the bicycle level of service (BLOS) is not a measure of vehicular flow or capacity as is the convention for other travel modes. Although methods do exist for quantifying bicycle flow and capacity, such performance measures are generally not

\footnotetext{
${ }^{1}$ Variables include separation from traffic, motorized traffic volumes and speeds, heavy vehicle percentage, and pavement quality. Note bicycle volume or speed is not used.

${ }^{2}$ Variables include separation from traffic, motorized traffic volumes and speeds, heavy vehicle percentage, on-highway parking and pavement quality. Note bicycle volume or speed is not used.

${ }^{3}$ Variables include separation from traffic, motorized traffic and volumes, heavy vehicle percentage, presence of parking, pavement quality. Intersections are included in the segment and include separation of traffic, cross street width. Note bicycle volume or speed not used.
} 
relevant for mixed-mode collectors and arterials in the United States, at least in the foreseeable future (Landis, Vattikuti, and Brannick 1997).”

The 2010 HCM states;

"Some vehicular measures are less applicable to bicycle mode. For example, bicycle density is difficult to assess, particularly with regard to facilities shared with pedestrians and others. Because of the severe deterioration of service quality at flow levels well below capacity (e.g., freedom to maneuver around other bicyclists), the concept of capacity has little utility in the design and analysis of bicycle facilities; rather, cyclists typically dismount and walk their bicycles before a facility reaches capacity. Values for capacity therefore reflect sparse data, generally from European studies or from simulation.”

\subsection{State of BLOS Measures that Include Bicycle Volumes}

The following is a summary of the state BLOS measures that include bicycle volumes as an input. Table 2 at the end of this section summarizes the methods and outlines the variables used in each method.

\subsubsection{BLOS methods for Off-Street Paths}

The developments of BLOS methods that include bicycle traffic flow are limited. One method that uses bicycle traffic volumes to calculate BLOS is explained in the seminal report by Hein Botma, Method to Determine Level of Service for Bicycle Paths and Pedestrian-Bicycle Paths, written in 1995 in the Netherlands. Botma's theory is that the 
number of passings and meeting of pedestrians and bicyclists on a path can be quantified and used to describe the level of service, capacity and perceived safety. Each passing and meeting event is referred to as "hindrance." The hindrance model is used to determine BLOS for two-lane pedestrian-only paths, bicycle-only paths and shared-use paths separated from motor vehicle traffic. The method considers the width of the path, the volumes and speeds of both pedestrians and cyclists (Botma 1995).

Botma simplified the model by observing that bicycles tend to be 4 times faster than walking on flat segments, which is appropriate for the Netherlands. Another simplification is to assume that traffic volumes travel 50 percent in each direction for two-way paths. The simplified equations determine BLOS based on bicycle and pedestrian volumes. The BLOS is determined from calculating and frequency of passings and meetings and then converting to "events per second".

In 2006, the FHWA developed a new off-road path BLOS method based on the "hindrance". The FHWA determined that the Botma method's shortcut calculations were not necessarily appropriate to use in the US because bicyclist behavior and bicycle facilities differ from Europe's. The FHWA report noted that US bicyclists are less experienced, have different mode splits between recreational and commuter cyclists and dimensions for facilities differ from Europe's. In addition, Americans ride different types of bicycles than are used in other countries (Patten et al. 2006). The report outlined new version of Botma's model that includes a variety of shared path users including runners, in line skaters, and child bicyclists. The method is based on the Botma model. However, 
it was developed from the results of a national study of 15 trails and a user perception study which included participants viewing video of the 15 trails. The following model was developed from the study. The method calculates the probability of passings and meeting between the various users using a cumulative distribution method. An easy to use workbook to make calculations was developed by the Toole Design Group as part of the FHWA project (Hummer et al. 2006).

The HCM 2010 LOS method for shared-use paths borrows from the Botma and FHWA hindrance methods but is much more complex and laborious. The method also includes cumulative distribution calculations to better estimate the randomness of passings and meetings along a segment. The HCM 2010 shared-use path method allows for more detailed data inputs about non-motorized modes (TRB 2010). Default values are given to simplify the calculations for variables such as mean speed and standard deviation that are not normally collected in the field. However, the method allows the freedom to create any mix of non-motorized mode share users, speeds and standard deviations. The method developed by Botma requires 3 calculations. The HCM 2010 method has 8 steps and more than 15 calculations including a cumulative distribution function to determine BLOS. A worksheet is available from the University of Idaho that calculates some of the steps from the HCM 2010. However, the most complicated calculations for the probability of passings and meeting must be developed for each segment (Callister and Lowry 2013). 


\subsubsection{BLOS for On-Street Bike Lanes}

There are no BLOS methods were developed exclusively for on-road segments that incorporate bicycle volumes. However, the Federal Highway Administration (FHWA) suggested that the off-road bicycle path method developed by Botma is reasonable to use for on-street bicycle lanes with moderate to low motor vehicle traffic and no disruption in flows (i.e. no intersections, driveways, or stops). The bike lane must be wide enough for two effective bicycle lanes or the motor vehicle volumes must be low enough that cyclists can use the motor vehicle lane to pass other cyclists safely (Allen et al. 1998).

The HCM 2010 does have BLOS methods for multilane highways and two lane highways. However, bicycle volumes are not considered and only BLOS comfort of facilities are calculated. Bicycle LOS methods are also available for urban street facilities in the HCM 2010 and utilize bicycle speed to calculate travel time. However, bicycle volumes are not considered (TRB 2010). This is common for most of the models developed for road segment BLOS (Landis, Vattikuti, and Brannick 1997; Callister and Lowry 2013; Parks et al. 2013).

Like the HCM 2010, The Danish BLOS model, developed by Soren Underlien Jensen, for on-roadway segments only calculates the comfort of bicycle facilities. The variables and coefficients were developed from survey responses based on videos of road segments. Linear regression was used to determine variables that were significant for 
developing a facility satisfaction BLOS model. This model does not consider bicycle volumes or bicycle congestion (Jensen 2007; Dowling et al. 2014)

A BLOS model for arterials has also been developed by the Florida DOT. This method considers the sum of road segments and intersections of an arterial. Similar to the development of BLOS models based on the perception of participants observing bicycle facilities, this study had participants ride on a bicycle route that included different types of facilities and answer a survey for each type of road segment. Again, this study does not consider bicycle traffic volumes, only facilities. No bicycle volumes are used to develop the final model (Petritsch et al. 2007; Dowling et al. 2014).

\subsubsection{Intersection BLOS}

Chapter 19 in the HCM 2000 includes an intersection bicycle capacity LOS method. There are two equations for the method; 1) bicycle capacity and 2) delay. The variables include saturation flow rate for bicycles with a default value of 2000 bicycles per hour. The effective green time for bicycles and the signal cycle length are needed to calculate capacity of a bicycle lane at an intersection. The control delay calculation uses the results from the bicycle capacity calculation and one way flow rate of bicycles for estimating bicycle delay. Control delay values are converted into BLOS intersection values (TRB 2000).

HCM 2010, Urban street segments, Chapter 18, also gives methods for BLOS at intersections. As in the HCM 2000, BLOS of signalized intersections bicycle lane 
capacity and delay are calculated using bicycle flow rate. However, these calculations are used to determine the BLOS for facility comfort, not bicycle traffic flow and capacity. The chapter discusses bicycle saturation rate and states that there is no recent information on calculating saturation flow for bicycles. The current standard default values for bicycle saturation flow is 2,000 bicycles/h (TRB 2010). The Florida DOT has also developed intersection BLOS methods but does not consider any bicycle metrics (Landis, Vattikuti, and Brannick 1997).

Soren Underlien Jensen, from Denmark also developed method for determining intersection BLOS. The variables for this method include width of bicycle lane, type of crossing facility for bicyclists, and the type of facility before the intersection. There are two different methods; one for when the cyclist crosses the intersection and another for when the bicyclist turns right. This right turning method is based on Danish left turn movements that are not used in the US. Bicycle volumes are not used as a variable. This method calculates perceived bicyclist satisfaction. (Jensen 2012).

No other BLOS methods are available for any other types of bicycle facility, such as bicycle boulevards for cycle tracks. Table 2 summarizes the methods described above. The checkmark designates the variables needed to calculate each method. The " $R$ " is the variables that are not needed in the calculation but are the required conditions that are needed to appropriately apply the methods. For example, the Botma on-way bicycle path does not use bicycle path width in the calculation, however, 
the path must fall within a certain range in order to be considered a two-lane path. "O" designates the variables that are optional. 
Table 2: Summary of BLOS Methods that Use Bicycle Traffic Flow as a Variable

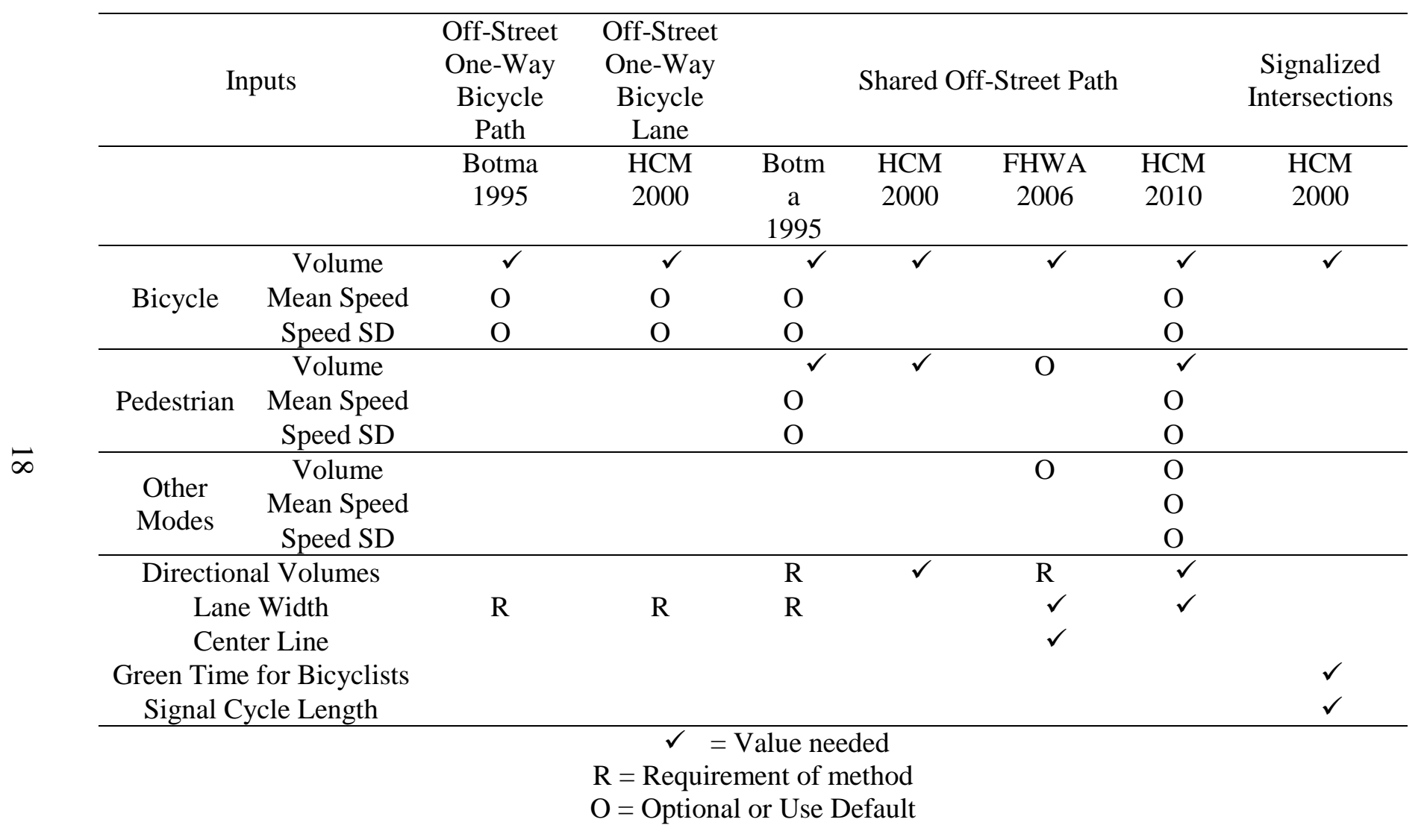




\subsection{Bicycle Density and Capacity Studies}

There have been no established guidelines for what constitutes an acceptable BLOS density, capacity or traffic flow. However, these methods have been successfully developed for pedestrians (Fruin 1992; HCM 2010).

Studies related to bicycle traffic density have been conducted in countries with higher population densities and a well-established bicycle ridership. In China, bicycle use has plummeted from $62 \%$ bike mode share in 1986 to $16 \%$ in 2010 (Fong 2013). Yet, research on bicycle capacity and congestion metrics is still conducted. Chinese research found that, as in the US, facilities, road geometry and motor vehicle traffic volumes contribute to cyclist's perception of comfort. However, bicycle traffic flow was also a significant factor on both separated bicycle paths and bike lanes (Li et al. 2012). Another Chinese study developed conversion factors that equate how many bicycle units equal a passenger car unit. These conversion factors were developed to model the interaction between bicycle congestion and motor vehicles (Kang, Xiong, and Mannering 2013). Due to differences in road geometry, and cultural differences in terms of driving and cycling behavior and rules-of-the-road, Chinese methods and models of level of service may not be transferrable to US bicycle traffic modeling.

Studies in Germany, California, and China have considered levels of service based on bicycle density. Table 3 summarizes each country's proposed BLOS grades for A and 
F. The density is described in square foot per bicyclist, the reciprocal of density, which is cyclist per unit. These are the same units used to describe the pedestrian density (Fruin 1992). This is different than the measurement for motor vehicles, which is described as vehicles per distance. However, bicycle travel is more fluid and bicycles do not always travel in a lane for with one vehicle behind another, like a motor vehicle. The table demonstrates the differences among cultures about what constitutes an A or F grade. German BLOS F is the same density as the Chinese equivalent BLOS A rating of $108 \mathrm{ft}^{2} /$ bicycle (Hummer et al. 2006).

Table 3: Density BLOS for Different Geographic Locations (Hummer et al. 2006)

\begin{tabular}{c|cc}
\hline Location & BLOS A & BLOS F \\
\hline California & $215 \mathrm{ft}^{2} /$ bicycle & $40 \mathrm{ft}^{2} /$ bicycle \\
Germany & $2150 \mathrm{ft}^{2} /$ bicycle & $108 \mathrm{ft}^{2} /$ bicycle \\
China & $108 \mathrm{ft}^{2} /$ bicycle & $24 \mathrm{ft}^{2} /$ bicycle \\
& (Very Comfortable) & (Dismount) \\
\hline
\end{tabular}

Table 4 illustrates the results from a variety of studies on bicycle saturation flow (Hummer et al. 2006). Note that for a one-lane path, the saturation flow rate is between 500 and 4,000 bicycles. Another report summarizing international studies on bicycle capacity concluded that the saturation flow rate for bicycles on a four foot bicycle lane was between 2,000 to 3,000 bicycles per hour. The report also noted that a BLOS of $F$ is not defined by the capacity or saturation flow rate. BLOS $\mathrm{F}$ is the perception that conditions are unacceptable (Allen et al. 1998). 
Table 4: Bicycle Saturation Flow Studies and Results (Hummer et al. 2006)

\begin{tabular}{c|ccc}
\hline Location & Study Year & Path Width & $\begin{array}{c}\text { Saturation Flow } \\
(\text { Bicycles } / \mathrm{h})\end{array}$ \\
\hline Davis, CA & 1975 & $1.2 \mathrm{~m}(4 \mathrm{ft})$. & 3,600 \\
Sweden & 1977 & $1.2 \mathrm{~m}(4 \mathrm{ft})$. & 1,500 \\
Netherlands & 1991 & $0.78(2.6 \mathrm{ft})$. & $3,000-3,500$ \\
China & 1993 & $1 \mathrm{~m}(3.3 \mathrm{ft})$. & $1,800-2,100$ \\
Canada & 1994 & $1.25(4.1 \mathrm{ft})$. & 4,000 \\
US (HCM) & 1994 & 1 to 2 lanes & $500-2,350$ \\
Netherlands & 1995 & $1 \mathrm{~m}(3.3 \mathrm{ft})$. & 3,200 \\
\hline
\end{tabular}

\subsection{Sensitivity Analysis}

In order to gain some insight into the BLOS methods that use bicycle volumes and to determine how sensitive each of the variables is in the various methods, a sensitivity analysis was developed. This section summarizes studies that were used to develop a sensitivity test. Other studies of BLOS methods have used sensitivity analysis to determine the significance of variables within the methods. Most of these sensitivity analyses evaluated bicycle facilities. One such sensitivity study compared the variation in BLOS scores between different sites. The purpose of the study was to test the HCM 2010 multi-modal level of service (MMLOS) scores as they were applied to four different locations. Each input was tested by varying the value of the input from the initial, base value used at each site. The method varied depending on the type of variable. For example, volumes were increased at $20 \%$ increments while all other inputs were held constant (Carter et al. 2013). This test showed that for bicycle LOS pavement condition and shoulder parking width had the largest changes in LOS; however these changes varied greatly for each site. Another project applied a sensitivity 
methodology to study 26 variables in the HCM 2010 MMLOS. The researcher tested most values at a $50 \%$ increase or decrease in values. Other changes in variables were based on realistic changes. For example, $5 \mathrm{mph}$ changes in speed were tested instead of changing them by a percentage (Elias 2010).

One study compared the HCM 2010 BLOS, the Danish Road Directorate BLOS and the Bicycle Environmental Quality Index (BEQI). The "Sensitivity to Key Design Factors" was tested. This sensitivity method was a qualitative comparison of how well design factors were "out of a transportation agency's control" and how sensitive the BLOS measurements were to before and after bicycle infrastructure improvements. In addition the research used a qualitative scale to measure how user friendly the tools were for calculating BLOS (Parks et al. 2013).

For this analysis a combination of the Carter and Elias sensitivity models were applied to each of the BLOS methods. A combination base of values was developed for this project based on real data or, where necessary, default values. For each model, each variable was increased and decreased by a $25 \%$ or $50 \%$ increment, with all other base values held constant. A percent change from the base value was measured and plotted. The plots include the BLOS threshold, measured as the percentage of the base variables. 


\subsection{METHODS}

To understand of the state of practice for BLOS capacity measures, methods that measure bicycle volumes as a variable were chosen for evaluation. Using the results of the literature review, a list of bicycle methods is summarized in Table 2. The following describes each of methods in detail.

\subsection{On-Street Segments}

\subsubsection{Botma LOS for Bicycle Paths}

As was previously described, Botma developed a capacity BLOS for off-street paths. However, the FHWA determined that under some circumstances, the Botma method for bicycle-only paths can be applied to on-street bicycle lanes (Allen et al. 1998)

Botma developed the concept of "hindrance;" the delay experienced by bicycles passing and maneuvering around other off-street path users. Three maneuvers, called events, were outlined in his model; 1) a bicyclist passing a user going in the same direction, 2) a bicyclist meeting another user going in the opposite direction, and 3) a combination of passing and meeting. The criterion to define BLOS is "the frequency of events with respect to time;" in particular, frequency $(\mathrm{F})$ will be expressed as "number of events per second." The method was developed for two-lane paths. Table 5 is a summary of what is considered a two-lane bicycle lane width. 


\section{Table 5: Botma Definition of Bicycle Lane Widths (Botma 1995)}

\begin{tabular}{cc}
\hline Number of lanes & Width of path, m (ft.) \\
\hline 1 & $0.75-1.00(2.5-3.3)$ \\
2 (Narrow) & $1.5(4.9)$ \\
2 (Generous) & $2(6.6)$ \\
\hline
\end{tabular}

A path width of $1.5 \mathrm{~m}$ (4.9 ft.) is considered just enough width for two bicycles to ride side by side. A $2 \mathrm{~m}$ (6.6 ft.) wide bike lane is comfortable for two bicycles riding side by side (Botma 1995).

Botma developed two different hindrance BLOS methods; one for bicycle-only paths and another for pedestrian-bicycle paths. A "path" is not clearly defined, except to say that a path is not intended for motor vehicles and bicycles together on the street.

Quality of operation, or BLOS, for a bicycle only path is based on frequency of passings, using the following equation.

$$
F=2 Q \sigma /\{U \sqrt{\pi}\}
$$

Where

$F=$ Frequency of passings

$U=$ the mean speed (default of $18 \mathrm{kmh}(11.2 \mathrm{mph}))$

$\sigma=$ standard deviation of speed (default of $3 \mathrm{kmh}(1.9 \mathrm{mph})$ )

$Q=$ volume of bicycles (bicycles $/ \mathrm{h}$ )

Equation (3.1) can be simplified using default values to

$$
F=0.188 Q
$$


Using default values, equation (3.2) yields Table 6 for a two lane, one way bicycle path. The definition of LOS F is the condition of $100 \%$ of cyclists experiencing hindrance along a one kilometer long path.

Table 6: Service Volumes and Frequency Of Events for One-Way, Two Lane Bicycle Paths Using Default Values (Botma 1995)

\begin{tabular}{c|ccc}
\hline & & \multicolumn{2}{c}{ One-Way } \\
\cline { 3 - 4 } LOS & $\begin{array}{c}\text { \% with hindrance } \\
\text { over } 1 \mathrm{~km}\end{array}$ & $\begin{array}{c}\text { Service Volume } \\
\text { bicycles/h }\end{array}$ & $\begin{array}{c}\text { Frequency } \\
\text { passings } \\
\text { events/s }\end{array}$ \\
$\mathrm{A}$ & $0-10$ & 130 & $<1 / 150$ \\
$\mathrm{~B}$ & $10-20$ & 260 & $<1 / 75$ \\
$\mathrm{C}$ & $20-40$ & 520 & $<1 / 35$ \\
$\mathrm{D}$ & $40-70$ & 910 & $<1 / 20$ \\
$\mathrm{E}$ & $70-100$ & 1300 & $<1 / 15$ \\
$\mathrm{~F}$ & 100 & $>1300$ & $>1 / 15$ \\
\hline
\end{tabular}

The frequency of passings in Table 6 can be described as one passing per 150 seconds. For example, an LOS A is when a cyclist only passes another cyclist every 2.5 minutes.

\subsubsection{HCM 2000, On-Street Bicycle Lanes}

The HCM 2000, Chapter 19 includes methods for evaluating different types of bicycle LOS, including a capacity LOS for on-street paths (TRB 2000). Chapter 19 and its methods were not included in the HCM 2010 due to a lack of research and testing. However, since it is the only on-street BLOS capacity method, it will be analyzed.

The main criteria for this method include either a bike lane or a paved shoulder that is not normally used as a motor vehicle lane. The method makes an assumption that, if a 
bicycle lane is narrow and motor vehicle traffic is relatively low, a cyclist could use the adjacent motor vehicle lane for passing. For an on-street path it is assumed that all bicycle traffic is traveling in the same direction. BLOS is based on the number of events. It is the same calculation as Botma off-street bicycle path in Equation (3.1) but with different recommended values and different thresholds for BLOS, given in Table 7.

The calculation is based on metric measurements. It is recommended to collect real bicycle traffic speeds. The default for bicycle speed is $18 \mathrm{~km} / \mathrm{h}(11.2 \mathrm{mph})$. The default standard deviation for speed is $1.5 \mathrm{~km} / \mathrm{h}(0.93 \mathrm{mph})$ for commuters, $3 \mathrm{~km} / \mathrm{h}(1.9 \mathrm{mph})$ for mixed user types, and $4.5 \mathrm{~km} / \mathrm{h}$ (2.8 $\mathrm{mph})$ for recreational users.

Table 7: HCM 2000 Bike Lane BLOS Thresholds (TRB 2000)

\begin{tabular}{c|c}
\hline BLOS & $\begin{array}{c}\text { Frequency of } \\
\text { events per hour }\end{array}$ \\
\hline A & $\leq 40$ \\
B & $>40-60$ \\
C & $>60-100$ \\
D & $>100-150$ \\
E & $>150-195$ \\
F & $>195$ \\
\hline
\end{tabular}




\subsection{Off-Street Paths}

\subsubsection{Botma LOS for Pedestrian- Bicycle Paths}

Botma's method for determining BLOS on paths is innovative and relatively simple to calculate. There are four different interactions between pedestrians and bicycles that produce hindrance: 1) pedestrians from other pedestrians, 2) pedestrians from bicycles, 3) bicycles from pedestrians, and 4) bicycles from bicycles. In addition, there are two different types of hindrances, meetings and passings. Meetings are when two users of the path pass each other face to face. Passings are when one user passes another user that is moving slower but in the same direction.

The following applies to two lane, two way bicycle and pedestrian separated paths. $Q_{p}=$ one-way volume of pedestrians, bicyclesh

$Q_{b}=$ one-way volume of bicycles, bicycles $h$

$U_{p}=$ mean speed of pedestrians in $\mathrm{kmh}$ with the default of $4.5 \mathrm{~km} / \mathrm{h}$

$U_{b}=$ mean speed of bicycles in $\mathrm{kmh}$ with a default of $18 \mathrm{~km} / \mathrm{h}$

Botma noticed, in general, a bicycle is four times faster than a pedestrian. In this model and using default values given above, $U_{b}$ is considered four times greater than $U_{p}$; a bicycle is on average four times faster than the average pedestrian and the bicycle will pass three times the pedestrians. Therefore,

$$
\operatorname{Fpass}_{b-p}=Q_{p}\left(\frac{U_{b}}{U_{p}}-1\right)=Q_{p}\left(\frac{18}{4.5}-1\right)=3 Q_{p}
$$


And a pedestrian will pass a bicyclist,

$$
\operatorname{Fpass}_{p-b}=Q_{b}\left(1-\frac{U_{p}}{U_{b}}\right)=Q_{b}\left(1-\frac{4.5}{18}\right)=.75 Q_{b}
$$

As explained in Equation (3.1) and (3.2), the frequency of a bicycle passing another bicycle is

$$
\operatorname{Fpass}_{b-b}=0.188 Q
$$

To calculate the number of meetings between mode users $Q_{1}$ is the flow in the primary direction, with a mean speed $U_{1}$ in the primary direction $1 . Q_{1}$ meets mode users, $Q_{2}$ with a mean speed $U_{2}$ within a segment length of $X$, within time $T$ is given with the equation

$$
N_{\text {meet }}=X T Q_{1} Q_{2}\left(\frac{1}{U_{1}}+\frac{1}{U_{2}}\right)
$$

. Pedestrians meeting a bicycle equals

$$
\begin{gathered}
\text { Fmeet }_{p-b}=Q_{b}\left(1+\frac{U_{p}}{U_{b}}\right)=Q_{b}\left(1+\frac{4.5}{18}\right)=1.25 Q_{b} \\
\text { Fmeet }_{b-p}=Q_{p}\left(1+\frac{U_{b}}{U_{p}}\right)=Q_{p}\left(1+\frac{18}{4.5}\right)=5 Q_{p}
\end{gathered}
$$

It follows that bicycles meeting bicycles equals

$$
\text { Fmeet }_{b-b}=2 Q_{b}
$$

Note that meetings receive half the weight of passings because it takes less time to meet than to pass. Combining the previous equations for passings and meetings, a total frequency of passings and meetings simplifies to 


$$
\begin{gathered}
\text { Ftotal }_{p}=1.375 Q_{b} \\
\text { Ftotal }_{b}=5.5 Q_{p}+1.188 Q_{b} \\
\text { Ftotal }_{\text {users }}=\left\{6.875 Q_{p} Q_{b}+1.188 Q_{b}^{2}\right\} /\left(Q_{p}+Q_{b}\right)
\end{gathered}
$$

Table 8: BLOS for Users of a Two-Way, Two Lane Path (Botma 1995)

\begin{tabular}{c|c}
\hline BLOS & $\begin{array}{c}\text { Frequency } \\
\text { events/s }\end{array}$ \\
\hline $\mathrm{A}$ & $<1 / 95$ \\
$\mathrm{~B}$ & $1 / 95-1 / 60$ \\
$\mathrm{C}$ & $1 / 60-1 / 35$ \\
$\mathrm{D}$ & $1 / 35-1 / 25$ \\
$\mathrm{E}$ & $1 / 25-1 / 20$ \\
$\mathrm{~F}$ & $>1 / 20$ \\
\hline
\end{tabular}

\subsubsection{HCM 2000 Shared Off-Street Paths}

The HCM 2000 method is based on the Botma method for LOS for pedestrian-bicycle paths. This method is also based on Botma's hindrance.

Unlike the Botma method that assumes a 50:50 direction split; this method allows the proportioning of directional split.

$$
\begin{gathered}
F_{p}=3 v_{p s}+0.188 v_{b s} \\
F_{m}=5 v_{p o}+2 v_{b o} \\
F=0.5 F_{m}+F_{p}
\end{gathered}
$$

Where

$F_{p}=$ number of passing events (events $\left./ \mathrm{h}\right)$

$F_{m}=$ number of opposing events (events $h$ ) 
$F=$ total number of events $($ events $/ \mathrm{h})$

$v_{p s}=$ flow rate of pedestrians in subject direction (peds $\left./ \mathrm{h}\right)$

$v_{b s}=$ flow rate of bicycle in subject direction (bicycles $/ \mathrm{h}$ )

$v_{p o}=$ flow rate of pedestrians in opposing direction $(\mathrm{peds} / \mathrm{h})$

$v_{b o}=$ flow rate of bicycle in the opposing direction (bicycles $/ \mathrm{h}$ )

If assuming that users directional split is 50:50 then the following equation can be used.

$$
F=v_{p}(2.5+0.5 p)+v_{b}(1-0.812 p)
$$

Where

$v_{p}=$ total pedestrian traffic $($ peds $/ \mathrm{h})$

$v_{b}=$ total bicycle traffic $($ bicycles $/ \mathrm{h})$

Table 9: BLOS for HCM 2000 Shared Off-Street Paths (TRB 2000)

\begin{tabular}{c|c}
\hline BLOS & $\begin{array}{c}\text { Frequency of } \\
\text { events }\end{array}$ \\
\hline A & $\leq 40$ \\
B & $>40-60$ \\
C & $>60-100$ \\
D & $>100-150$ \\
E & $>150-195$ \\
F & $>195$ \\
\hline
\end{tabular}

\subsubsection{FHWA Shared Use Path Analysis Tool}

In 2006, the FHWA sponsored a study and published a report titled Shared-Use Path Level of Service Calculator, A User's Guide (Patten et al. 2006). The Toole Design 
Group developed an easy-to-use analysis workbook for determining BLOS for shared paths. The following is an explanation of the method.

$$
\text { SUPLOS }=5.446-0.00809(E)-15.86(R W)-0.287(C L)-(D P F)
$$

Where

$E=$ Events $=$ Meetings per minute +10 (active passes per minute)

$R W=$ Reciprocal of path width

$C L=1$ if trail has a centerline, 0 if trail has no centerline

$D P F=$ Delayed pass factor

Table 10: BLOS for FHWA Shared Use Path Analysis Tool (Patten et al. 2006)

\begin{tabular}{c|c}
\hline BLOS & $\begin{array}{c}\text { Frequency of } \\
\text { events }\end{array}$ \\
\hline A & $\mathrm{X} \geq 4.0$ \\
B & $3.5 \leq \mathrm{X}<4.0$ \\
C & $3.0 \leq \mathrm{X}<3.5$ \\
D & $2.5 \leq \mathrm{X}<3.0$ \\
E & $2.0 \leq \mathrm{X}<2.5$ \\
F & $\mathrm{X}<2.0$ \\
\hline
\end{tabular}

The variables needed include the path width, presence of center line, volume for all users and the mode split between bicycles, pedestrians, runners, inline skaters, and child bicyclists. The worksheet calculates a cumulative distribution function for meetings and passing of each mode. This model assumes a 50:50 directional mode share user split for all users. Screenshots of the worksheets are shown in Figure 1and Figure 2. 


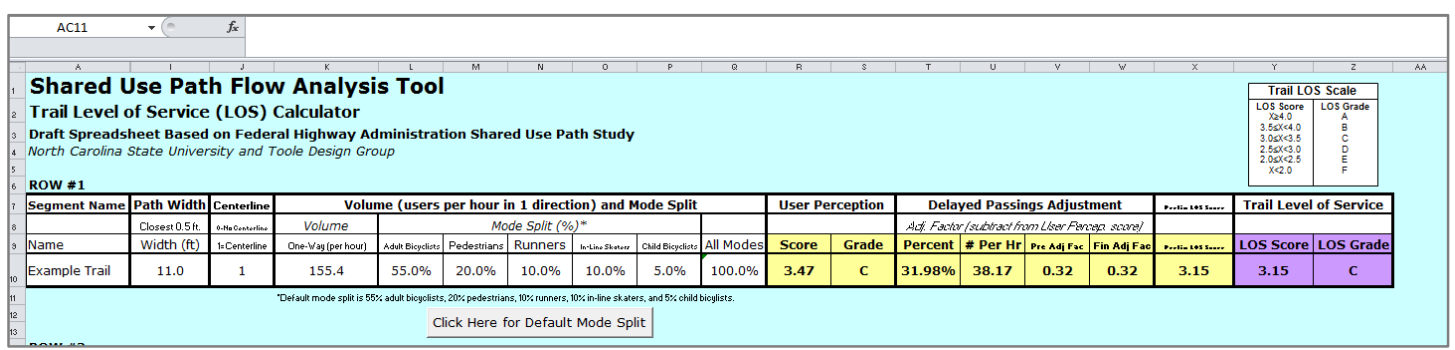

Figure 1: Screenshot of Shared Use Path Flow Analysis Tool, FHWA

\begin{tabular}{|c|c|c|c|c|c|c|c|c|c|}
\hline $\begin{array}{l}\text { Draft Spreads } \\
\text { North Carolina } \\
\text { ROW \#1 }\end{array}$ & $\begin{array}{l}\text { heet Based } \\
\text { State Univer }\end{array}$ & $\begin{array}{l}\text { on Fede } \\
\text { rsity and } 7\end{array}$ & $\begin{array}{l}\text { al Highway Ac } \\
\text { pole Design Gro }\end{array}$ & $\begin{array}{l}\text { ministrat } \\
\text { up }\end{array}$ & tion Share & ed Use F & th Stud & & \\
\hline Segment Name & Path width & Centerline & Volu & ne (users & per hour i & n 1 direct & on) and I & Iode Split & \\
\hline & Closest $0.5 \mathrm{ft}$. & O-MaCenterline & Volume & & & de Split (\%) & & & \\
\hline Name & Width $(\mathrm{ft}$ ) & $1=$ Centerline & One-Way (per hour) & Adult Bicyclizts & \begin{tabular}{|l|} 
Pedestrians \\
\end{tabular} & Runners & In-Lino Skatorr & Child Bisycliste & All Modes \\
\hline Example Trail & 11.0 & 1 & 155.4 & $55.0 \%$ & $20.0 \%$ & $10.0 \%$ & $10.0 \%$ & $5.0 \%$ & $100.0 \%$ \\
\hline & & & a colve & $\begin{array}{r}\text { Uult bicyclists } \\
\mathrm{Cl}\end{array}$ & $\begin{array}{l}\text { lick Here } \mathrm{f} \\
\text { lick pedestrar }\end{array}$ & $\begin{array}{l}\text { s. } 10 \% \text { runners, } \\
\text { or Defaul }\end{array}$ & $\begin{array}{l}0 \% \text { in-line skat } \\
\text { Mode Sp }\end{array}$ & is , and $5 \%$ oh & \\
\hline
\end{tabular}

Figure 2: Screenshot of Shared Use Path Flow Analysis Tool. Inputs, FHWA

\subsubsection{HCM 2010 Method for BLOS for Off -Street Paths}

The most intensive method for determining Capacity BLOS is the HCM method for offstreet paths. This method is also based on the framework developed by Botma. It is more flexible for calculating different width paths and different volumes. The HCM 2010 BLOS for off-street paths calculates the probability of passings and meetings using a cumulative distribution method. The process of calculating the HCM BLOS for off-street paths is described hereafter.

The data needed for this method includes hourly volumes by direction per user (bicyclists, pedestrians, runners, in-line skaters, child bicyclists, or other). Depending on 
the purposes of analysis, hourly, ADT, or peak volumes can be used. Other data that is needed include average speed for each mode and proportion of path users represented by each mode. Path width and presence of center line are also required for evaluation. Average speeds should be collected for each mode on each segment being evaluated, however in the absence of such data, default values for average speed and standard deviation are given for bicycles and pedestrians; $12.8 \mathrm{mph}(20.1 \mathrm{~km} / \mathrm{h})$ with a standard deviation of $3.4 \mathrm{mph}(5.5 \mathrm{~km} / \mathrm{h})$ and $3.4 \mathrm{mph}(5.5 \mathrm{~km} / \mathrm{h})$ with a standard deviation of $0.6 \mathrm{mph}(1 \mathrm{~km} / \mathrm{h})$ respectively.

1) Calculate directional flow rate.

Once data is collected the directional flow rate, $q_{i}$, is calculated for each $i$ mode.

$$
q_{i}=\frac{Q_{T} * p_{i}}{P H F}
$$

Where

$Q_{T}=$ total hourly directional path demand ( all modes by direction $/ \mathrm{hr}$ )

$p_{i}=$ percent path mode split for each mode $i$

$P H F=$ Peak hour factor $=$ average volume per hour/ $(4 *$ volume during peak 15 minute period)

2) Calculate active passings per minute

Active passings refer to the events in which a bicycle passes another mode user moving in the same direction. For example, when a bicycle passes another bicycle or pedestrian going in the same direction but is moving at a slower speed. 


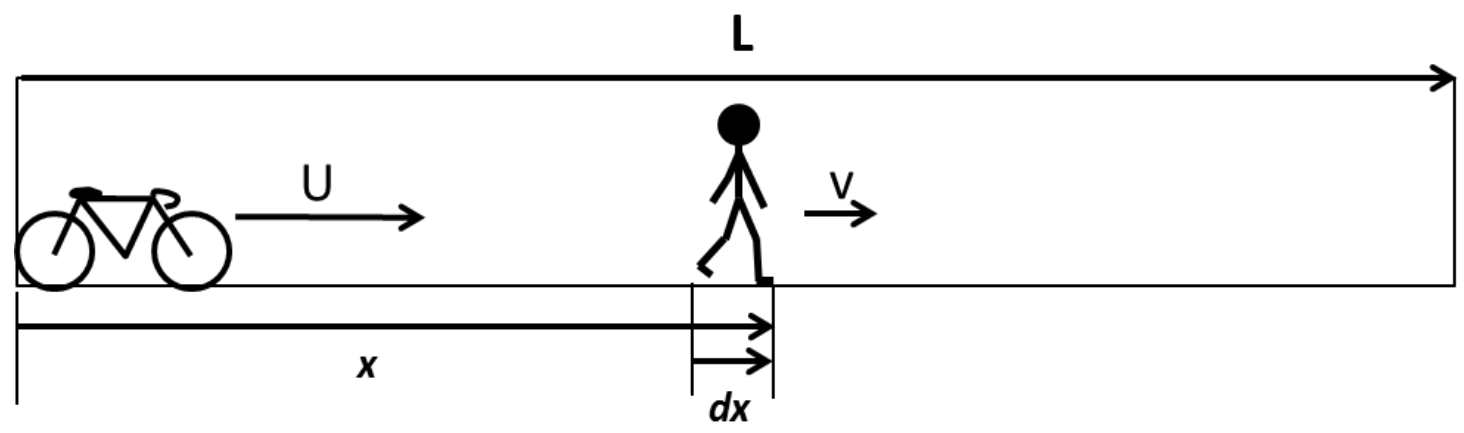

Figure 3: Schematic of Passings

Calculating passings for shared use paths requires the calculation of a cumulative probability of normal distribution. The probability of being passed is expressed by the following equation.

$$
P\left(v_{i}\right)=P\left[v_{i}<U\left(1-\frac{x}{L}\right)\right]
$$

Where

$U=$ speed of the average bicyclist (mph)

$\mathrm{V}_{\mathrm{i}}=$ speed of the other path user mode $i(\mathrm{mph})$

$L=$ length of the segment (mi)

$x=$ distance from average bicyclist to user (mph) 
Because $v_{i}$ is normally distributed it can be estimated for each segment using the following equation.

$$
P\left(v_{i}\right)=0.5[F(x-d x)+F(x)]
$$

Where

$P\left(v_{i}\right)=$ estimated average probabilities at the start and end of each slice

Dividing the length of the segment into dx pieces, the average probability of a passing in each segment can be estimated as the average of the probabilities at the beginning and end of each piece, $\mathrm{dx}$. 0.01 miles is used for the value of $\mathrm{dx}$.

The next step in calculating the probability of passings is by multiplying $P\left(v_{i}\right)$ for each slice of the segment by the density of users of mode i and summing all of the segments. This is done by using the following equation.

$$
A_{i}=\sum_{j=1}^{n} P\left(v_{i}\right) * \frac{q_{i}}{\mu_{i}} * \frac{1}{t} d x_{j}
$$

Where

$A_{i}=$ expected passings per minute by mode $i$ by average bicyclist

$q_{i}=$ directional hourly flow rate of mode i ((modal users $\left.) h\right)$

$\mu_{i}=$ average speed of mode $\mathrm{i}(\mathrm{mph})$

$t=$ path segment travel time for average bicyclist (min)

$d x_{i}=$ length of discrete segment $\mathrm{j}$ (mi) 
This calculation must be repeated for each mode on the path; bicyclists, pedestrians, runners, in-line skaters, and child bicyclists. The final step for determining passings is to sum all the expected number of passings per minute for each mode, $A_{i}$.

$$
A_{T}=\sum_{i} A_{i}
$$

Where $A_{T}$ is the expected active passings for the average bicyclist during the peak 15 minute period.

3) Calculate meetings per minute

Meetings are the numbers of times that a bicycle passes users of the path that are traveling in the opposite direction. At the moment the bicyclist enters the off-street bicycle segment, a set number of users moving in the opposite direction will be on the segment and the bicyclist will pass all of these users. This is represented by the following equation.

$$
M_{1}=\frac{U}{60} \sum_{i} \frac{q_{i}}{\mu_{i}}
$$

Where $M_{1}$ are the meetings per minute of users already on the path segment and $U$ is the speed of the average bicyclist. A second equation is calculated in order to account for the probability of users who have yet to enter the segment during the time that it takes the bicyclist to ride the length of the segment. This is determined by the following equation. 


$$
P\left(v_{0 i}\right)=P\left(v_{i}>X \frac{U}{L}\right)
$$

Where

$P\left(v_{0 i}\right)=$ probability of meeting opposing user of mode $i$

$X=$ the distance of user beyond end of path segment

All other variables were previously defined.

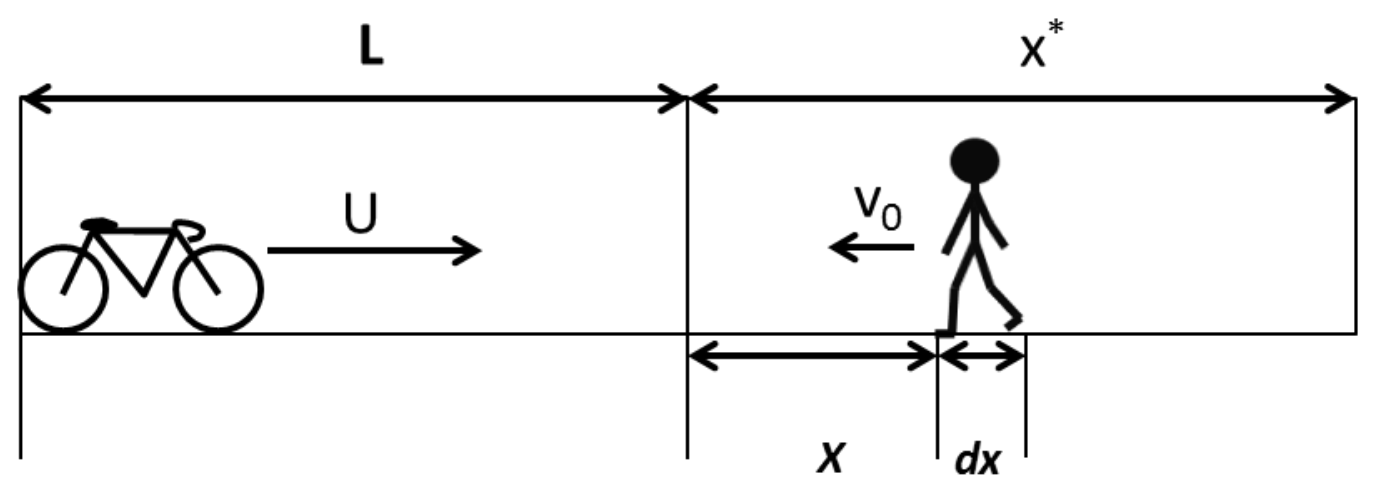

Figure 4: Schematic of Meetings

Because $P\left(v_{0 i}\right)$ is normally distributed, a version of equation (3.19) can be used to estimate the additional meetings.

$$
P\left(v_{0 i}\right)=0.5[F(x-d x)+F(x)]
$$

Where $x^{*}$ is the length of the path outside of the segment in which users travel before entering the segment area. This is based on the time it takes the average bicycle to complete riding on segment, $L$. For meeting bicycles $x^{*}$ would equal $L$ because they would be going the same speed in the same time. For meeting pedestrians, $x^{*}$ is equal to the length that the average pedestrian can cover at speed $v_{0}$ in the same time that it 
takes the average bicycle to complete riding on segment $L$. Again the appropriate length of $\mathrm{dx}$ is equal to 0.01 miles.

Once $P\left(v_{0 i}\right)$ is calculated for each slice of segment $x^{*}$, then each slice is multiplied by $f$, the density of users of mode $i$ and summing all of the segments using the following equation.

$$
M_{2 i}=\sum_{j=1}^{n} P\left(v_{0 i}\right) * \frac{q_{i}}{\mu_{i}} * \frac{1}{t} d x_{j}
$$

Where $M_{2 i}$ is the expected meetings per minute of user of mode $i$ that enters the segment while the average bicyclist enters the segment. The total number of meeting per each mode is calculated by the following equation.

$$
M_{T}=\left(M_{1}+\sum_{i} M_{2 i}\right)
$$

4) The probability of delayed passings

The next variable that is necessary for calculating off-street paths is the probability of delayed passings. This is the delay in minutes from the occurrence of two users that are meeting while the bicyclist wants complete a passing. The bicyclist must delay or slow its passing maneuver.

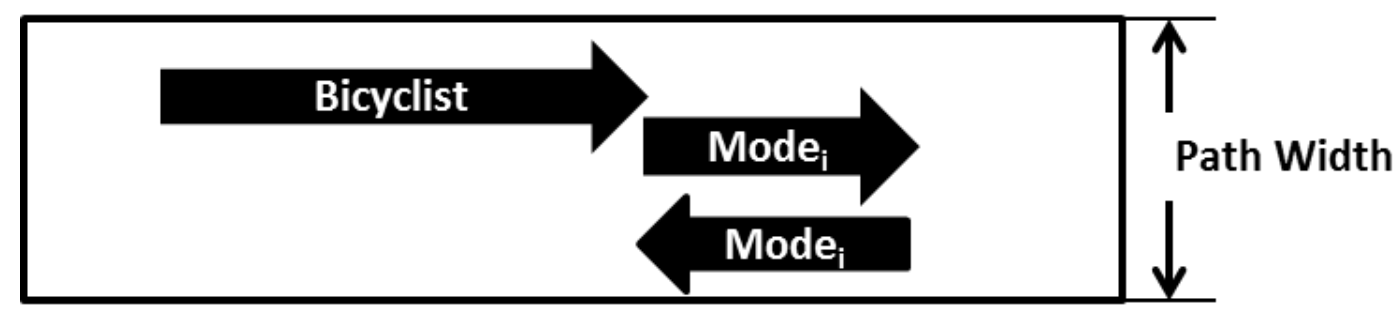

Figure 5: Delay from Cyclist Passing a Meeting of Two Path Users 
The calculation of the probability of delayed passings is dependent on the width of the path. The probability of passing section being blocked by mode $i$ is give by the following equation.

$$
P_{n i}=1-e^{-p_{i} k_{i}}
$$

Where

$P_{n i}=$ probability of passing sections being blocked by mode $i$

$P_{i}=$ distance required to pass mode $i$

$k_{i}=$ density of user mode $i$ ( users per mile)

The width of the path determines the number of lanes in the path regardless of markings. The following table shows the effective number of operational lanes based on path width.

Table 11: Number of Operational Path Lanes Based on Path Width (TRB 2010)

\begin{tabular}{cc}
\hline Path width, $\mathrm{ft}$. & Lanes \\
\hline $8.0-10.5$ & 2 \\
$11.0-14.5$ & 3 \\
$15.0-20.0$ & 4 \\
\hline
\end{tabular}

For two-lane paths there are two scenarios for a bicyclist (subject); both lanes taken by a user mode (opposing), blocking the bicyclist, and only one lane used by a user mode, not blocking bicyclist.

The probability of delayed passings in the subject direction, $\mathrm{P}_{\mathrm{ds}}$ and the opposing direction $P_{d o}$ are calculated using the following equations. 


$$
\begin{aligned}
& P_{d s}=P_{n o} P_{n s}+P_{n o}\left(1-P_{n s}\right)\left(1-P_{d o}\right) \\
& P_{d o}=P_{n o} P_{n s}+P_{n s}\left(1-P_{n o}\right)\left(1-P_{d s}\right)
\end{aligned}
$$

Where

$P_{d s}=$ probability of delayed passing in subject direction

$P_{d o}=$ probability of delayed passing in opposing direction

$P_{n o}=$ probability of blocked lane in opposing direction

$P_{d s}=$ probability of blocked lane in subject direction

Combining equations 3.27 and 3.28 ,

$$
P_{d s}=\frac{P_{n o} P_{n s}+P_{n o}\left(1-P_{n s}\right)^{2}}{1-P_{n o} P_{n s}\left(1-P_{n o}\right)\left(1-P_{n s}\right)}
$$

Equations 3.26 and 3.29 are then used to solve for $P_{d s}$. This must be calculated for all modal pairs. Since we are only considering bicyclists and pedestrians, only two sets of calculations need to be made.

Next, the total probability of delayed passings, $P_{T d s}$, must be calculated from all mode pairs. As described above, there are only two solutions for $P_{d s}$; the bicycle/bicycle passings and the pedestrian/bicycle passings.

The total probability of delayed passings is calculated by

$$
P_{T d s}=1-\prod_{m}\left(1-P_{m d s}\right)
$$

The last calculation is the total delayed passings per minute.

$$
\text { Delayed passings per minute }=A_{T} * P_{T d s} * P H F
$$


Once the values for total meetings per minute, the active passings per minute, and the delayed passings per minute in the same direction of travel have been calculated, the HCM BLOS worksheet for Pathways, BLOS for off street paths can now be determined.

For this study, a workbook was developed to calculate the total meetings per minute, active passings per minute, and the delayed passings per minute. These values were entered into the HCM BLOS worksheet for off-street paths.

\subsection{Signalized intersections}

\subsubsection{HCM 2000 Signalized Intersections}

One method for determining BLOS at intersections was found that incorporates bicycle volumes is found in the HCM 2000. This method was removed in the HCM 2010 because of minimal testing of the methodology and insufficient evidence for default values.

This method uses the measurement of control delay, in seconds per bicycle, to determine the BLOS score. First, the capacity of the bicycle lane is estimated. It is recommended that at saturation flow rate of 2000 bicycles/hour be used.

$$
c_{b}=s_{b} \frac{g}{C}=2000 \frac{g}{C}
$$

Where 
$c_{b}=$ bicycle lane capacity, bicyclesh

$s_{b}=$ saturation flow rate, bicycles $\mathrm{h}=2000$

$g=$ effective green time for the bicycle lane, $\mathrm{s}$

$C=$ Signal Cycle Length (s)

The bicycle lane capacity is used to solve the equation for control delay,

$$
d_{b}=\frac{0.5 C\left(1-\frac{g}{c}\right)^{2}}{1-\left[\frac{g}{c} \min \left(\frac{v_{b}}{c_{b}}, 1.0\right)\right]}
$$

Where

$d_{b}=$ control delay for bicycles, $\mathrm{s} /$ bicycle

$c_{b}=$ bicycle volume for one direction bicycle lane, bicycle $/ \mathrm{h}$

\subsection{SITE DESCRIPTION}

The site chosen for the application of the BLOS methods with bicycle volumes is the Hawthorne Bridge Corridor. The following is a description of the study area and its location in the city.

Portland, Oregon is located on the Willamette River. The downtown central business district, southwest and northwest neighborhoods are located on the west bank of the river. The southeast, northeast, and north neighborhoods are on the east side of the river. See Figure 6. Beyond the downtown district, along the west side of the river, west side 
neighborhoods have steep topography and curvilinear roads. Bicycle and pedestrian connectivity between neighborhoods is generally poor. For bicyclists, steep topography, narrow winding roads and fast-moving traffic make these west side neighborhoods less enticing for traveling or commuting by bicycle.

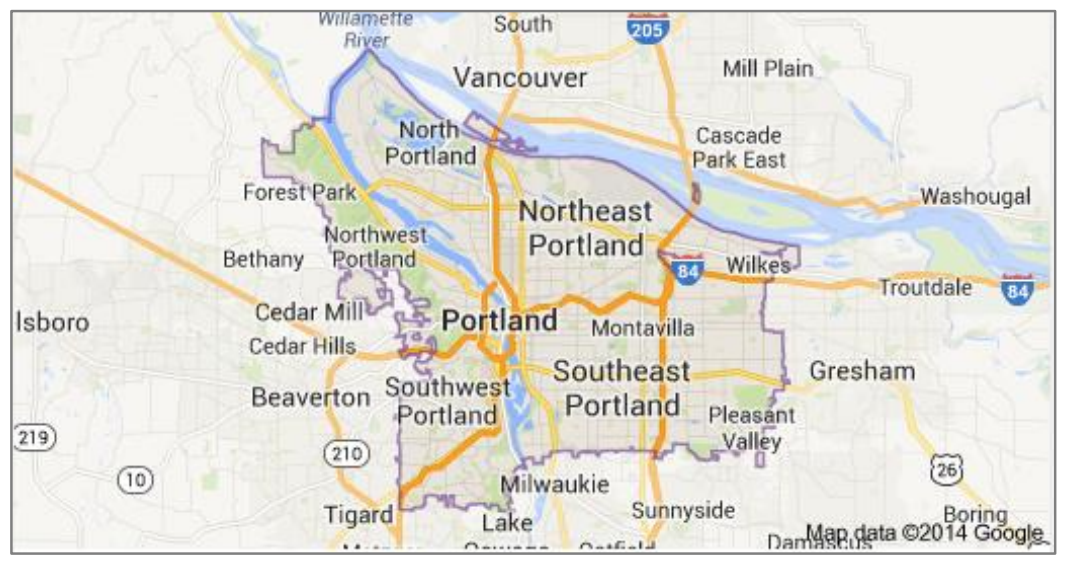

Figure 6: Area Map of Portland Oregon Source: Google Maps

In contrast, the east side of the Willamette River is less steep. Most neighborhoods have grid plan street layouts. Bicycle boulevards are located on lower volume roads, parallel to major arterials, and bicycle facilities have relatively good connectivity. Because of these attributes, the east side neighborhoods are more attractive for bicycling. Some east side neighborhoods, close to downtown, have a bicycle mode share of $10 \%$ to $13 \%$ (Geller 2013).

The Portland Downtown commercial business district is located on the west bank of the Willamette River. Travel between the east and west sides require access by a bridge. Portland has 11 bridges that cross the Willamette River. These bridges act as traffic 
bottlenecks between the east and west sides of the city. Three bridges are closed to bicycle traffic; two are freeway bridges and the third is an exclusive freight bridge. The remaining eight bridges have some bicycle and pedestrian facilities but vary in convenience, quality and comfort. Eight of the bridges that are connected to downtown Portland are shown in Figure 7. The 2012 estimated bicycle Annual Average Daily Traffic (AADT) is given for each bridge. The Hawthorne Bridge has the highest bicycle AADT, estimated at 8,000 (PBOT 2012). 


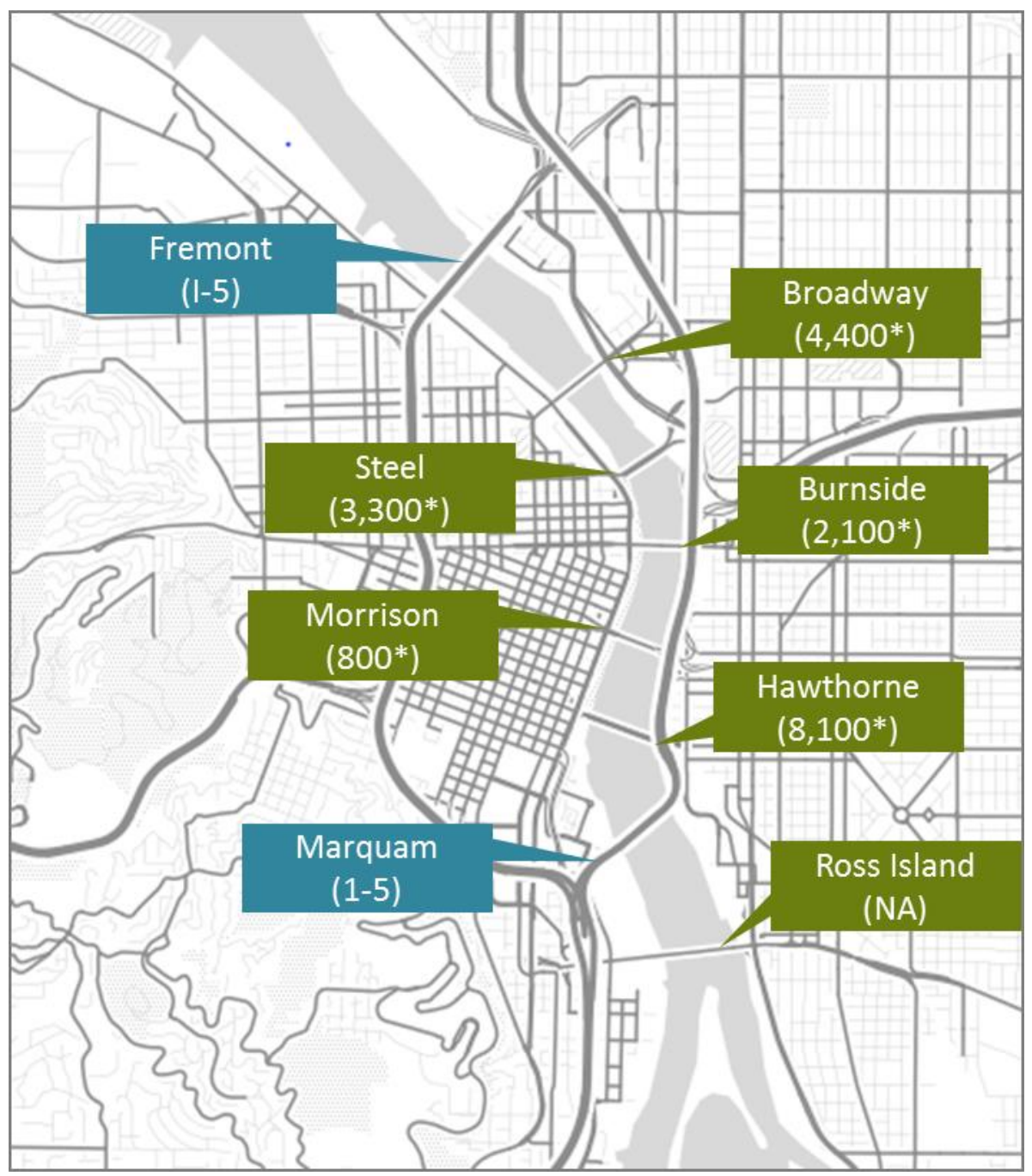

Figure 7: 2012 Estimated Portland Bridge Bicycle AADT (PBOT 2012) Map Source: maps.stamen.com

The study area, which will be referred to as the Hawthorne Bridge Corridor, is illustrated in Figure 8. The Hawthorne Bridge Corridor was chosen because it has several advantages over other locations. First, this location has the highest bicycle traffic volume in Portland. The goal of this study is to explore if current bicycle traffic volumes are great enough to warrant the development of an LOS for bicycle traffic 
flow, therefore choosing a site with the largest known bicycle volumes is appropriate. Second, this segment contains many different types and configurations of bicycle amenities with minimal changes in traffic volumes. Within the chosen study area there was limited access to the segment. The segment is located on a raised viaduct with only four access points where bicycle traffic could increase or decrease. This will be discussed in more detail later in this section. The importance of having limited access points was so that BLOS methods could be tested with the same estimated traffic volumes. Third, this location has the most multi-modal data available in Portland. Fourth, The Hawthorne Bridge is a good example of a typical bottleneck traffic constraint in many large cities. Many major cities are built on or along rivers and require the use of bridges to access key areas of the city. 


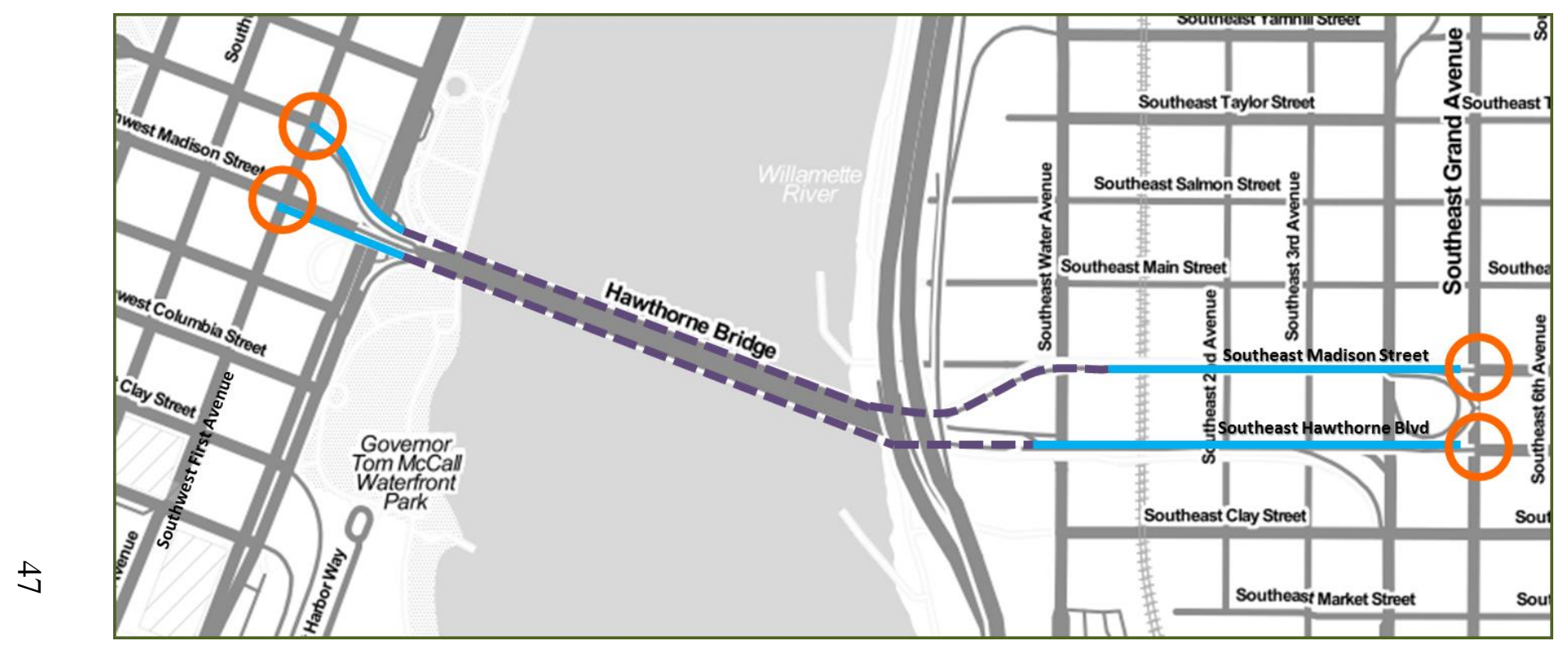

Figure 8: Hawthorne Bridge Corridor Study Area 


\subsection{The Hawthorne Bridge Corridor Study Area}

The Hawthorne Bridge was built in 1910 and is the oldest vertical lift bridge in the US that is still functioning. ${ }^{4}$ The bridge is owned and maintained by Multnomah County. It was renovated in 1999. During the renovation, sidewalks were widened from six to ten feet to accommodate increasing bicycle and pedestrian traffic. In a joint effort between a local bicycle advocacy group, Cycle Oregon, and the City of Portland, the bridge received a permanent bicycle data collection system in 2011. The permanent data collection equipment consists of pneumatic tubes placed on the bridge on each side of the bridge. Additionally, a public bicycle count display, known as The Totem, is located on the west side of the bridge counts in real time.

Viaducts lead traffic onto and off of the Hawthorne Bridge. They begin and end at signalized intersections. The distance between them is approximately three quarters of a mile. On the east side, access to the bridge is reached by a viaduct that begins at a major east side arterial couplet; northbound 99W, or SE Grand Avenue, illustrated in Figure 8 and circled on the east, or right side of the map. This viaduct is split into two structures; westbound and eastbound. The westbound viaduct begins at the intersection of SE Grand Avenue and Madison Street, and will be referred to as the Westbound Madison

\footnotetext{
${ }^{4}$ http://web.multco.us/bridges/hawthorne-bridge
} 
Viaduct. The Eastbound viaduct ends at SE Grand and Hawthorne Boulevard, and will be referred to as the Eastbound Hawthorne Viaduct. The Westbound Madison Viaduct will be considered the beginning location of the study area.

The West side of the bridge includes a short viaduct that splits to two one way ramps illustrated in Figure 8. The westbound ramp terminates at the intersection of First Avenue and Main Street. This is where the westbound study area ends, illustrated by the two circles on the west side, or left side of the map. The westbound viaduct also includes a left turn ramp onto SW First Avenue, a one-way southbound street.

The Eastbound ramp begins at SW first and Madison. A second east bound ramp is located on Naito Parkway. Note that the eastbound bicycle traffic must cross the ramp from Naito Parkway. Bicycle traffic from Waterfront Park accesses the Hawthorne Bridge via the Naito Parkway ramp on the sidewalk. There are two main paths that are taken by bicycle traffic.

\subsection{Segment Descriptions}

The area of study was broken into 14 different elements; on-road bike lanes (designated by solid blue lines), off-road shared paths (designated by dashed purple lines), and signalized intersections (designated by orange circles) illustrated in Figure 9. The onroad and off-road egments are divided into lengths of consistent bicycle facilities. For example, if a value of a variable used in calculating BLOS changes, such as a bike lane 
width, then a new sub-segment begins. Each element is labels with number, circled in red.

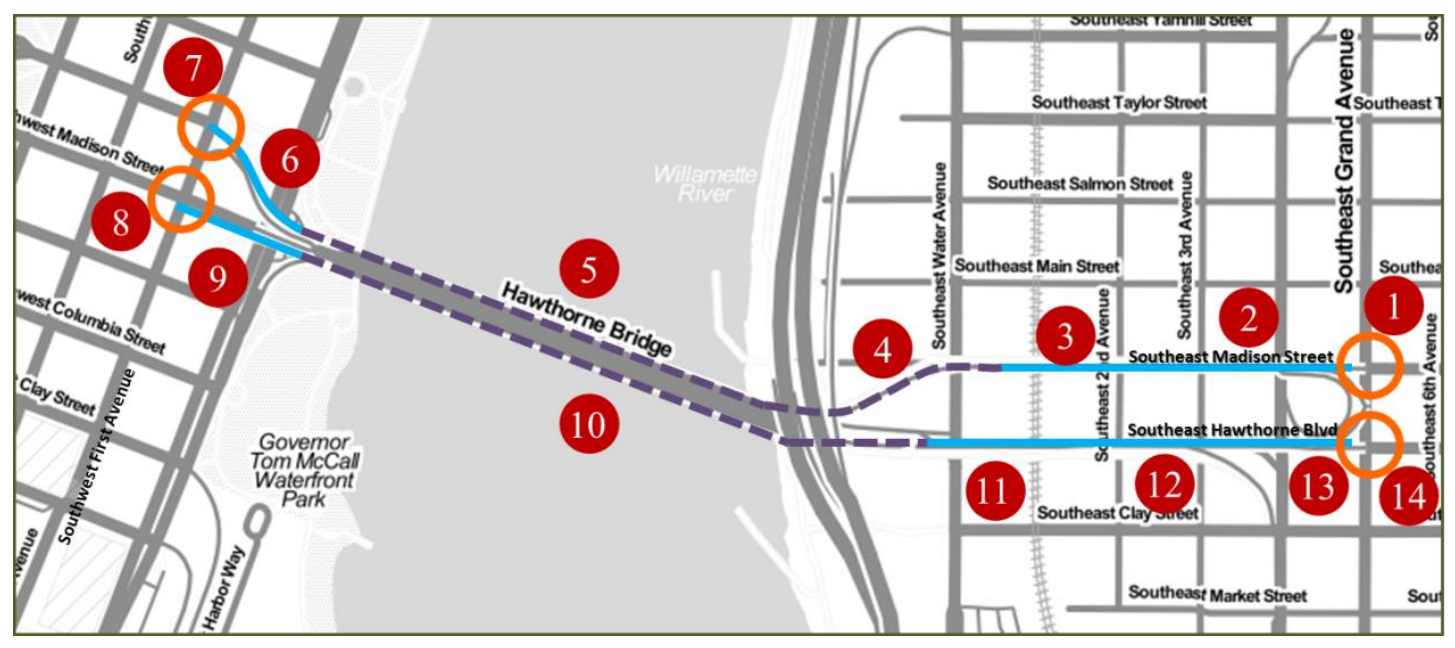

Figure 9: Hawthorne Bridge Study Corridor with Element Numbers

The area of study begins and ends at the controlled intersections on the east side, following the direction of travel. Table 12, Table 13, and Table 14 describe each set of elements; on-street, off-street, and signalized intersections respectively.

Table 12 provides a photo of each on-street bike lane segment, the number designated in Figure 9 , the name, the length, width of the lane, and the unique features in the segment. Table 13 also gives the same variables for off-street path segments as Table 12 gave for on-street segments. Table 14 provides a photo of the intersections, the designated number given in Figure 9, the bicycle green time, the cycle length and the important features of the intersections. 
Table 12: On-Street Segments

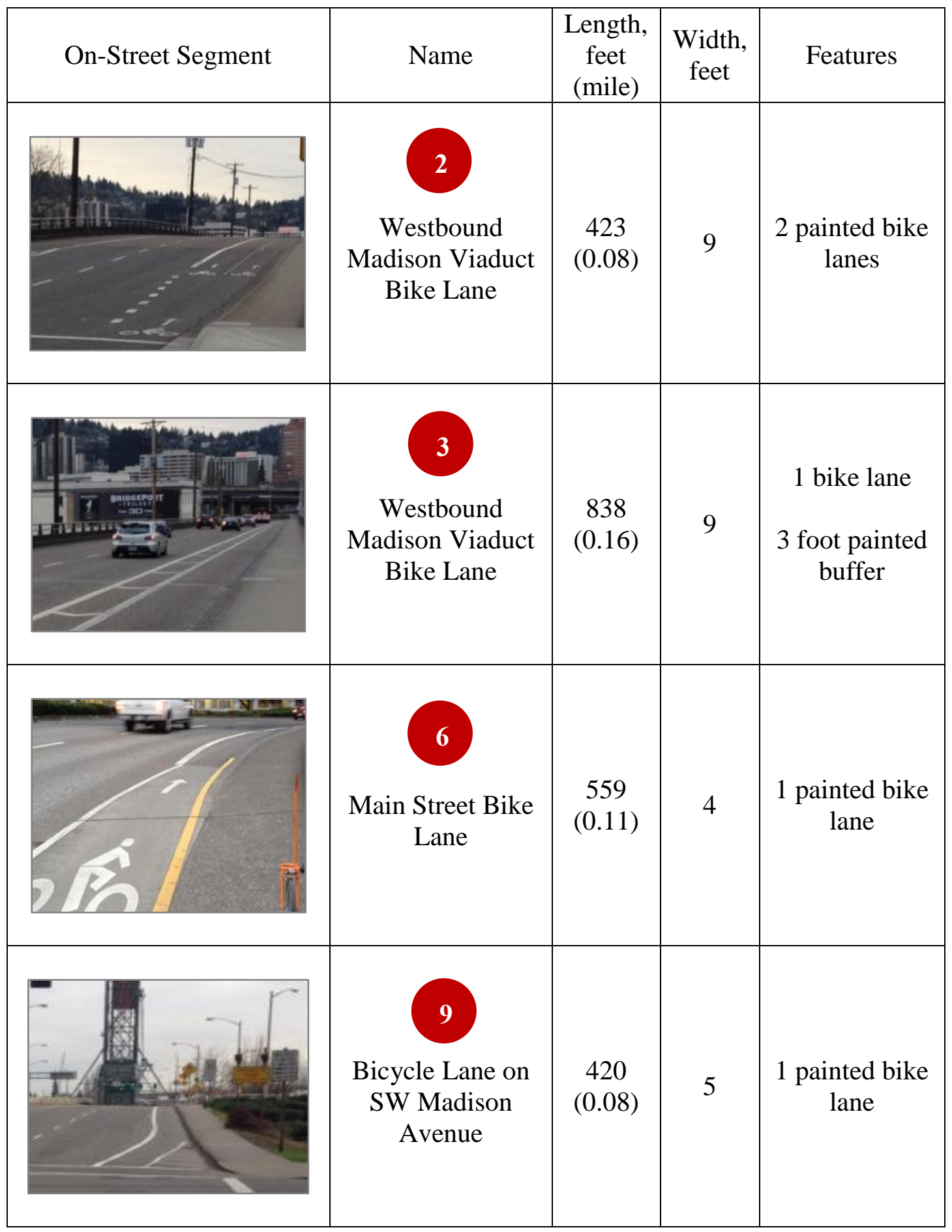




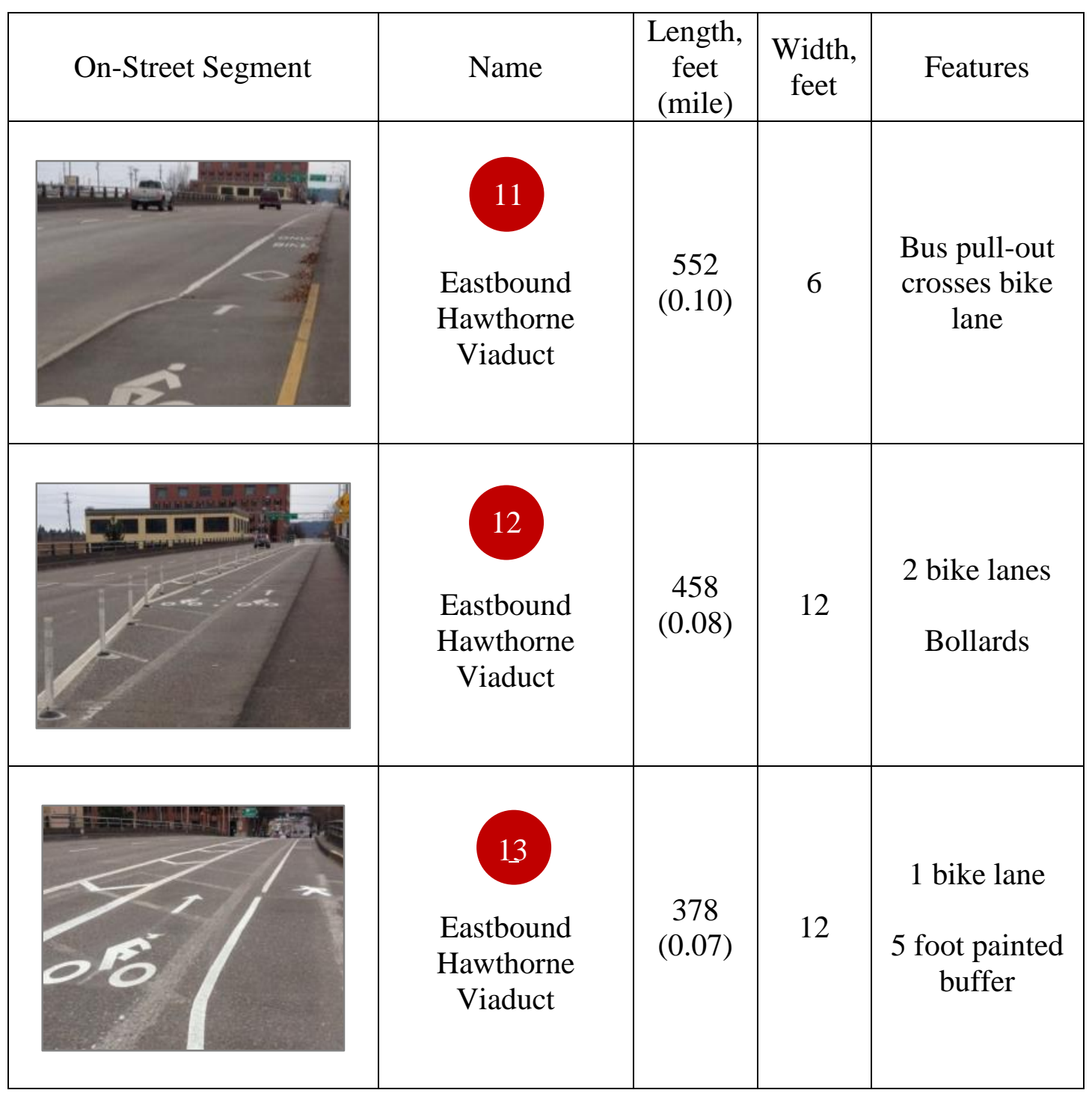


Table 13: Off-Street, Shared Path Segments

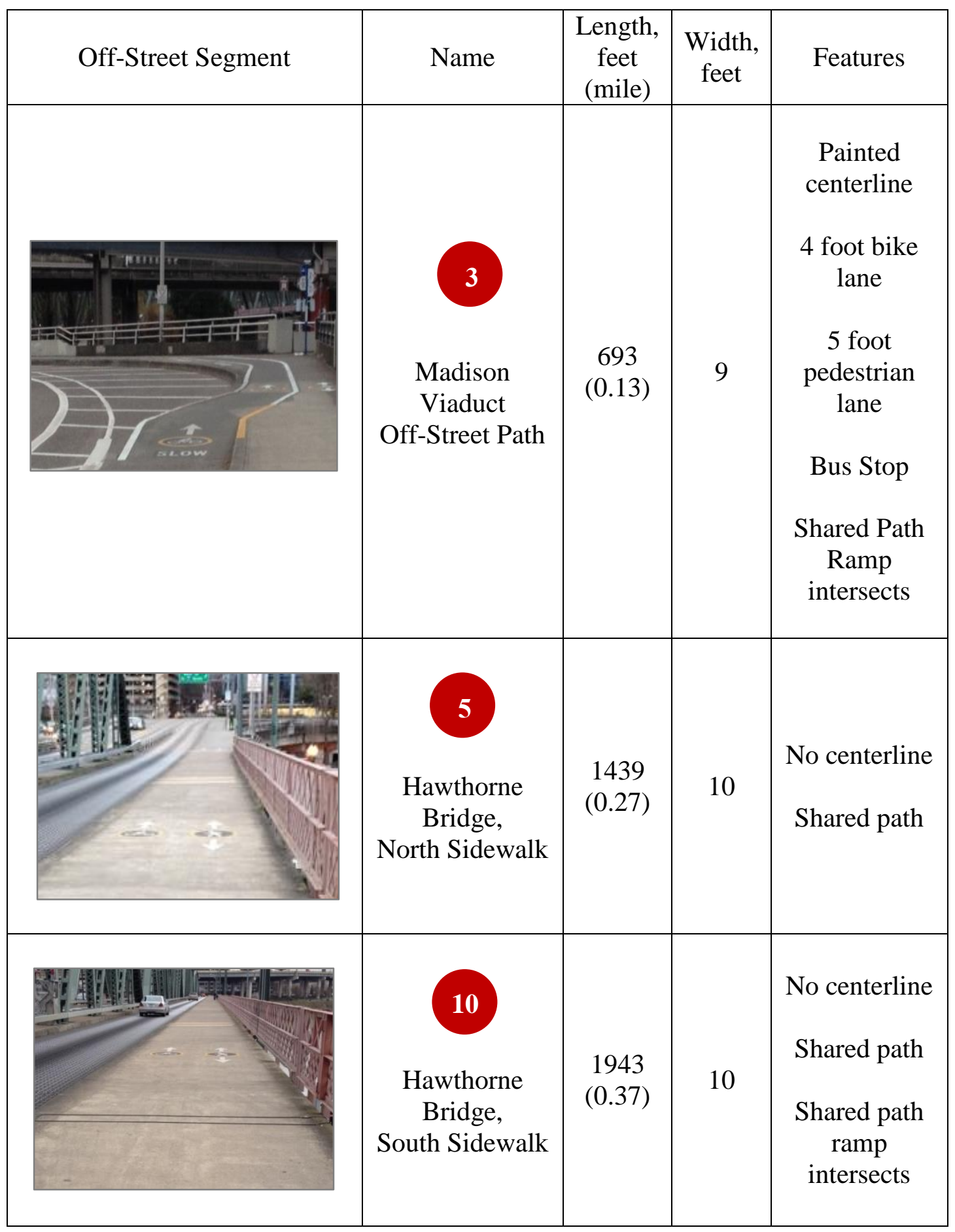


Table 14: Signalized Intersections

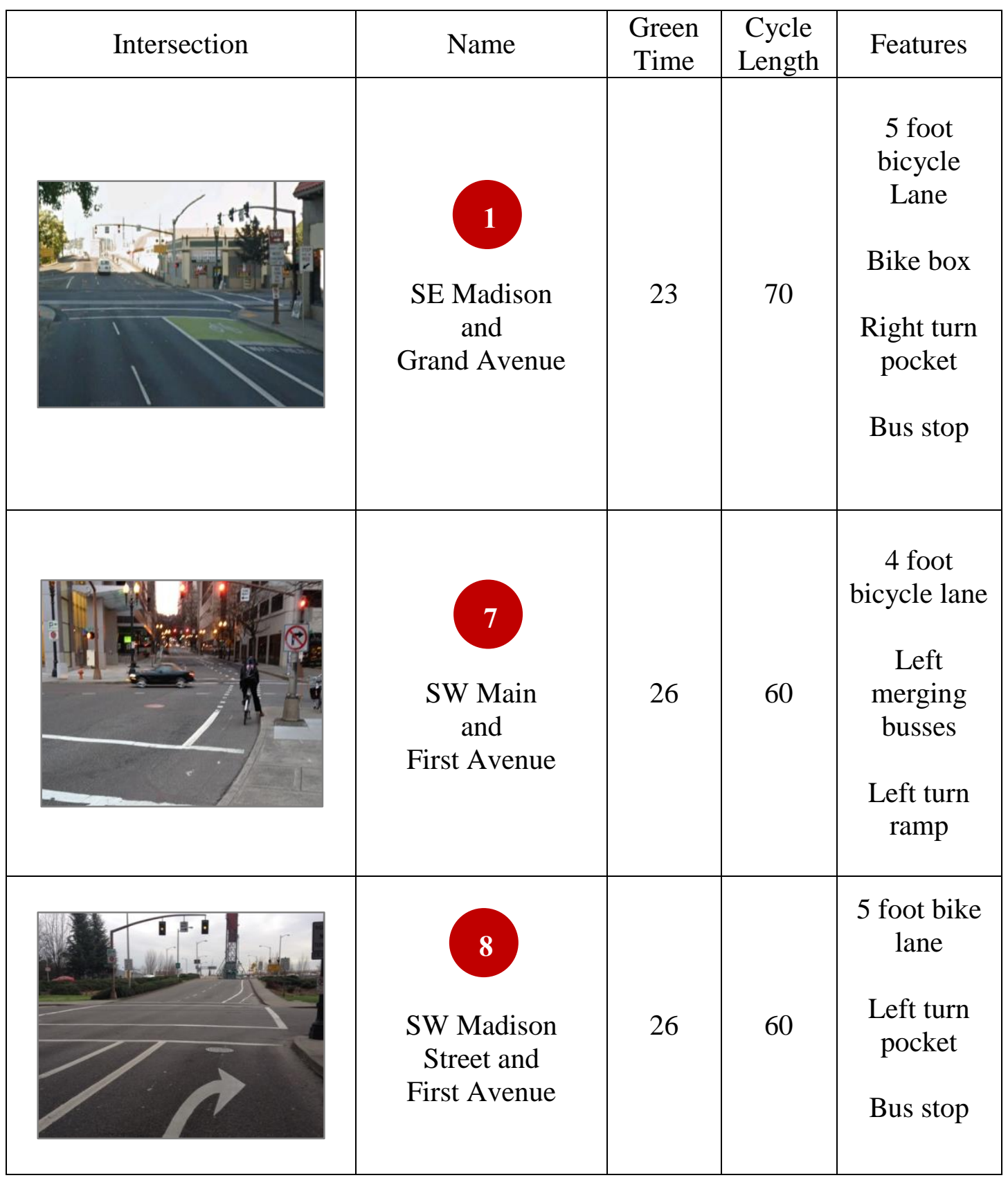




\begin{tabular}{|c|c|c|c|c|}
\hline Intersection & Name & $\begin{array}{c}\text { Green } \\
\text { Time }\end{array}$ & $\begin{array}{c}\text { Cycle } \\
\text { Length }\end{array}$ & Features \\
\hline & 14 & 23 & 70 & $\begin{array}{c}7 \text { foot } \\
\text { bicycle line } \\
\text { SE Hawthorne } \\
\text { Boulevard } \\
\text { and } \\
\text { Grand Avenue } \\
\text { painted } \\
\text { buffer }\end{array}$ \\
\hline
\end{tabular}




\subsection{DATA COLLECTION}

Data along the Hawthorne Bridge Corridor were collected from the Portland Bureau of Transportation (PBOT). In addition, geometric data and directional mode share of bicycles and pedestrians were manually collected to fill gaps in the data.

\subsection{Hawthorne Bridge Data}

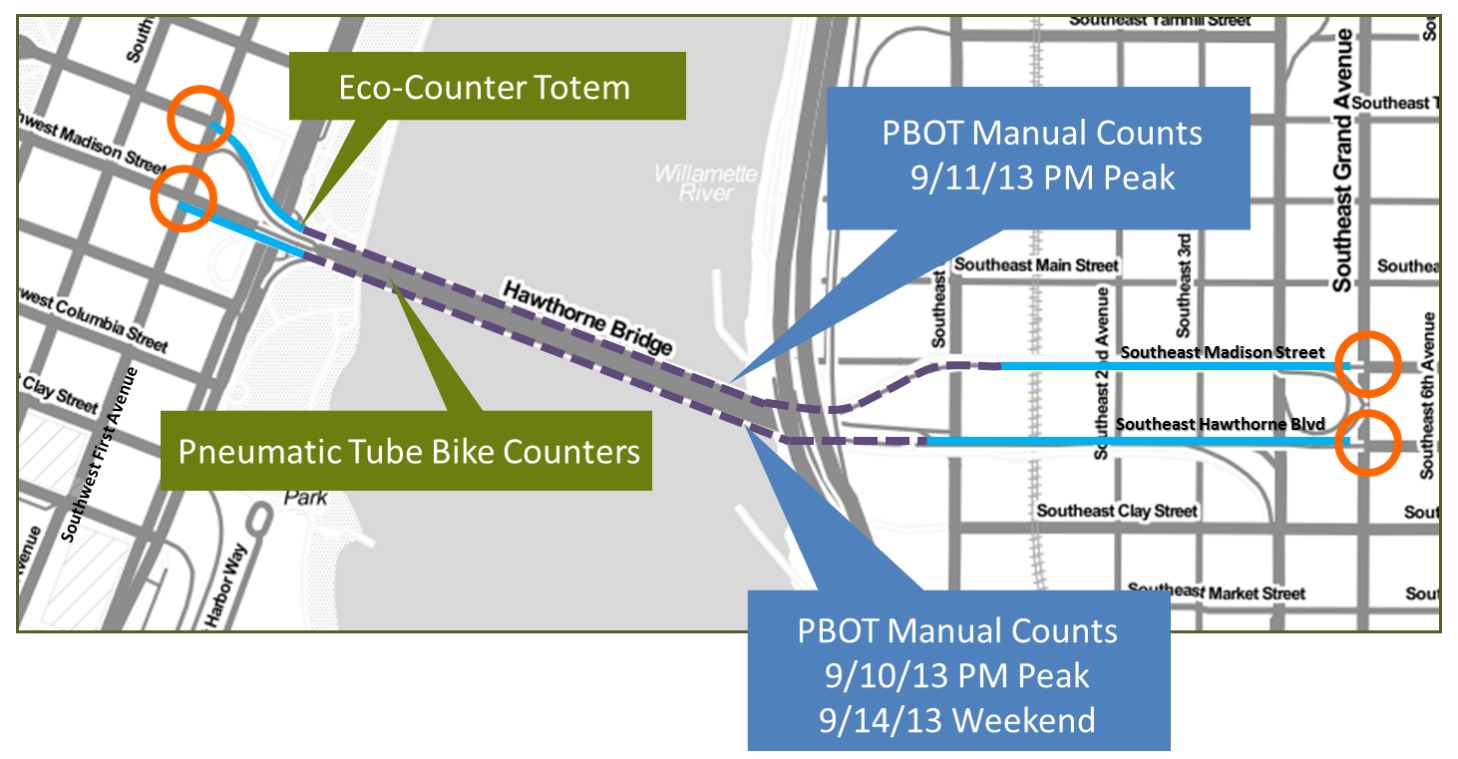

Figure 10: Collected Data from the Hawthorne Bridge

\subsubsection{Portland Bureau of Transportation Manual Counts}

Yearly manual bicycle and pedestrian counts collected by the PBOT were used for this study. The manual counts are collected annually by trained volunteers, usually during the second and third weeks of September as part of the National Bicycle and Pedestrian Documentation Project. Typically, bicycle and pedestrian counts are collected in 15 
minute increments for two hours, during traditional peak traffic hours of 7AM to 9 AM and 5PM to 7 PM. Data is also collected on the weekends between the hours of 9AM and 11AM.

The counts used in this study were collected on the south and north sidewalks of the Hawthorne Bridge at the location illustrated in Figure 10. The north sidewalk bicycle traffic is predominantly westbound, to downtown Portland. Peak traffic for all modes on the north side of the bridge is during the morning peak. The South Sidewalk traffic is predominantly eastbound and the peak traffic is during the evening peak. The counts include bicycle and pedestrians volumes by gender. The directional split is unknown. Table 15 is a summary of the counts that were used in this study.

Table 15: PBOT Manual Counts

\begin{tabular}{ccccccc}
\hline Date & Location & $\begin{array}{c}\text { Start } \\
\text { Time }\end{array}$ & $\begin{array}{c}\text { End } \\
\text { Time }\end{array}$ & Bikes & Peds & Total \\
\hline $\begin{array}{c}\text { Tuesday, } \\
\text { September 10, } \\
2013\end{array}$ & $\begin{array}{c}\text { South } \\
\text { Sidewalk }\end{array}$ & 5 PM & 7 PM & 1522 & 205 & 1727 \\
$\begin{array}{c}\text { Wednesday, } \\
\text { September 11, } \\
2013\end{array}$ & $\begin{array}{c}\text { North } \\
\text { Sidewalk }\end{array}$ & 5PM & 7PM & 243 & 271 & 514 \\
$\begin{array}{c}\text { Saturday, } \\
\text { September 14, } \\
2013\end{array}$ & $\begin{array}{c}\text { South } \\
\text { Sidewalk }\end{array}$ & 9 AM & 11AM & 243 & 271 & 514 \\
\hline
\end{tabular}

Note that the volumes in Table 15 are two hour counts. The Tuesday, September 10 count was during the peak hour. The mode split was $88 \%$ bicycles and $12 \%$ pedestrians. For the Wednesday, September 11 the count was also collected during the PM peak 
period. However, it is not the peak period for the north side of the bridge, which carries commuter traffic during the AM peak. The mode split during this time was $47 \%$ bicycles and 53\% pedestrians. The Saturday, September 14 mode split was $43 \%$ bicycles and $57 \%$ pedestrians.

\subsubsection{Hawthorne Bridge Continuous Bicycle Counts}

Portland Bureau of Transportation, in conjunction with Multnomah County and Cycle Oregon, installed an Eco-Counter ${ }^{\mathrm{TM}}$ automated continuous bicycle counter display on the deck of the Hawthorne Bridge (PBOT 2013). One set of tubes was installed on the south sidewalk and another on the north sidewalk. Pneumatic tubes count bicyclists and can detect the direction of travel. The bicycle counts are recorded in 15-minute increments. A public bicycle count display, the Totem, is located on the west side of the Hawthorne Bridge, illustrated in Figure 10. The Totem displays bicycle counts in real time from both sets of tubes on the bridge and also displays the yearly accumulated bicycle volumes, shown in Figure 11. Figure 12 is a screenshot of the Eco Counter website, displaying the data in an hourly format. Data can be downloaded in yearly, daily, hourly, and 15 minute increments . Spreadsheets can also be easily be downloaded from the website in Microsoft Excel format. 


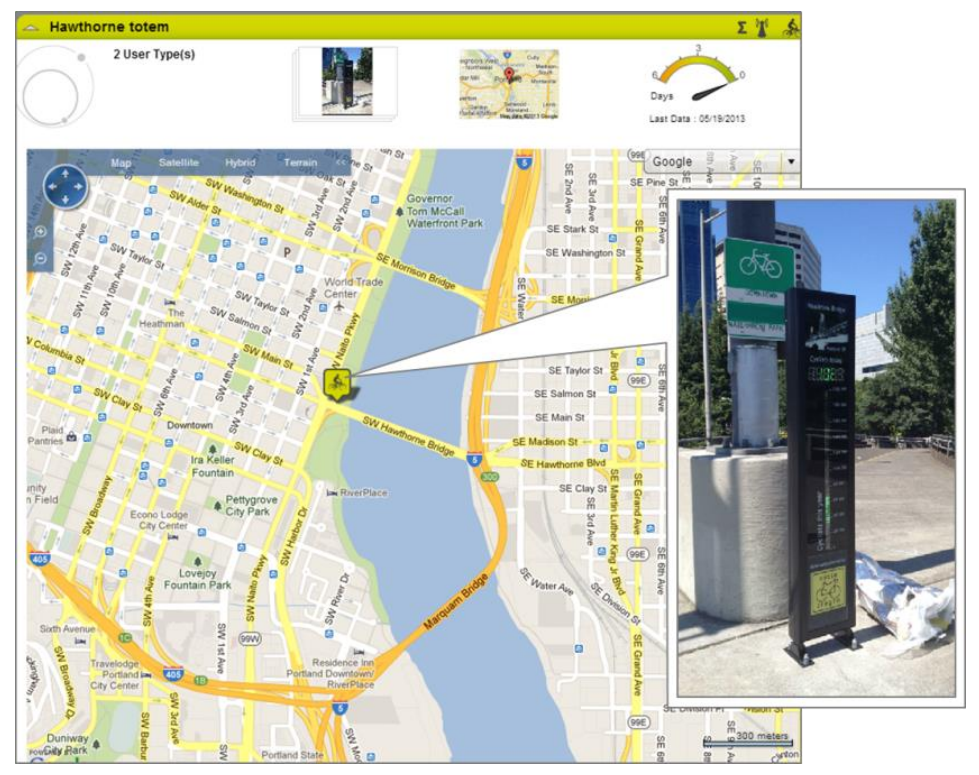

Figure 11: Vicinity map of Hawthorne Bridge from Eco Counter Website and Hawthorne Totem Counter Source: EcoVisio

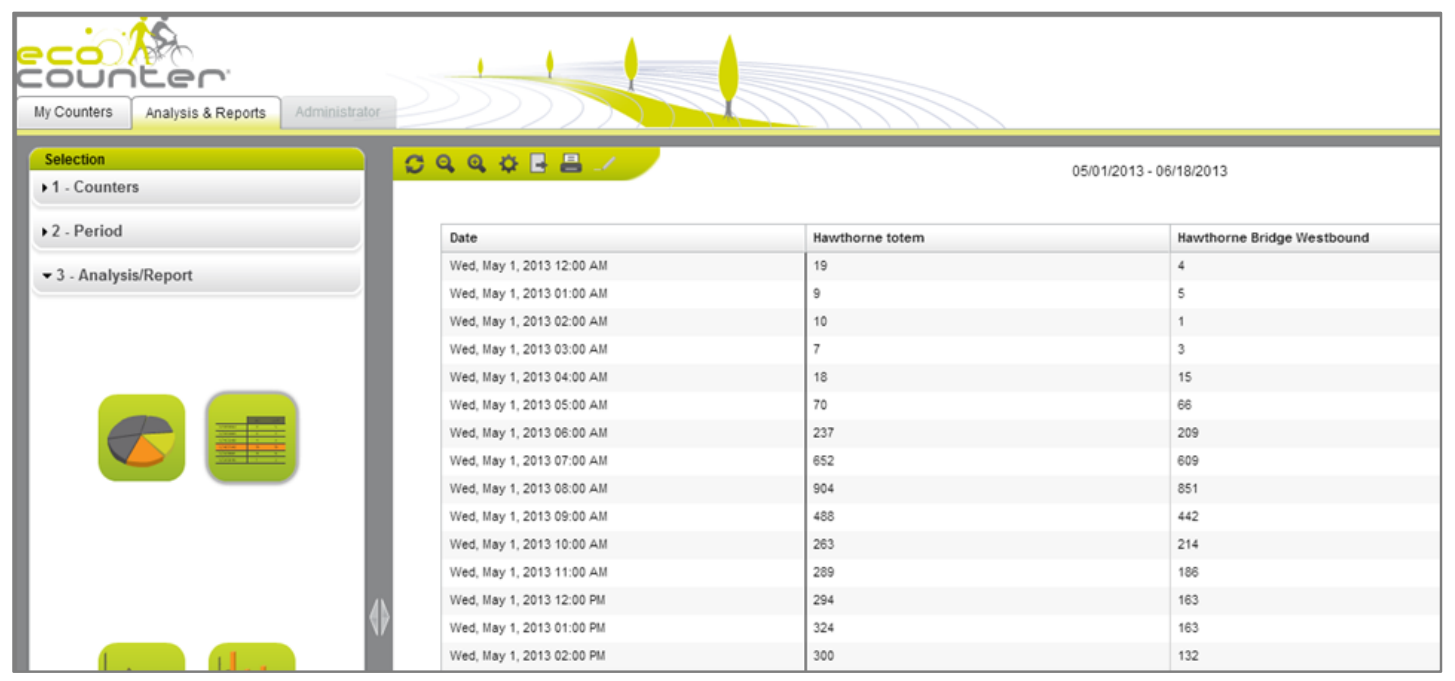

Figure 12: Screenshot of the Eco Counter Website Displaying Available data Format Source:EcoVisio 
Hourly and daily counts from 2013 and 2014 were downloaded. The combined directional 2013 bicycle AADT was 4,670 and the highest weekday volume was 8,452. The highest weekend volume was 9,834 bicyclists.

A typical summer day (June 2013 - September 2013) had an average bicycle AADT of 5780 and an hourly average of 240 bicycles per hour. A typical 8AM Peak hour on the north sidewalk was 716 and with a high of 969 . The average 5 PM peak count of 765 with a high of 1,010 . The greatest one hour summer count was 1697 bikes per hour in June 2013.

A typical 2013/2014 winter day (December 2013- February 2014) had an average bicycle AADT of 3,032 and an hourly average of 126 bikes per hour. A typical 8AM peak hour count on the north side of the bridge was 490 bicycles per hour and the 5PM peak on the south sidewalk was 451 . Weekend 1 PM counts averaged 126 bicycles per hour, combining north and south sidewalks.

Average summer and winter hourly volumes are illustrated in Figure 13. The Hawthorne Bridge has typical commute bicycle volumes; a peak in volumes between 7AM and 9AM and between 5PM and 7PM. The month with the greatest bicycle volumes was in August. The weekday peak hour on the north side of the Hawthorne Bridge in August was 976 on Tuesday, August 13 at 8AM. The highest hourly count on the south sidewalk was 950 bicycle on Wednesday, August 7 at 5PM. 


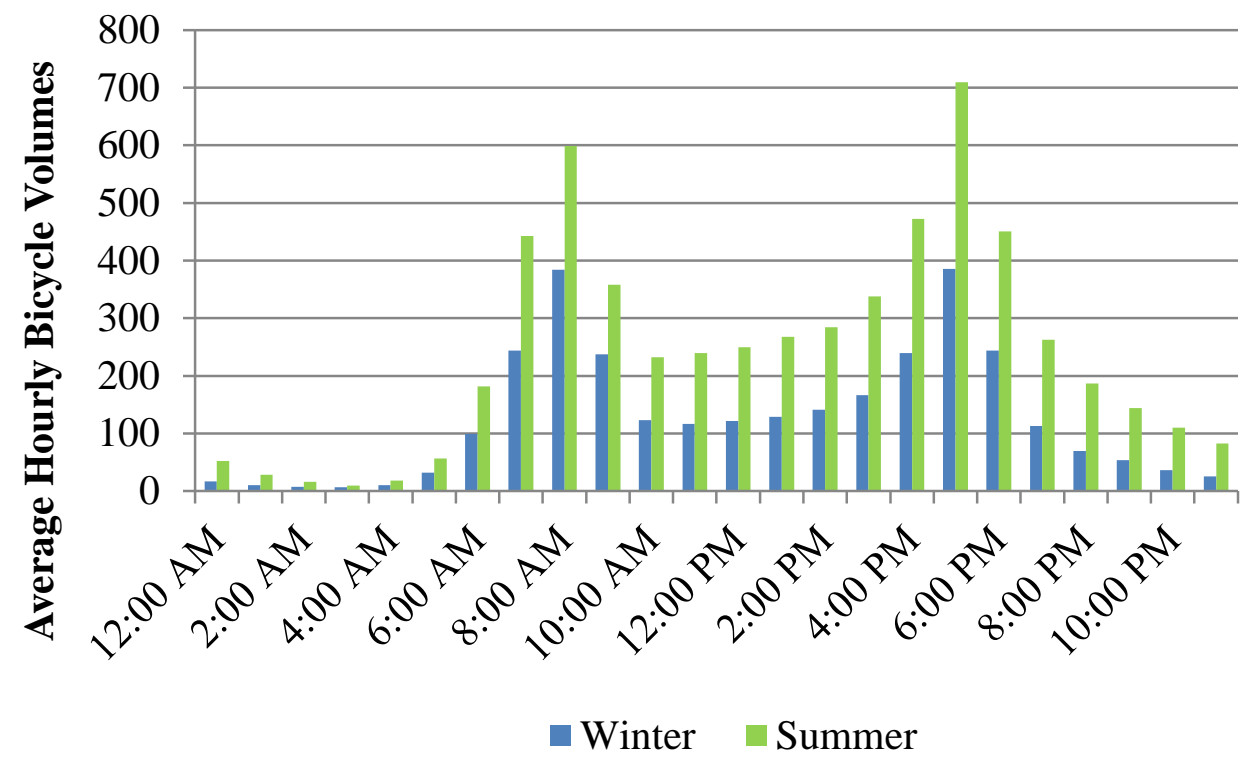

Figure 13: Average 2014 Winter and Summer Hourly Bicycle Volumes

All hourly bicycle counts for 2013 were plotted in numerical rank order in Figure 14. The 90th percentile for all hourly bike counts is 212 bikes. The plot illustrates that for 90 percent of the hours in a year, the hourly bicycle volumes are less than 212 . 


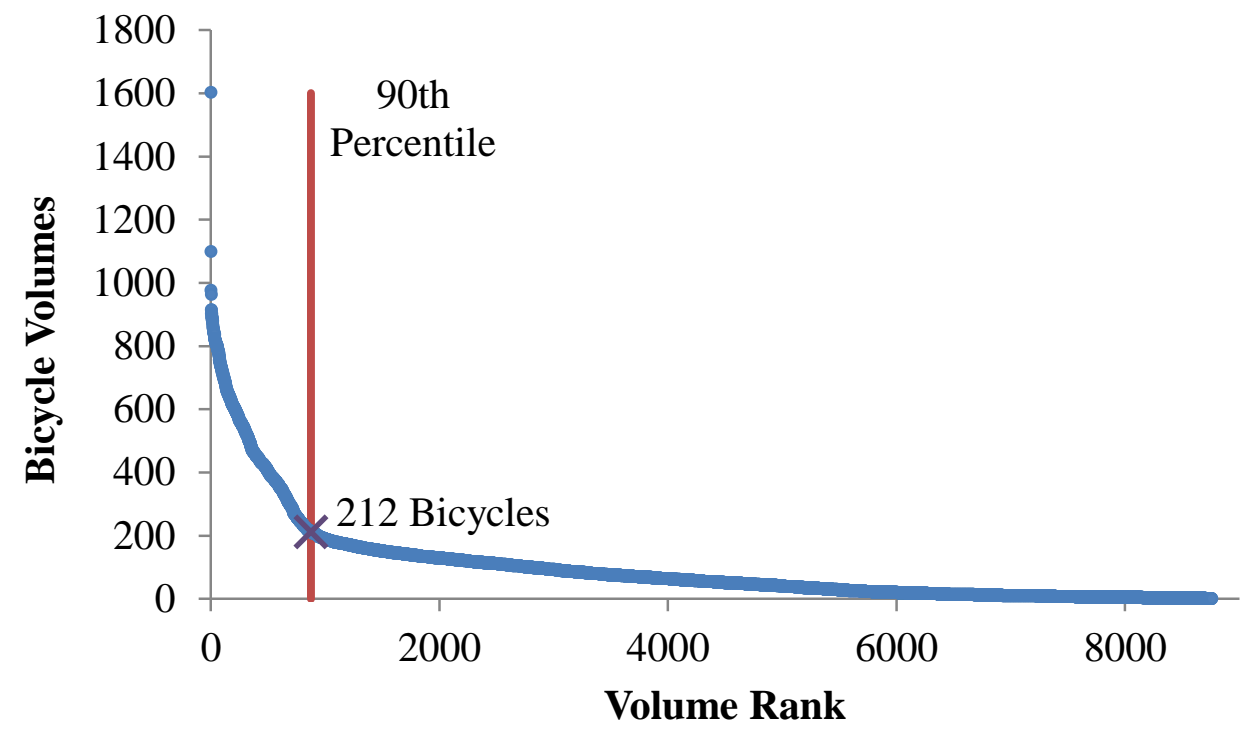

Figure 14: 2013 Hawthorne Bridge North Sidewalk Hourly Bicycle Volumes

Figure 15 and Figure 16 show typical current peak hour traffic on the Hawthorne Bridge. The photo in Figure 15 was taken on Segment 2 in April 2014 during the morning peak period between 7:30 AM and 8 AM. Bicycles must maneuver around each other because of the varying speeds and abilities of the cyclists. The photo in Figure 16 was taken on the same day during the PM peak period at Segment 10 during the $5 \mathrm{PM}$ hour and illustrates the bicycle and pedestrian congestion that can be experienced on the bridge. Also note the confined conditions between the bridge railing and the motor vehicle lane; there is no room for bicycle error. 


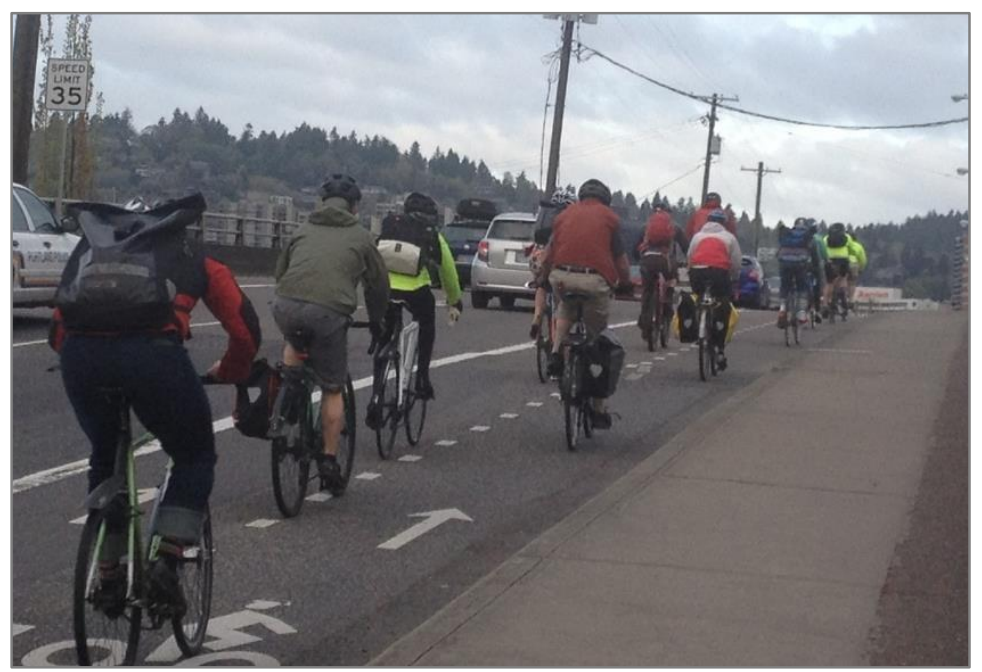

Figure 15: AM Peak Period Bicycle Traffic on Segment 2

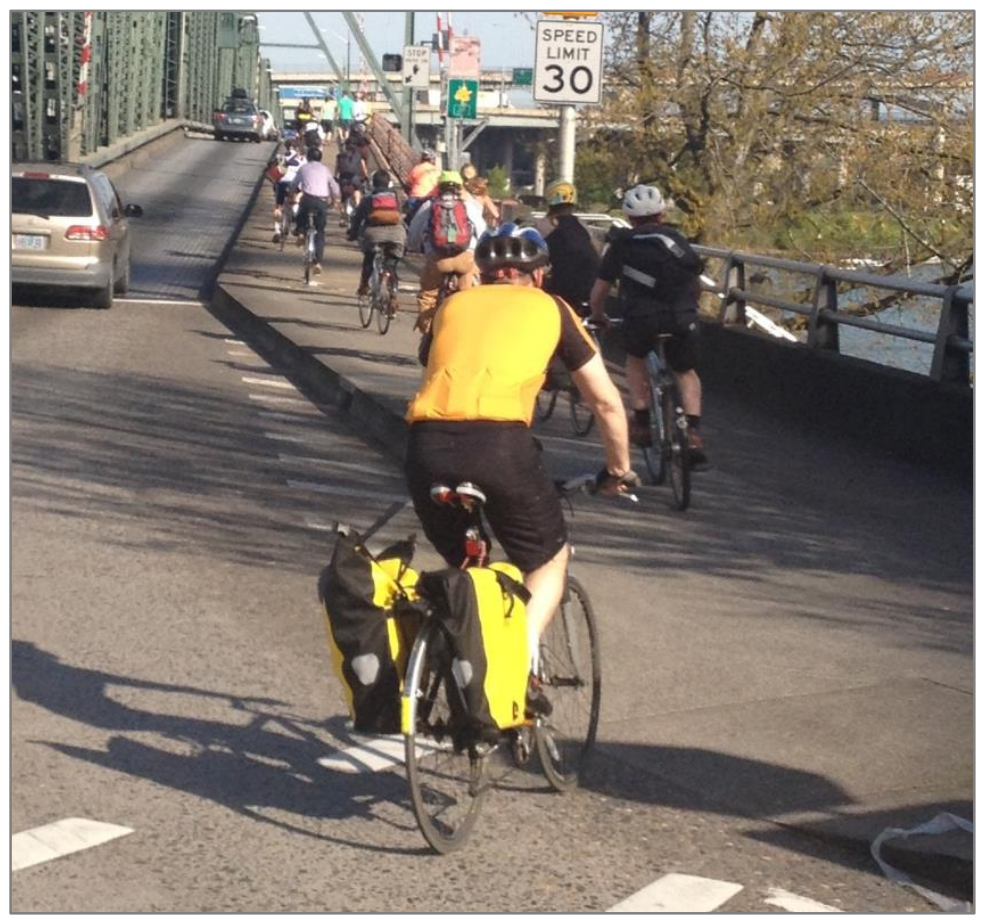

Figure 16: PM Peak Period Bicycle Traffic on Segment 10 


\subsubsection{Portland Maps and Online Data Collection}

Other data sources were explored online. Motor vehicle, bicycle, and pedestrian counts within the study area corridor counts were found on PortlandMaps.com. This website, maintained by the City of Portland, archives short term traffic counts and is available to the public. Intersection counts, pedestrian counts, peak hour motor vehicle traffic, and AADT were collected and compared with collected data.

\subsection{Manually Collected Data}

Additional data was collected to supplement the available data. Data collections included three manual counts of directional pedestrian data and bicycle route information. Geometric information was collected on-site along the corridor. In addition, an intercept study was conducted, explained in Chapter 7. 


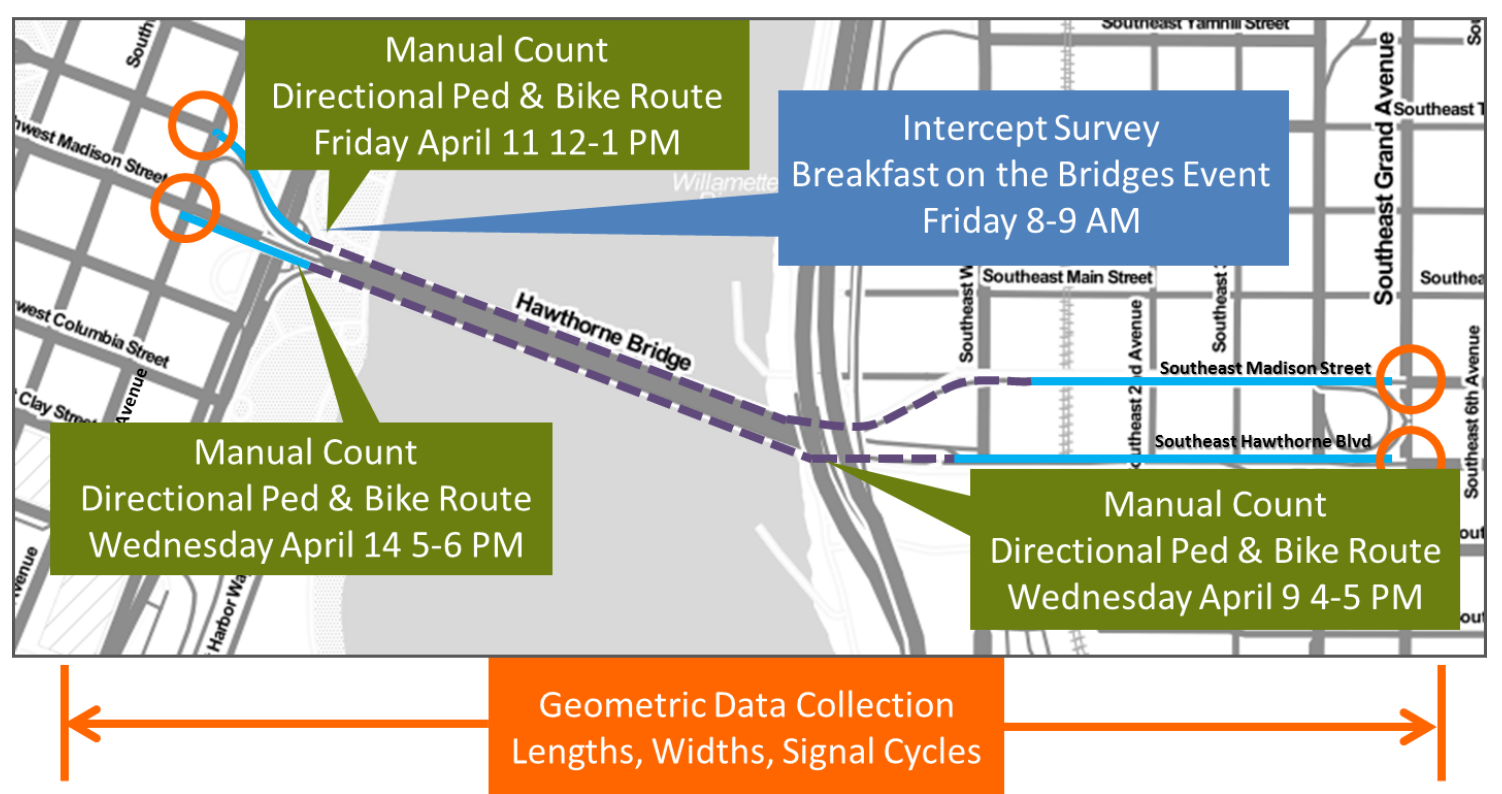

Figure 17: Manual Data Collection

\subsubsection{Geometric Data Collection}

The City of Portland has made many bicycle and pedestrian facility changes within the Hawthorne Bridge Corridor in recent years. In order to get the most up-to-date road dimensions, geometric data was collected on-site. Bicycle lanes, vehicle lanes, and sidewalk widths were measured manually. Segment lengths, posted speeds, signal cycle lengths and effective green time for bicycles were also collected.

\subsubsection{Data Collection for directional and route mode share}

While analyzing the different BLOS methods, it became clear that some directional data would be useful for analysis. Accurate bicycle traffic volumes and directional data were available from continuous counters on the Bridge. However, pedestrian data was lacking. Few pedestrian counts were available; only PBOT manual counts and some 
short term intersection counts. Most important, there were no pedestrian directional counts.

In order to get a sense of the directional traffic patterns on the Hawthorne Bridge, three one-hour manual counts were conducted at different locations, shown in Figure 17.

Count locations were chosen based on view and ease of counting. Directional counts of pedestrians and bicyclists were collected.

The first count took place on the east end of the south side of the Hawthorne Bridge on Wednesday, April 9 at 4PM to 5PM. The second count took place on Friday April 11 between 12PM and 1PM on the west end of the north sidewalk on the bridge. The third count took place Monday, April 14, 5PM to 6PM on the west end of the south sidewalk. A summary of the results are given in Table 16.

Table 16: Manual Directional Counts of Bicyclists and Pedestrians

\begin{tabular}{|c|c|c|c|c|c|}
\hline \multirow[t]{2}{*}{ Date and Location } & \multicolumn{2}{|c|}{$\begin{array}{c}\text { Bicycles } \\
\% \text { in each direction } \\
\text { (bicyclists } / \mathrm{h} \text { ) }\end{array}$} & \multicolumn{2}{|c|}{$\begin{array}{c}\text { Pedestrians } \\
\% \text { in each direction } \\
(\text { Pedestrians } / \mathrm{h})\end{array}$} & \multirow[t]{2}{*}{ Total Users } \\
\hline & EB & WB & EB & WB & \\
\hline Wednesday, April 9 & & & & & \\
\hline 4-5 PM & $100 \%$ & $0 \%$ & $63 \%$ & $37 \%$ & 622 \\
\hline South Sidewalk & $(476)$ & $(0)$ & (92) & $(54)$ & $0 \angle 2$ \\
\hline Friday, April 11 & & & & & \\
\hline 12-1 PM & $0 \%$ & $100 \%$ & $29 \%$ & $71 \%$ & 423 \\
\hline North Sidewalk & $(0)$ & $(113)$ & (90) & $(220)$ & 423 \\
\hline $\begin{array}{c}\text { Monday April } 14 \\
\text { 5-6PM } \\
\text { South Sidewalk }\end{array}$ & $\begin{array}{l}100 \% \\
(906)\end{array}$ & $\begin{array}{l}0 \% \\
(0)\end{array}$ & $\begin{array}{c}80 \% \\
(152)\end{array}$ & $\begin{array}{l}20 \% \\
(38)\end{array}$ & 1096 \\
\hline
\end{tabular}


Table 16 shows the percent of bicycles per direction. The directional bicycle count volumes are in the parenthesis. Bicycle are encouraged to follow the same traffic patterns as motor vehicles; use the north side of the bridge for westbound traffic and the south side for eastbound traffic. During this data count, all bicyclists used the "correct" side of the bridge and had a 100:0 directional split. This agrees with the Eco-Counter data, which typically has daily directional bicycle splits of 99:1 to $97: 3$.

Pedestrians have a different directional split pattern than bicyclists on the Hawthorne Bridge. Table 16 shows that the directional split for pedestrians is about 60 to 80 percent in the dominant bicycle and motor vehicle direction.

In summary, directional pedestrian volumes are not always 50:50. This is important when considering the accuracy of using shared path hindrance methods with assumed equal directional splits. However, it is difficult to make estimates about bicycle route splits from one-hour counts at each of the three locations. This data collection was only three hours; one hour at each location. Further study of directional counts, mode share, and routes taken would be useful for this analysis.

\subsection{Final Base Data Values}

A collection of base data values were needed for the analysis. For bicycle and pedestrian volumes, the City of Portland manual counts were used. The time and date chosen was the PM Peak for Tuesday, September 10, 2013. It was the only one of the three manual counts that took place on the side of the bridge during its peak period. The reason the manual count was chosen over other types of data to develop base peak 
period values was because it included both actual bicycle and pedestrian counts at a peak hour. No other collected data at the time of method analysis had pedestrian data.

A reasonable estimated peak hour was formulated from the two hour count. The four 15-minute periods with the highest volumes were chosen from the Tuesday, September 10 data. See Table 17for values. The volume during the 5:15 PM to 6:15 PM hour was the highest hourly volume during the peak period; 974 bicycles and 105 pedestrians. Since this is an estimation of typical bicycle and pedestrian volumes, the values were rounded to 975 bicycles and 100 pedestrians.

\section{Table 17: PBOT Peak Hour Manual Counts Used for Base Values}

\begin{tabular}{cccc}
\hline Date & Time & Bicycles & Pedestrians \\
\hline & $5: 15 \mathrm{PM}$ & 354 & 41 \\
$9 / 10 / 13$ & $5: 30 \mathrm{PM}$ & 205 & 24 \\
& $5: 45 \mathrm{PM}$ & 196 & 23 \\
& $6: 00 \mathrm{PM}$ & 219 & 17 \\
\hline Peak Hour & & 974 & 105 \\
Total & & & \\
\hline
\end{tabular}

The base value for bicycles was similar to the August data from the Totem Eco-Counter data, with peak hourly values of 976 and 950. It is also similar to the April 14, 2014 manual count of 906 bicycles.

The remaining base values include bicycle and pedestrian speeds and standard deviations for speed. These are the default values given in the HCM. There was no speed data available within the study area.. Some of the BLOS methods have other 
additional variables that require base values. These will be discussed in each method analysis.

\section{Table 18: Base Variables}

\begin{tabular}{c|cc}
\hline Variable & Bicycles & Pedestrians \\
\hline Volumes & 975 & 100 \\
Speed & $12.8 \mathrm{mph}(20.1 \mathrm{~km} / \mathrm{h})$ & $3.4(5.5 \mathrm{~km} / \mathrm{h})$ \\
Standard Deviation & $3.4 \mathrm{mph}(5.5 \mathrm{~km} / \mathrm{h})$ & $0.6(0.9 \mathrm{~km} / \mathrm{h})$ \\
\hline
\end{tabular}




\subsection{DATA ANALYSIS AND RESULTS}

A collection of BLOS methods that use bicycle volume as a variable were tested on bicycle facilities within the study area. A table of the methods, the source of the method and the facilities that the methods are applicable to are given in Table 19.

Table 19: BLOS Methods Tested

\begin{tabular}{c|cc}
\hline Facility & Source & Method \\
\hline On-street & Botma & LOS for Bicycle Paths \\
Segments & HCM 2000 & On-Street Bicycle Lanes \\
\hline & Botma & LOS for Pedestrian-Bicycle \\
Off-street & HCM 2000 & Path \\
segments & FHWA & Shared Off-Street Paths \\
& HCM 2010 & Shared use path Analysis tool \\
& HCM 2000 & Pathways \\
\hline Intersections & &
\end{tabular}

The following describes the analysis of each of the BLOS method as they were applied to the elements/segments in the Hawthorne Bridge the study area. For each method tested, there will be 1) a short description of the method, 2) a list of the segments/elements that the methods were applied to 3) a description of variables that were needed for the analysis 4) BLOS results as each method was applied to each of the elements/segments 5) a sensitivity plot and analysis including BLOS thresholds for each of the methods 6) A summary of results and gaps in the methods as it pertains to the elements. 


\subsection{On-Street Segments}

Two methods were evaluated for on-street segments; Botma's LOS for Bicycle Paths and the HCM 2000 LOS for On-Street Bicycle Lanes. However, Botma's method is carried out in two ways. First, the LOS for bicycle paths is carried out using the original default values. Second, the Botma method is calculated using the HCM default values for speed and standard deviation. The second method for on-street bicycle lanes in the HCM 2000 is essentially the same as the Botma method but with different default values and BLOS grading thresholds. The variables needed are given in Table 20.

Table 20: Methods and Variables Used for On-Street Bicycle Lanes

\begin{tabular}{c|cc}
\hline \multirow{2}{*}{ Inputs } & $\begin{array}{c}\text { Off-Street Bicycle Path } \\
\text { One-way }\end{array}$ & $\begin{array}{c}\text { On-Street Bicycle Lane } \\
\text { One-way }\end{array}$ \\
& Botma 1995 & HCM 2000 \\
\hline Volume & $\checkmark$ & $\checkmark$ \\
Mean Speed & Can use Default & Uses Default \\
Speed SD & Can use Default & Uses Default \\
Lane Width & Width Requirements & Width Requirements \\
& (4.9 to 6.6 feet) & (4.9 to 6.6 feet) \\
\hline
\end{tabular}

Figure 18 illustrates the on-street segments that the above methods were applied to.

However, four of the seven on-street segments do not meet the lane width requirements. The segments that do not meet the requirements are designated with the shaded call boxes in Figure 18. 


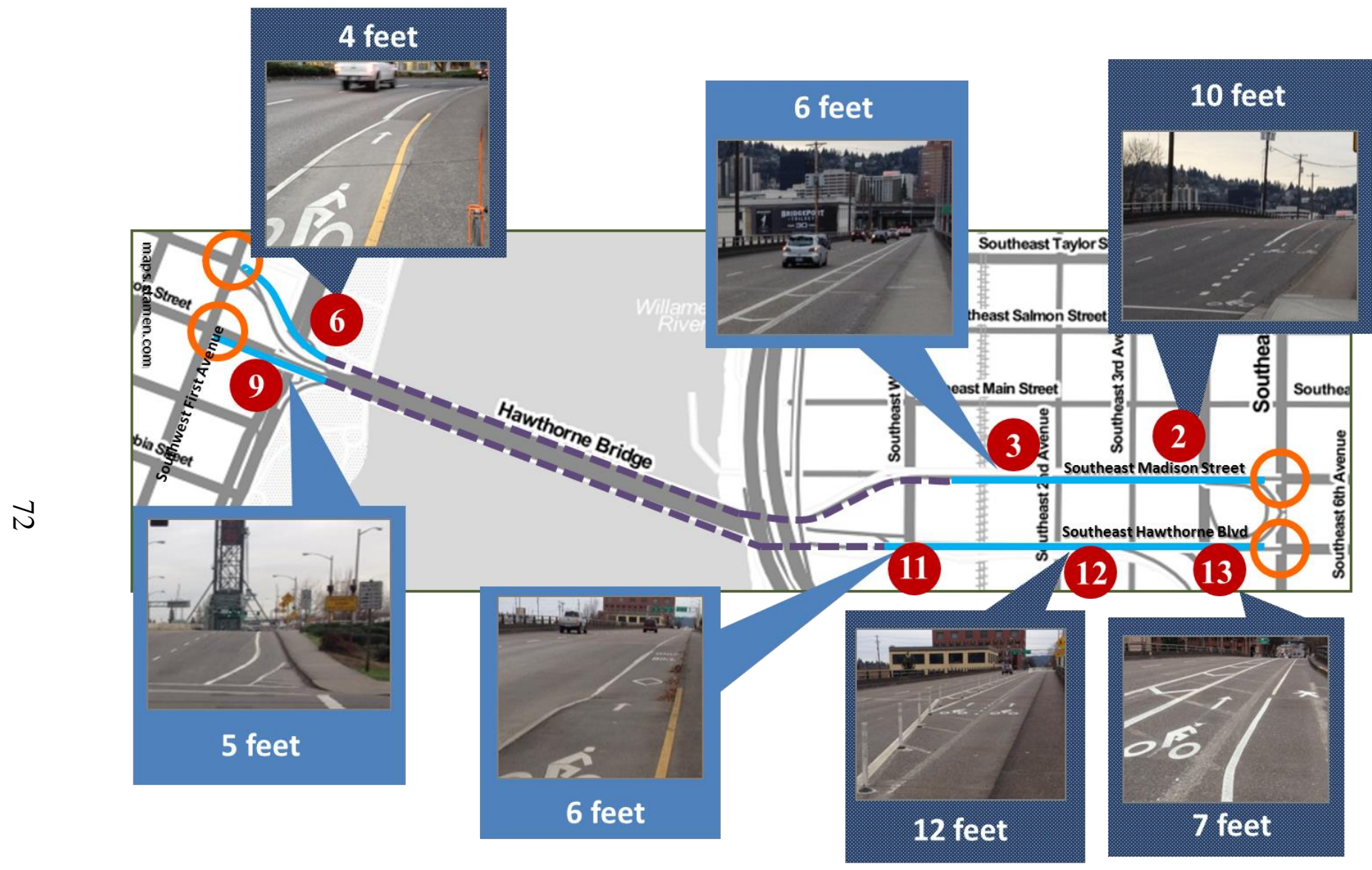

Figure 18: On-Street Bicycle Lanes and Locations 


\subsubsection{Botma LOS for One-Way Bicycle Paths}

The LOS method for one-way bicycle paths was not intended for on-street bike lanes (Botma 1995). However, the HCM 2000 recommends this method for on-street bicycle paths (TRB 2000). This method was chosen because it determines BLOS using bicycle volumes to determine hindrance; the delay based on passing other cyclists. This method was applied to seven on-street bicycle path segments in the study area, shown in Figure 18.

The default values for the mean speed and standard deviation are $18 \mathrm{~km}(11.2 \mathrm{mph})$ and $3 \mathrm{~km}(1.9 \mathrm{mph})$ respectively. The frequency equation is simplified using default values to

$$
F=0.188 Q
$$

where $Q$ is the hourly volume of bicycles. This equation is for a two lane, one-way bicycle path with path width requirements between 4.9 feet and 6.6 feet. Only segments 3, 9, and 11 have widths that fall within the required range. There is no guidance for one lane bicycle paths. However, conclusions can be drawn for BLOS of a one lane bicycle path based on calculations for a two lane path. Three of the seven segments, 2,12 , and 13 would be considered three lane bicycle paths based on Botma's assumptions. Botma does not give any guidance for three lane paths. 
This method does not use lane width as a variable in the method equation. The lane widths in Table 20 are only guidelines to determine if the method is appropriate for each segment. For all segments, all inputs are the same therefore there is one answer for all segments. The result for of the Botma method using default values is given in the first column in Table 21.

Table 21: Variables Used and BLOS Results for On-Street, One-Way Segments

\begin{tabular}{c|ccccccc}
\hline & Botma & \multicolumn{3}{c}{ Botma HCM } & \multicolumn{3}{c}{ HCM 2000 } \\
\hline Q, Volume & 975 & 975 & 975 & 975 & 975 & 975 & 975 \\
U, Mean Speed, & 18 & 20.6 & 20.6 & 20.6 & 20.6 & 20.6 & 20.6 \\
$\mathrm{~km} / \mathrm{h}$ & & & & & & & \\
$\begin{array}{c}\sigma, \text { Std Dev, km/h } \\
\text { F, Frequency, events } \\
\text { per hour }\end{array}$ & 3 & 5.5 & 3 & 1.5 & 5.5 & 3 & 1.5 \\
$\begin{array}{c}\text { Frequency of } \\
\text { Passings }\end{array}$ & $1 / 19.7$ & $1 / 12$ & $1 / 22$ & $1 / 45$ & & & \\
\hline BLOS & E & F & D & C & F & E & C \\
\hline
\end{tabular}

The results show that a BLOS score of E for all tested segments. Comparing values in Table 22, the frequency of passings of $1 / 19.7$ is near the requirements for a BLOS score of D. The determination of BLOS is only based on the volume of bicycles and the assumptions of a two lane path, a default mean speed of $18 \mathrm{~km} / \mathrm{h}$ and a default bicycle speed standard deviation of $3 \mathrm{~km} / \mathrm{h}$. 
Table 22: Service Volumes and Frequency of Events for One-Way, Two Lane Bicycle Paths Using Default Values (Botma 1995)

\begin{tabular}{c|ccc}
\hline & \multirow{2}{*}{\begin{tabular}{c} 
\% with \\
hindrance \\
\cline { 3 - 4 } over 1 km
\end{tabular}} & $\begin{array}{c}\text { Service } \\
\text { Volume } \\
\text { bicycles/hour }\end{array}$ & $\begin{array}{c}\text { Frequency } \\
\text { passings }\end{array}$ \\
A & $0-10$ & 130 & $<1 / 150$ \\
B & $10-20$ & 260 & $<1 / 75$ \\
C & $20-40$ & 520 & $<1 / 35$ \\
D & $40-70$ & 910 & $<1 / 20$ \\
E & $70-100$ & 1300 & $<1 / 15$ \\
F & 100 & $>1300$ & $>1 / 15$ \\
\hline
\end{tabular}

\subsubsection{Botma LOS for One-Way Bicycle Paths with HCM Default Values}

Both the HCM 2000 and HCM 2010 default values for mean and standard deviation bicycle speeds are $20.6 \mathrm{~km} / \mathrm{h}(12.8 \mathrm{mph})$ and $5.5 \mathrm{~km} / \mathrm{h}(3.4 \mathrm{mph})$ respectively. The HCM 2000 also assigned standard deviation for commuters as $1.5 \mathrm{~km} / \mathrm{h}(.9 \mathrm{mph})$, $3 \mathrm{~km} / \mathrm{h}(1.9 \mathrm{mph})$ for mixed users and $5.5 \mathrm{~km} / \mathrm{h}(3.4 \mathrm{mph})$ for recreational users. The frequency equation for bicycle LOS for a bicycle only path is based on frequency of passings by Botma is

$$
F=2 Q \sigma /\{U \sqrt{\pi}\}
$$

Where $Q$ is the bicycle volume, $\sigma$ is the standard deviation and $U$ is the mean speed in kilometers.

Using the US default values (in SI units) for speed and the three different values for the standard deviation the Botma equation for frequency was calculated. See results in 
Table 21 under the heading "Botma HCM" With a Standard deviation of $1.5 \mathrm{~km} / \mathrm{h}$ the BLOS is C, for $3 \mathrm{~km} / \mathrm{h}$ it is D and for $5.5 \mathrm{~km} / \mathrm{h}$ it is F. This makes sense that as the range of speed variation increases, there will be more passings compared to cyclists that have similar speeds and a smaller standard deviation.

\subsubsection{HCM 2000 LOS for One-Way Bicycle Paths}

The HCM 2000 uses the same method and equations developed by Botma but use a different table of BLOS values. Table 23 illustrates the difference in BLOS score thresholds based on frequencies of passings and meetings. The Botma method has a smaller range for A and B scores compared to the HCM method. However, the overall range of all scores is wider; there can be a greater frequency of passings and meetings before reaching a BLOS score of F compared to the HCM 2000 BLOS thresholds.

\section{Table 23: BLOS Comparison of Frequency Thresholds}

\begin{tabular}{c|cc}
\hline \multirow{2}{*}{ BLOS } & \multicolumn{2}{|c}{$\begin{array}{c}\text { Frequency Thresholds } \\
\text { Passings/h }\end{array}$} \\
\cline { 2 - 3 } & Botma & HCM \\
A & 24 & 40 \\
B & 48 & 60 \\
C & 103 & 100 \\
D & 180 & 150 \\
E & 240 & 195 \\
F & $>240$ & $>195$ \\
\hline
\end{tabular}

The BLOS results are given in Table 21, The HCM 2000 BLOS thresholds yields a BLOS of F for a standard deviation of $5.5 \mathrm{~km} / \mathrm{h}$, E for $3 \mathrm{~km} / \mathrm{h}$, and C for $1.5 \mathrm{~km} / \mathrm{h}$. 
Using the HCM thresholds, the BLOS score is different between the Botma and HCM 2000 for the standard deviation of $3 \mathrm{~km} / \mathrm{h}$.

\subsubsection{Sensitivity Analysis}

A sensitivity analysis was conducted to test the sensitivity of each method to its input variables. The default values were held constant in each of the equations as each of the variables was tested. Each variable was increased and decreased by certain percentages from the default, or base values. The percent change in the frequencies or BLOS score was compared to the frequency of the base values. The results are illustrated in Figure 19 and 28. Since the same equation was used in both methods, the percent change is the same in both figures. The difference is in the BLOS thresholds for the Botma method and the HCM 2000 method.

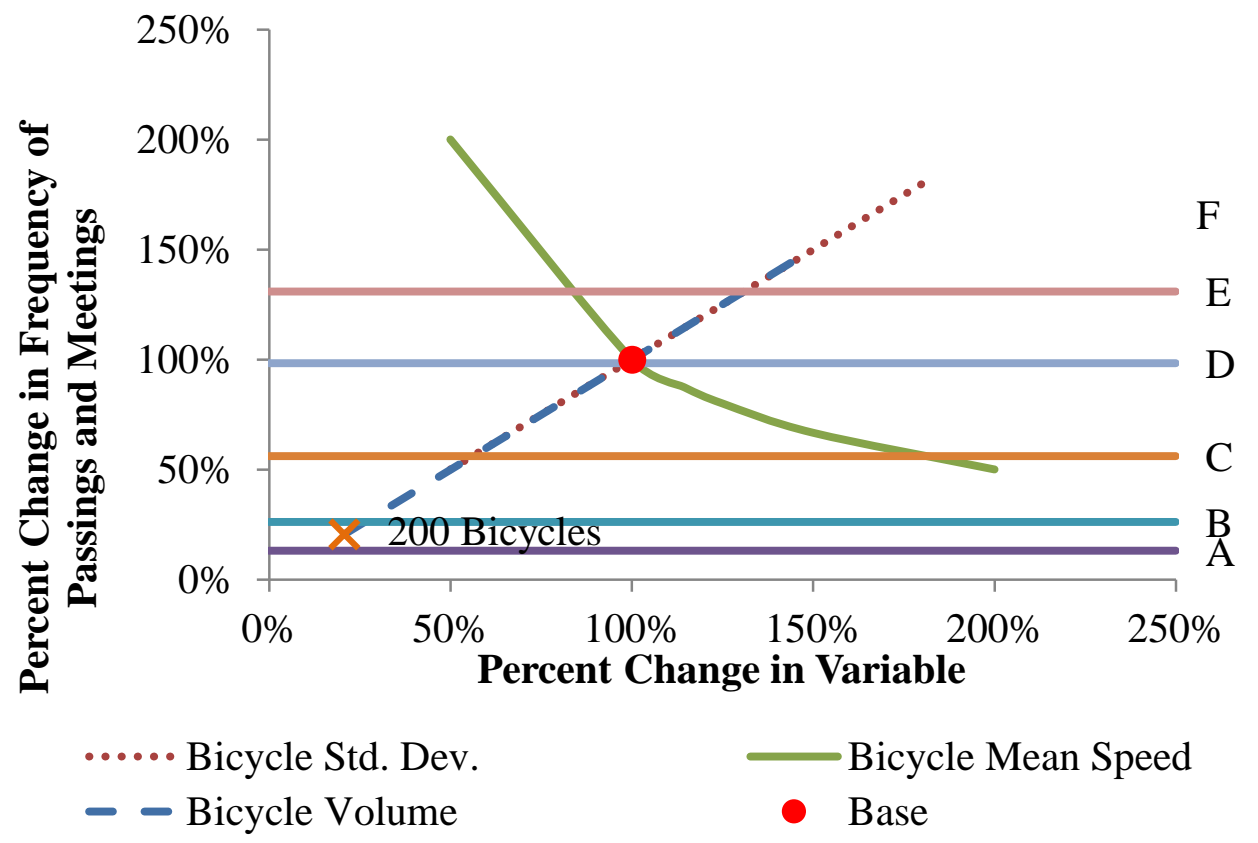




\section{Figure 19: Sensitivity of Variables in Botma One-Way Path With Botma BLOS}

Thresholds

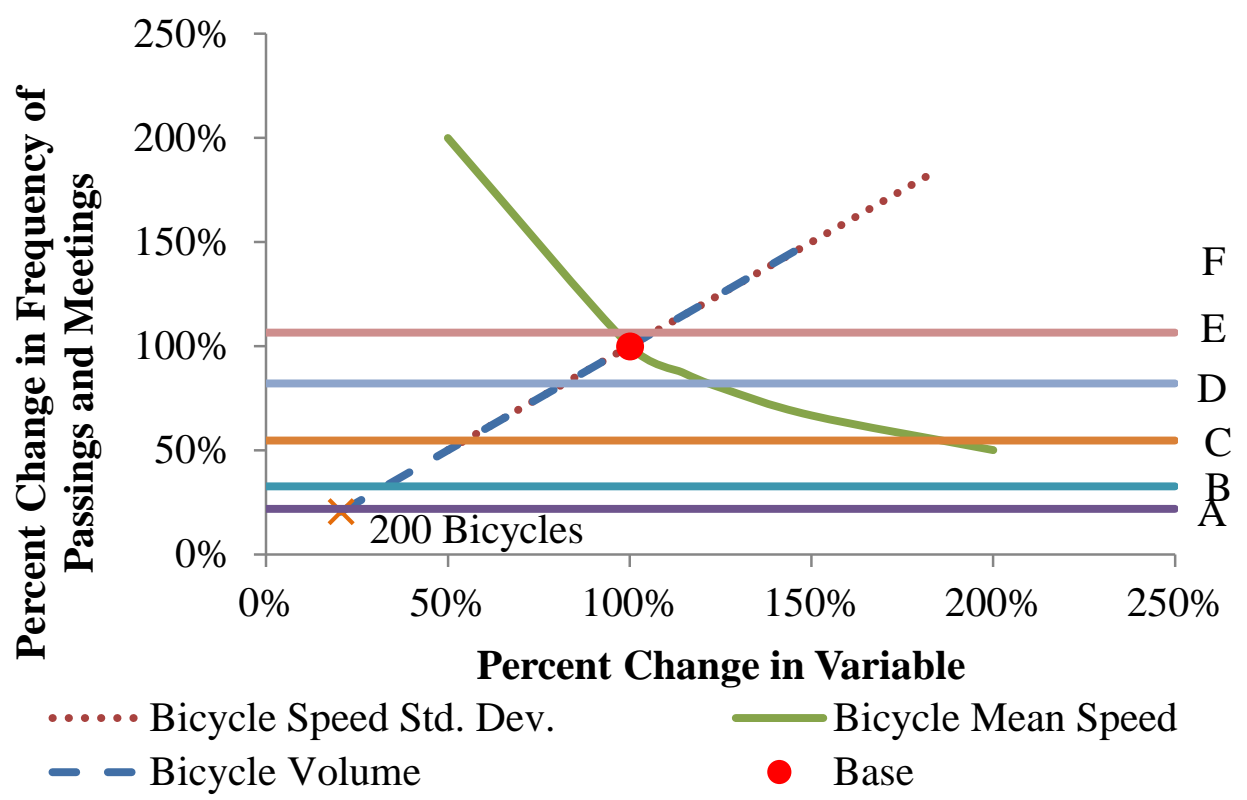

Figure 20: Sensitivity of Variables in Botma One-Way Bicycle Path With HCM 2000 BLOS Thresholds

The change in standard deviation and volume, $Q$, are proportional to the changes in frequency. In contrast, the change in mean speed varies. Slower speeds, below $18 \mathrm{~km} / \mathrm{h}$, produce a larger change in frequency than speeds greater than $18 \mathrm{~km} / \mathrm{h}$. This illustrates that the mean speed is less predictable and varies the most than changes in standard deviations and volume.

In addition to the percentage increase and decrease of volumes, 200 bicycles were also plotted. The value of 200 bicycles was to show a value close to the $90^{\text {th }}$ percentile of 
hourly bicycle volumes, which was 212 bicycles. A volume of 200 bicycle garners an LOS score of B under the Botma thresholds and an A using the HCM 2000 values.

The methods used for on-street segments was not intended to be used as such; they were intended for one-way bicycle paths separated from motor vehicle traffic. There are no actual lane width variables but Botma's method was developed for a two lane path up to 6.6 feet wide. This constraint did not fit most our on-street segments. Those segments that did fit the lane width constraints had other differences that were not considered. This yielded the same results for all three segments. Additionally, each segment will have its own unique mean speed. Mean bicycle speed can be measured but it is not data that is commonly collected for bicycles. These methods may be adequate for on-street paths but they were not developed by Botma from on-street bicycle path data and have not been adequately researched and tested.

Table 24: Summary of BLOS Scores for On-Street Bicycle Lanes

\begin{tabular}{|c|c|c|c|}
\hline On-Street Segment & Name & $\begin{array}{c}\text { Botma } \\
1995\end{array}$ & $\begin{array}{c}\text { HCM } \\
2000\end{array}$ \\
\hline & 2 & & \\
\hline & $\begin{array}{c}\text { Westbound } \\
\text { Madison Viaduct } \\
\text { Bike Lane }\end{array}$ & $\mathbf{E}$ & $\mathbf{F}$ \\
\hline & & \\
\hline
\end{tabular}




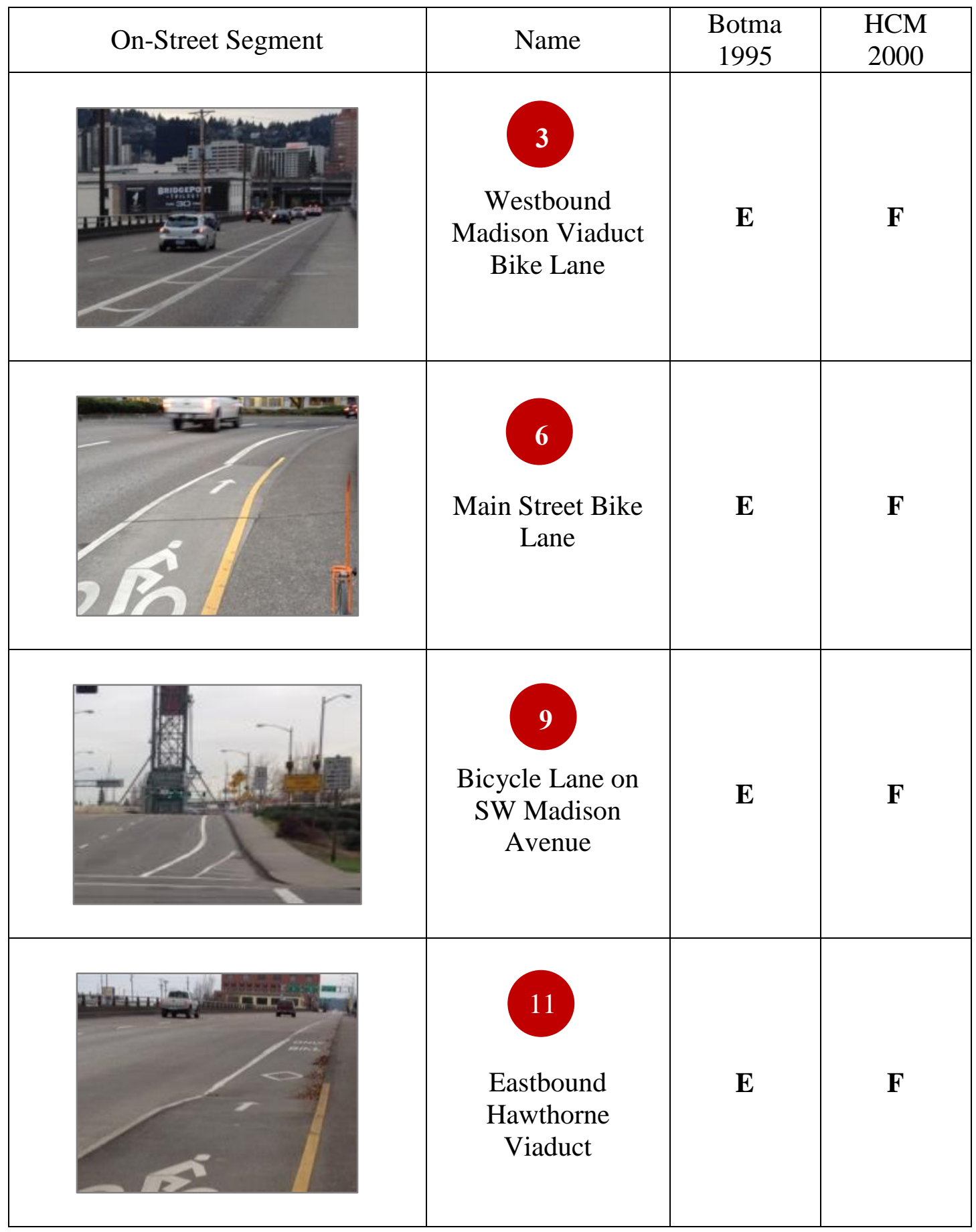




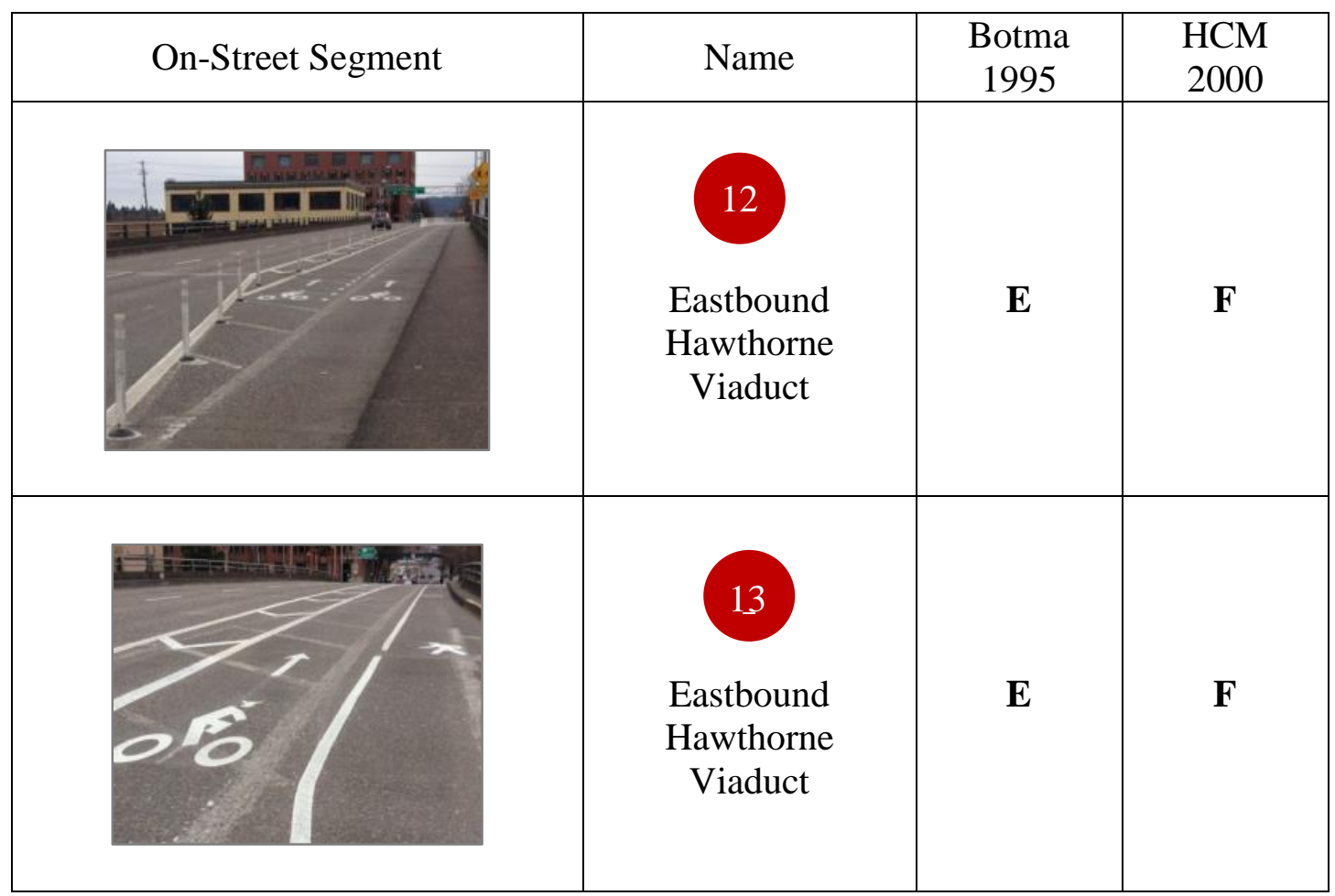




\subsection{Off-Street Paths}

Most of the BLOS methods that consider bicycle volumes were developed for off-street paths. Like the one-way bicycle path, the method that all other methods build on were developed by Botma (Botma 1995). For this analysis, tests of four off-street path methods were performed: 1) the original Botma LOS for Pedestrian-Bicycle Paths, 2) HCM 2000 Shared Paths equations, 3) The FHWA Worksheet, and 4) the HCM 2010 methods and worksheet for pathways, developed at the University of Idaho.

There are three segments that the following methods are most applicable to; Segments 4, 5 and 10, illustrated in Figure 21. Segments 5 and 10 represent the shared use sidewalks on the Hawthorne Bridge. Segment 4 is located on the sidewalk on the northeast side of the bridge. The locations of the three segments are illustrated in Figure 21. The width of the Hawthorne Bridge sidewalk is 10 feet and is a shared path with pedestrians. There is no separation of traffic with lane markings. Segment 4 is 9 feet wide with separation of pedestrians and bicycles with a painted lane marking. These values are given in Table 25. 


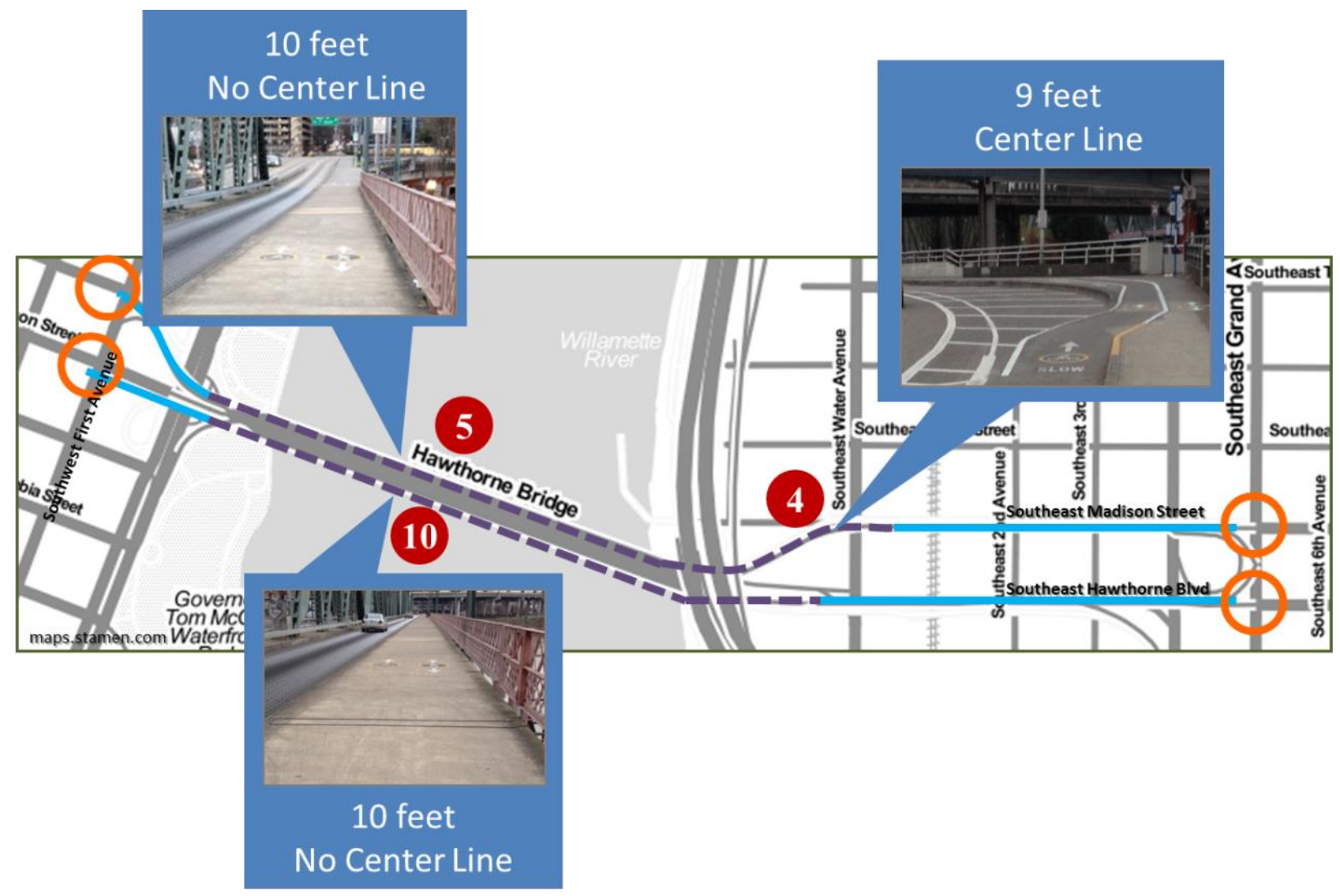

Figure 21: Off-Street Bicycle Lanes 
Table 25: Off-Street Path Segments and Variables

\begin{tabular}{ccccc}
\hline Segment & $\begin{array}{c}\text { Path } \\
\text { width }\end{array}$ & Centerline & $\begin{array}{c}\text { Total } \\
\text { Bicycles }\end{array}$ & $\begin{array}{c}\text { Total } \\
\text { Pedestrians }\end{array}$ \\
\hline 4 & 9 & Yes & & \\
5 & 10 & No & 975 & 100 \\
10 & 10 & No & & \\
\hline
\end{tabular}

\subsubsection{Botma LOS for Pedestrian- Bicycle Paths}

Botma's method determines the BLOS based on all users of a mixed-use path. The method is innovative and relatively simple to calculate. However, for the evaluation of this study area there are many shortcomings and limitations. Botma limits his method to a two lane path; the segment that this method is most applicable, the sidewalk on the Hawthorne Bridge, is a 10 foot wide path, which would be considered a three lane path. Another constraint of this method is that it makes the assumption that the directional split for each non-motorized mode is 50:50. For the segments that we are analyzing, the directional split for bicycles on the Hawthorne Bridge is 98:2 and for pedestrians it is unknown, but it may be closer to $70: 30$ or $80: 20$ split, based on manual counts for this thesis.

This method was calculated in two ways. First, the simplified equations that used the default values of $18 \mathrm{~km} / \mathrm{h}$ for the bicycle mean speed and a pedestrian mean speed of $4.5 \mathrm{~km} / \mathrm{h}$ will be calculated. Second, the original equations will be calculated using the 
HCM mean speeds for bicycles and pedestrians of $20.6 \mathrm{~km} / \mathrm{h}(12.8 \mathrm{mph})$ and $5.5 \mathrm{~km} / \mathrm{h}$ (3.4 $\mathrm{mph}$ ) respectively.

Despite its limitations, this method was applied to the Hawthorne Bridge sidewalk using the bicycle and pedestrian peak volume default value of 975 bicyclists per hour. The corresponding pedestrian traffic volume of 100 was also used in this analysis. No other values are needed for this simplified method.

The requirement for this equation is to use the value of half of the traffic volume in the equation, representing a 50:50 split, the bicycle and pedestrian volumes were halved. This default value is used in all of the simplified methods in this section, even if there is a change in the actual mean speed. The sensitivity of the mean speed, $U$, and the standard deviation, $\sigma$, were analyzed in this study. Botma's default values are changed to the HCM default values.

Table 26: BLOS Value Comparison Between Botma Default Values versus HCM Default Values For Mean Speeds

\begin{tabular}{c|cc}
\hline Method & $\begin{array}{c}1 /(\text { User } \\
\text { events/sec) }\end{array}$ & BLOS \\
\hline $\begin{array}{c}\text { Simple } \\
\text { (Botma) } \\
\text { Long } \\
\text { (HCM) }\end{array}$ & 4.2 & $\mathrm{~F}$ \\
\hline
\end{tabular}

meetings. Using the volume of 487, or half of the total bicycles, and 50 or half of the pedestrians, yields a BLOS score of F for all users, illustrated in Table 26 and Table 8. 
Note that this method is for a two lane path and that it is assumed that all directional volumes are 50:50.

Comparing the values in Table 26 concludes that the values are not substantially different between the Botma and HCM bicycle and pedestrian default speeds. This is probably due to the fact that the ratios are similar; the ratio for the Botma default mean speed values for pedestrians and bicycles is $4.5 / 18$ or 0.25 . Using HCM values the ratio is $5.5 / 20.6$ or 0.27 .

\section{Table 27: BLOS for Users of a Two-Way, Two Lane Path (Botma 1995)}

\begin{tabular}{c|c}
\hline BLOS & $\begin{array}{c}\text { Frequency } \\
\text { (events per second) }\end{array}$ \\
\hline $\mathrm{A}$ & $<1 / 95$ \\
$\mathrm{~B}$ & $1 / 95-1 / 60$ \\
$\mathrm{C}$ & $1 / 60-1 / 35$ \\
$\mathrm{D}$ & $1 / 35-1 / 25$ \\
$\mathrm{E}$ & $1 / 25-1 / 20$ \\
$\mathrm{~F}$ & $>1 / 20$ \\
\hline
\end{tabular}

\subsubsection{Sensitivity Analysis}

Using the long method, in which there are no set default values, a sensitivity analysis was tested. Six tests were calculated. For each of the variables, all other variables were held constant using the default values. The variables are 1) Bicycle volume (975) pedestrian volume (100), 3) mean bicycle speed $(18 \mathrm{~km} / \mathrm{h}), 4)$ mean pedestrian speed (4.5), 5) mean bicycle flow, $U(18 \mathrm{~km} / \mathrm{h}), 6)$ standard deviation, $\sigma(3 \mathrm{~km} / \mathrm{h})$. The mean bicycle and pedestrian flows are values used in the frequency equation and are used as a 
default, or base, value in the Botma report. With the base equaling $100 \%$, each of the variables was adjusted to values $50 \%$ to $200 \%$ of the base value. The calculations were made and the solutions were measured as a percent of the value from the base conditions solution.

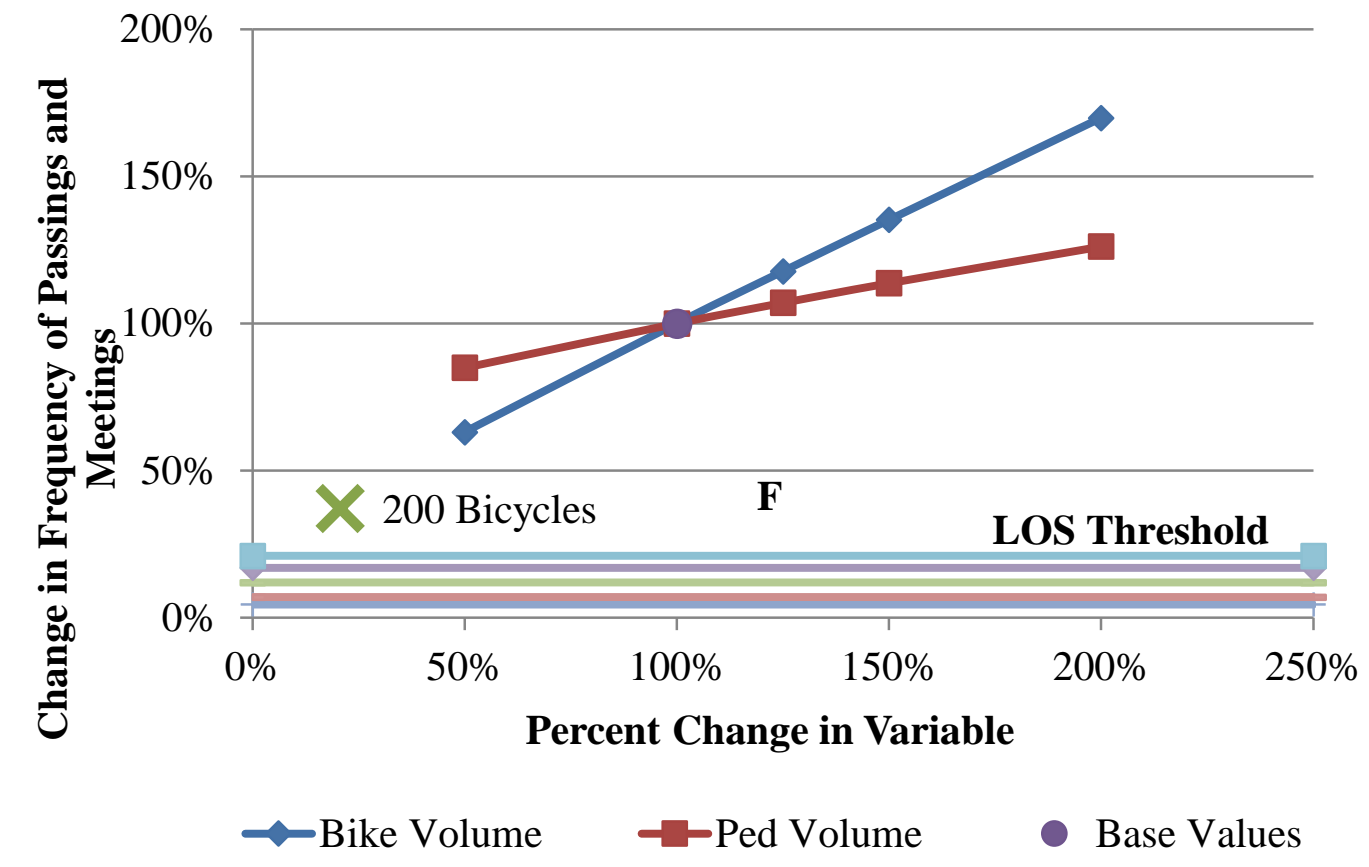

Figure 22: Sensitivity Analysis of Bicycle and Pedestrian Volumes and BLOS Thresholds 


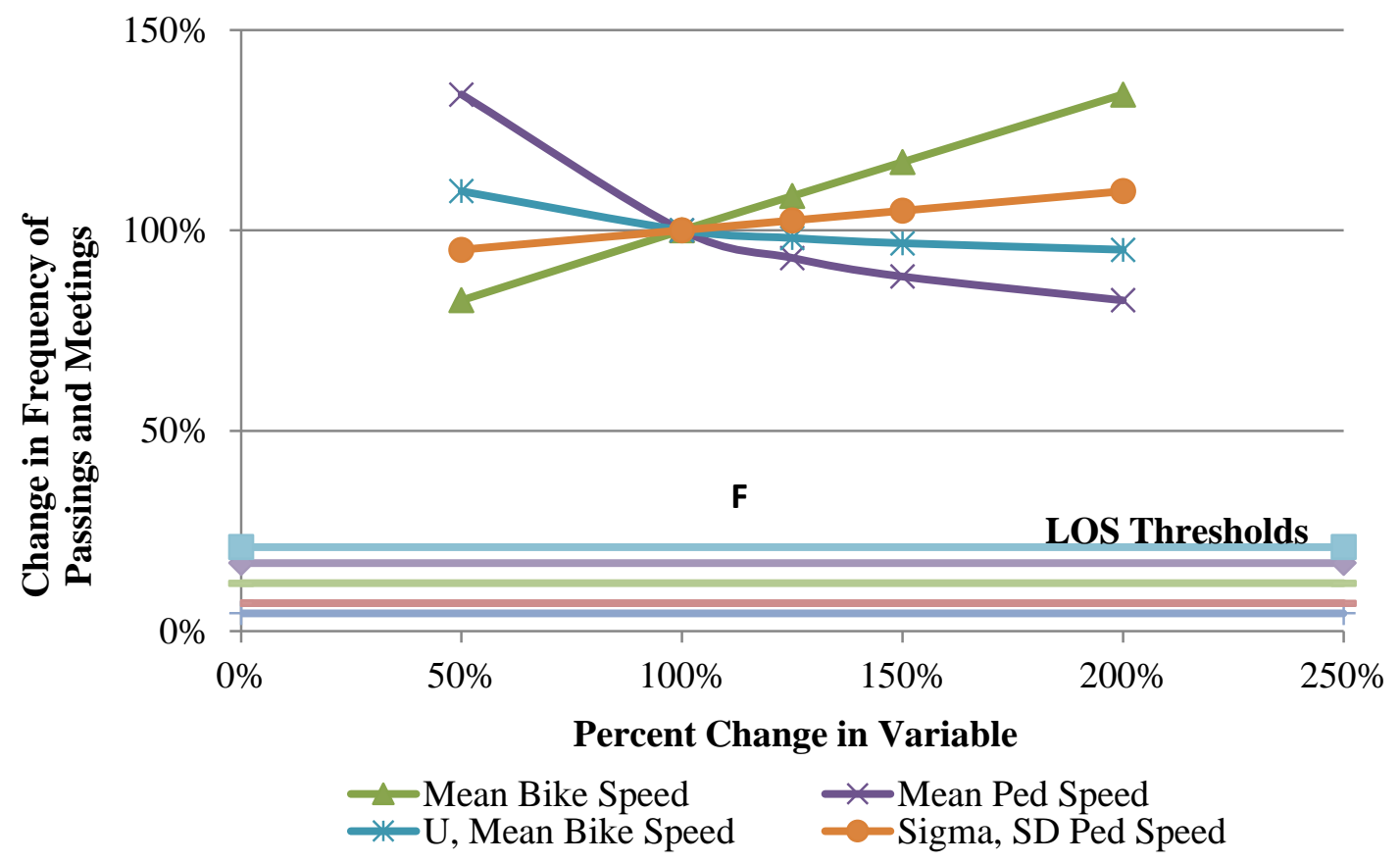

Figure 23: Sensitivity Analysis of Mean Speeds and BLOS Thresholds

Figure 22 and Figure 23 plots illustrate the percent change in the frequency of passings and meetings when there is a percentage change in each of the variables with all other variables held constant. The BLOS thresholds are plotted in each figure. Percent changes in bicycle and pedestrian volumes are shown in Figure 22. As bicycle volumes increase, frequencies of meetings and passings increase linearly. Most important is the relationship of the frequencies to the BLOS thresholds. The lowest bicycle volume used in this sensitivity analysis is a one-way volume of 200 bicycles per hour. Using the base values for all other variables, including 100 pedestrians, the total bicycle volume would have to be less than 85 bicycles per hour to achieve an E score. With no 
pedestrians, bicycle volume would have to be 300 bicycles per hour to reach a BLOS score of $\mathrm{E}$ and 63 cyclists per hour for an A score.

Figure 23 display the sensitivity of the method to mean speeds for bicycles and pedestrians. There are two mean bicycle speeds that are used in this method; Mean bicycle speed, $U$ is used in the equation for the frequency, $F$ and the mean bicycle speed is used in the remaining equations. For mean bicycle speed, $U$ is here is more sensitivity as the value decreases and less sensitivity as its value increases. Mean bicycle speed has a linear relationship to Mean bicycle speed, $\sigma$, has the least amount of sensitivity of all the mean speed variables. $\sigma$ also has a linear relationship to frequency. The mean pedestrian speed the method is also more sensitive to $\sigma$ at lower speeds; the slower you walk the greater the probability of meeting or being passed increases. As in Figure 22, the BLOS thresholds are plotted in Figure 23. It would be difficult to bring these values within the BLOS thresholds of BLOS A to E.

This BLOS method has may drawbacks. First, the assumption of a 50:50 split in direction for each mode is not appropriate for any of our segments. Second, the method assumes a two lane two way path. This assumption does not fit most of the elements in the study area. This probably explains why it is so difficult to reach the LOS; or sites do not fit the method well enough. 


\subsubsection{HCM 2000 Shared Off-Street Paths}

One improvement of this method compared to the last method is that directional splits can be designated. Also, this method applies to both two and three shared paths. The same method is used for both but each has unique BLOS threshold; the two lane path is the same as Table 8 in the previous method and Table 28 for three lane paths. This method uses the default used in the previous sections for developing the frequency with mean bicycle flow, $U$ of $18 \mathrm{~km} / \mathrm{h}$ and a standard deviation, $\sigma$, of $3 \mathrm{~km} / \mathrm{h}$.

Table 28: BLOS Table for HCM 2000 Shared Paths for a Three Lane Path (HCM 2000)

\begin{tabular}{c|c}
\hline BLOS & $\begin{array}{c}\text { Frequency of } \\
\text { events }\end{array}$ \\
\hline A & $\leq 90$ \\
B & $>90-140$ \\
C & $>140-210$ \\
D & $>210-300$ \\
E & $>300-375$ \\
F & $>375$ \\
\hline
\end{tabular}

Table 29: Directional Splits Modeled for Bicycle and Pedestrians

\begin{tabular}{c|ccccc}
\hline $\begin{array}{c}\text { Bikes } \\
\text { total }\end{array}$ & $\begin{array}{c}\text { Bikes, } \\
\text { subject } \\
\text { Direction }\end{array}$ & $\begin{array}{c}\text { Bikes } \\
\text { Opposite } \\
\text { Direction }\end{array}$ & $\begin{array}{c}\text { Peds } \\
\text { total }\end{array}$ & $\begin{array}{c}\text { Peds, } \\
\text { Subject } \\
\text { Direction }\end{array}$ & $\begin{array}{c}\text { Peds, } \\
\text { opposite } \\
\text { Direction }\end{array}$ \\
\hline 975 & $100 \%$ & $0 \%$ & 100 & $100 \%$ & $0 \%$ \\
& $99 \%$ & $1 \%$ & & $90 \%$ & $10 \%$ \\
& $97 \%$ & $3 \%$ & & $80 \%$ & $20 \%$ \\
& $80 \%$ & $20 \%$ & & $70 \%$ & $30 \%$ \\
& $70 \%$ & $30 \%$ & & $60 \%$ & $40 \%$ \\
& & & & $50 \%$ & $50 \%$ \\
\hline
\end{tabular}


To evaluate the method with directional variables, a list of various combinations of directional volumes was constructed. Table 29 lists the directional splits that were computed for bicycles and pedestrians. For each of the directional splits for bicycles, each combination of pedestrian splits was paired. For example, for a bicycle directional split of 99:1 is paired with pedestrian split of 100:0, 90:10, 80:20, 70:30, 60:40, and 50:50. The 100\%, 99\%, and 97\% subject directional split values were chosen because these are the percent splits that exist on the Hawthorne Bridge. All combinations received as BLOS score of $\mathrm{F}$.

\subsubsection{Sensitivity Analysis}

Sensitivity plots were constructed for volumes and directional splits in Figure 24 and Figure 25. Figure 24 illustrates the change in frequency of passings and meetings from a percentage change in bicycle and pedestrian volumes, with all other base values held constant. Both bicycles and pedestrians have linear relationships to frequency. The model is more sensitive to changes in bicycle volumes than pedestrian volumes. A similar plot was constructed to illustrate the sensitivity of directional variation in volumes for bicycles and pedestrians. The change in variables refers to a change in the subjective direction from the base case of a 50:50 split. For example, the 50\% change refers to $50 \%$ of the $50: 50$ directional split, half of 487 or 273 bicycles in the subject direction. In order for the bicycle volume to remain steady, the opposing direction volume was $975-273$. The method is more sensitive to variations in directional bicycle volumes. Pedestrian directional sensitivity is low, illustrated in Figure 25. Note 
that, despite the higher levels of passing and meeting frequency thresholds for a three lane BLOS, the range of the BLOS thresholds are small and all values fall in the BLOS F category.

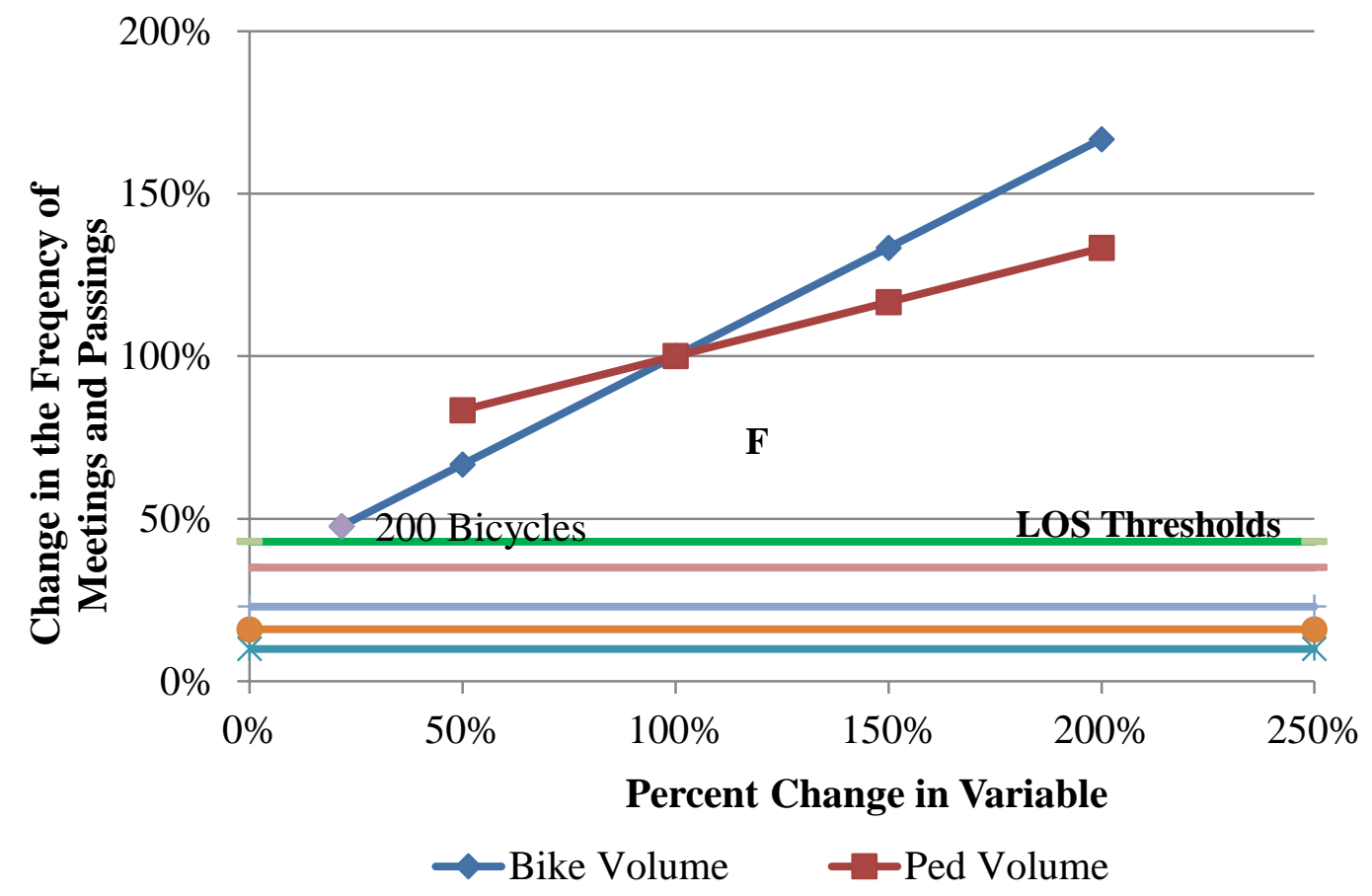

Figure 24: Sensitivity of Bicycle and Pedestrian Volumes and BLOS Thresholds 


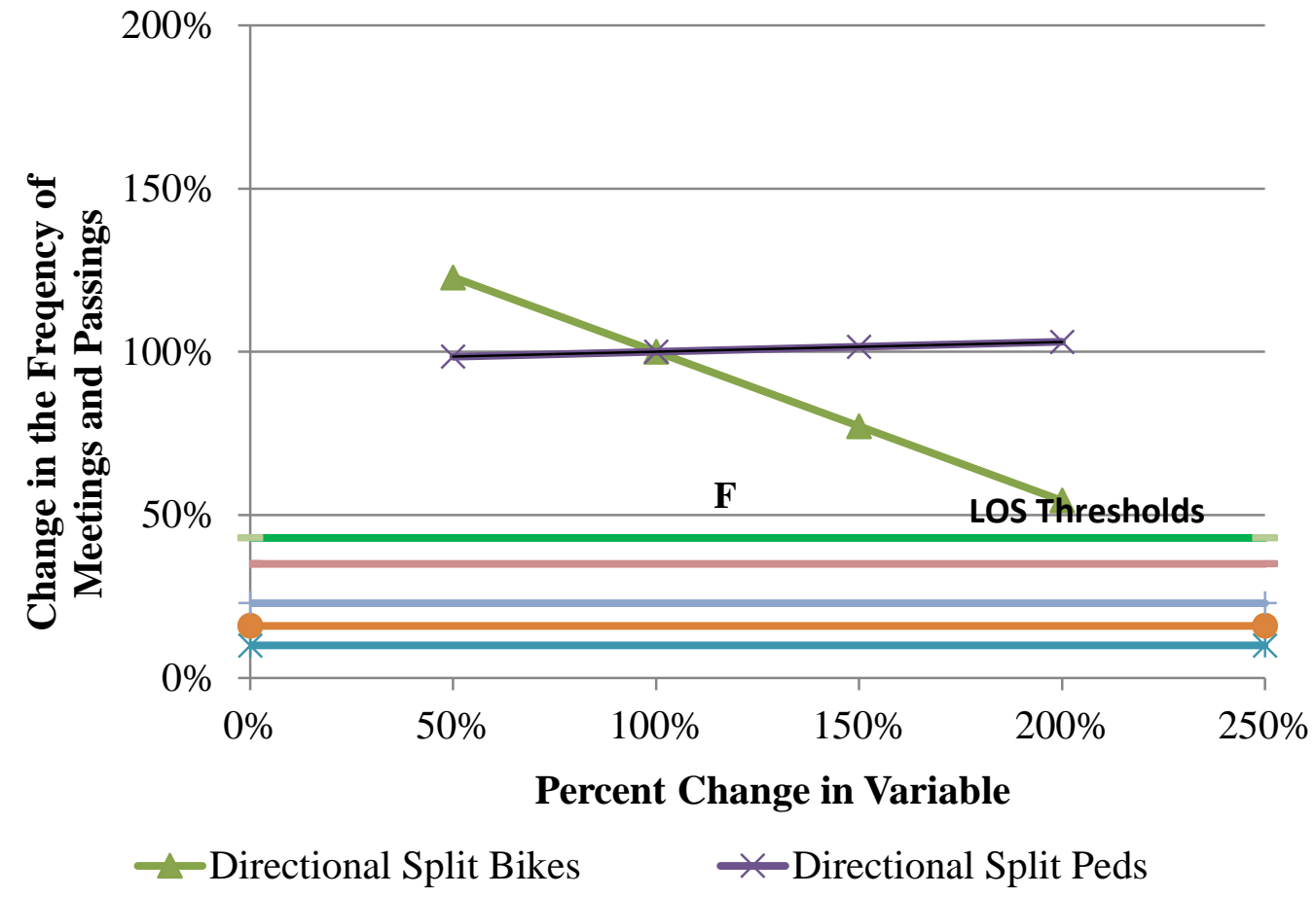

Figure 25: Sensitivity of Directional Splits for Bicycles and Pedestrians Volumes

In order to fall into a BLOS grade between A and E, a bicycle/pedestrian volume of no more than 480/0 will give a BLOS Score of A and 75/120 will give a BLOS score of E.

This method is an improvement to the previous methods; true directional splits can be used and there are separated BLOS thresholds for three lane paths. Using this HCM 2000 Method for shared off-street paths still give us a BLOS score of F for our offstreet shared sidewalk segments. 


\subsubsection{FHWA Shared Use Path Analysis Tool}

In 2006, the FHWA sponsored a study and the development of a shared use path workbook. The workbook was developed by The Toole Design Group. The variables needed include the width of the path, if the path has a center line or not, the directional volume for all users and the mode split. This model assumes a 50:50 directional user split on a shared path or trail (Hummer et al. 2006). This method is intended for recreational use than urban commuter traffic. Table 30 summarizes the segments to which the method can be applied and their base variables. BLOS thresholds are given in Table 31. These BLOS thresholds are applied in decending numerical order; all the methods evaulated thus far have had an assending value of frequency to apply LOS Scores. As illustrated in sensitivity plots in Figure 26, Figure 27 and Figure 28.

\section{Table 30: Shared Off-Street Path Segments and Base Values}

\begin{tabular}{ccccccc}
\hline Segment & $\begin{array}{c}\text { Path } \\
\text { width }\end{array}$ & Centerline & $\begin{array}{c}\text { Total } \\
\text { Bicycles }\end{array}$ & $\begin{array}{c}\text { Total } \\
\text { Pedestrians }\end{array}$ & $\begin{array}{c}\text { Bicycle } \\
\text { Mode } \\
\text { Split }\end{array}$ & $\begin{array}{c}\text { Pedestrian } \\
\text { Mode } \\
\text { Split }\end{array}$ \\
\hline 4 & 9 & Yes & & & & \\
5 & 10 & No & 975 & 100 & $90 \%$ & $10 \%$ \\
10 & 10 & No & & & & \\
\hline
\end{tabular}


Table 31: BLOS Thresholds for Shared Use Path Flow Analysis Tool (Hummer et al. 2006)

\begin{tabular}{cc}
\hline BLOS & Scores \\
\hline A & $\geq 4$ \\
B & 3.5 \\
C & 3 \\
D & 2.5 \\
E & 2 \\
F & $<2$ \\
\hline
\end{tabular}

Again, using base values in Table 30, all segments received an F BLOS grade.

\subsubsection{Sensitivity Analysis}

Sensitivity analysis was applied to all variables and is illustrated with BLOS thresholds in Figure 26, Figure 27 and Figure 28. Each variable was tested with all other variables held at the base values. The change in BLOS score with change in total volume and change in path with are shown in Figure 26. The base value for total volume is 1075 , 975 bicycle plus 100 pedestrians. Because the assumed directional volume split is 50:50, half of the total volume, 537 users was used in the worksheet. The BLOS thresholds are in the reversed order compared to the previous sensitivity plots. This is because the previous BLOS scores were based on frequency; the higher the frequency, the lower the score. These sensitivity plots compare changes in variables to a percent change in BLOS score; the higher the score, the better the conditions. Decreasing the 
volume $50 \%$ brought the BLOS score to E and dropping the volume to a $25 \%$ level brought the BLOS value to D. Increasing path width by $150 \%$ brought the BLOS to E.

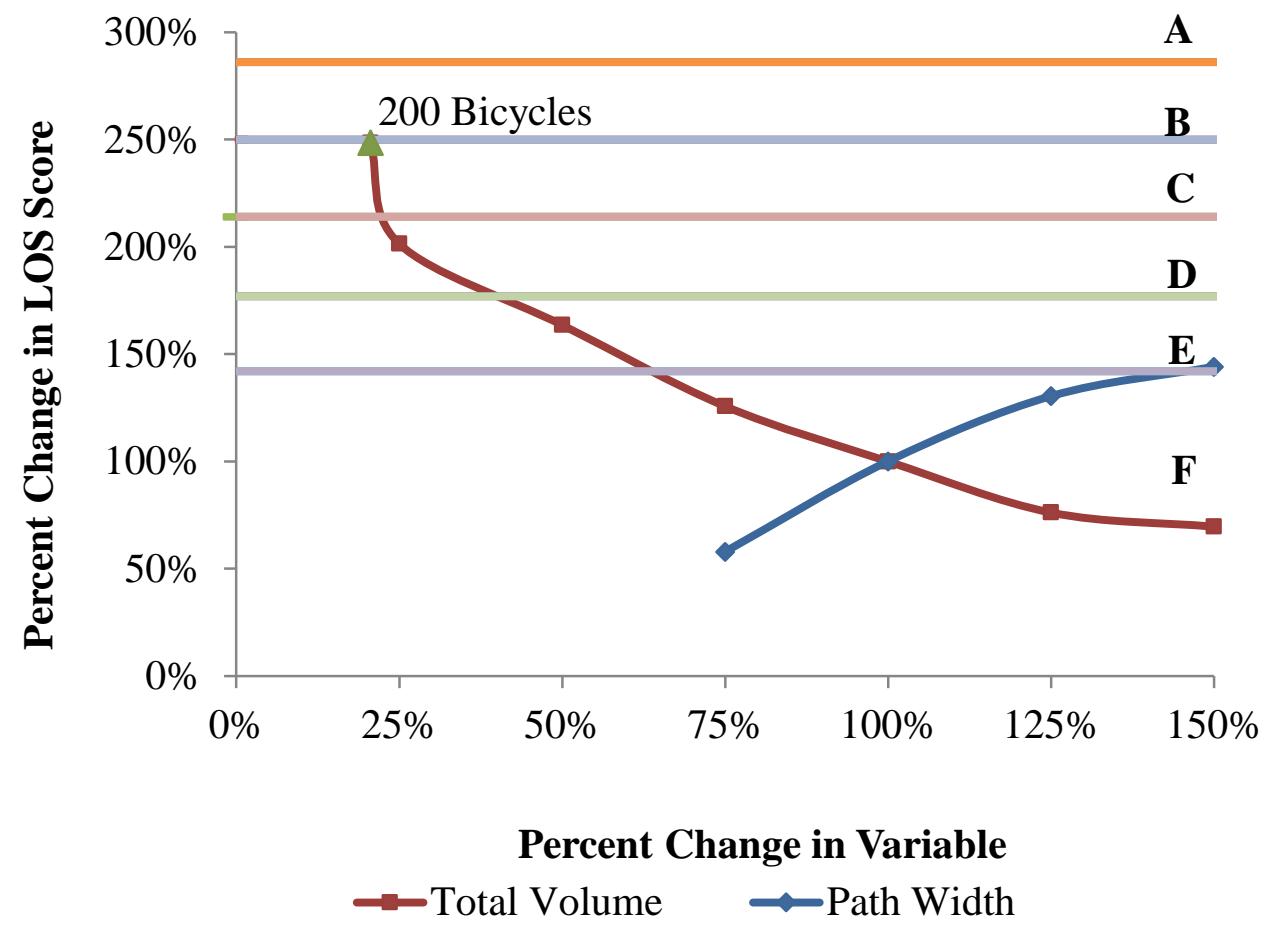

Figure 26: Percent Change in BLOS Score with Percent Change in Total Volume and Path Width

The worksheet allows for an unlimited combination of 5 modes; bicycle, pedestrians, runners, inline skaters, and child bicyclists. In order to test the sensitivity of all of these modes, pedestrians, runners, inline skaters, and child bicyclists were paired with cyclists and tested with various percent change in bicycle mode. The percent change was made from a base bicycle percent mode share of $90 \%$. Figure 27 displays the results of this analysis. The method is most sensitive to inline skaters relative to the other modes. 
However, as bicycles have a smaller mode share, inline skaters increase mode share and BLOS decreases again.

Bicycles versus pedestrians have a linear relationship, as bicycle mode share increases and pedestrian mode in decreases, BLOS improves. However when percent bicycle changes to $110 \%$ of base percentage of $90 \%$, or $99 \%$ mode share, BLOS Drops. A similar trend is developed with runners. Child bicyclists have the least amount of sensitivity, with a decrease in BLOS as child cyclists increase and bicycles decrease.

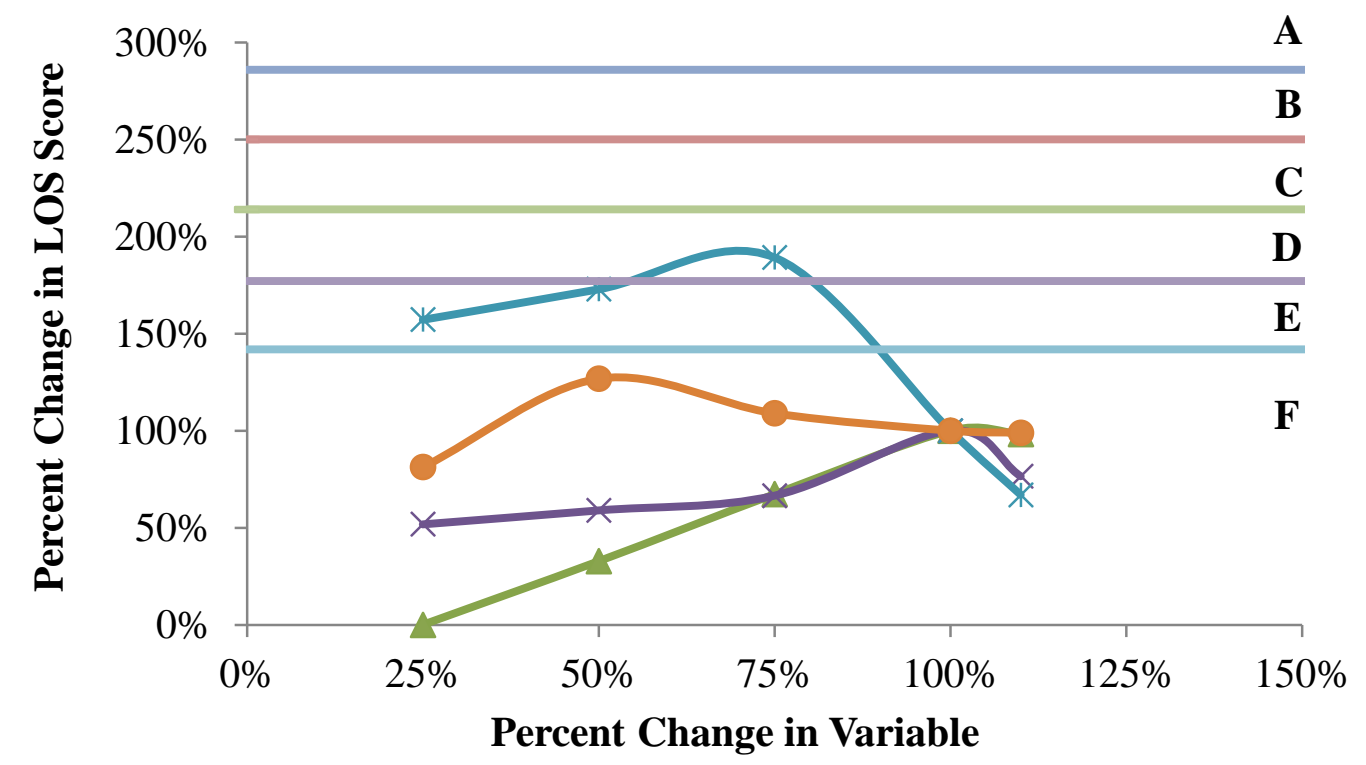
$\rightarrow$ Percent Bicycle vs. Peds
* Percent Bicycles vs Runners
*-Percent Bicycles vs Inline Skaters
- Percent Bicycles vs Child Bicyclists

\section{Figure 27: Percent Change in BLOS Score with Percent Changes in Bicycle Proportion versus Other Modes}

Figure 28 illustrates the impact that a painted center line has on BLOS. Our base case uses a center line. No centerline can increase a change in BLOS score by $20 \%$. 


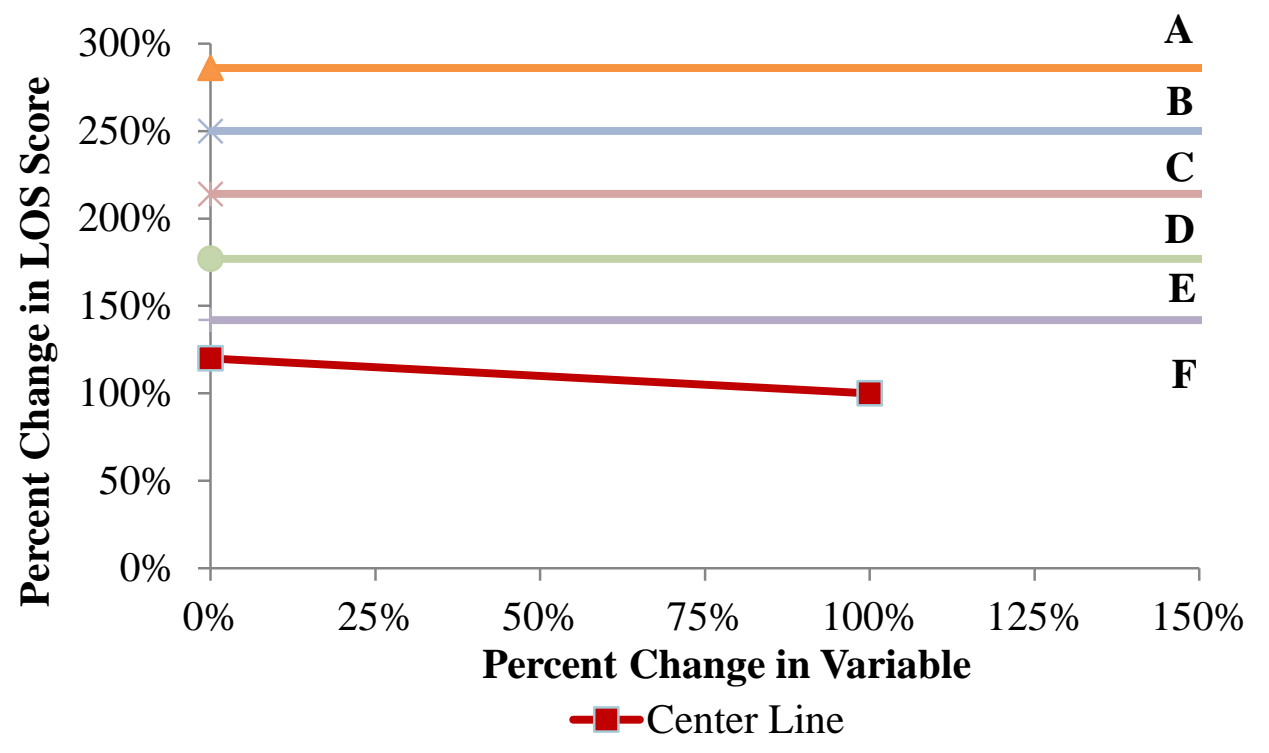

Figure 28: Percent Change in BLOS Score with Change in With or Without Center Line

The FHWA Shared Use Path Analysis Tool is intended for recreational path use. One of the advantages of this tool is that it makes a complicated method easy to use. Another advantage is that it considers more that bicycle and pedestrians; one of the reasons that this method is complicated. It also considers path width and presence of a center lane marking. The major drawback to this method is that it assumes a 50:50 directional split for all modes, which is not appropriate for our study area. This method has more sensitive BLOS thresholds than all previous methods described. However all base values and mode share splits received an $\mathrm{F}$ grade. 


\subsubsection{HCM 2010 method for BLOS for off street paths}

The most intensive method for determining Capacity BLOS is the HCM method for offstreet paths. This method is based on the framework developed by Botha, and is more flexible for calculating for different width paths and different volumes. The BLOS is determined by calculating three values using a cumulative distribution function: 1) the number of passings per minute, 2) number of meetings per minute and 3) the probability of delayed passings. These three values are then input in a spreadsheet developed by the University of Idaho using HCM 2010 methods.

An example problem will not be explicitly calculated, only the results calculated from the workbooks will be given. Only bicyclists and pedestrians were considered. Analysis will considered directional bicycle splits of 100:0, 99:1, and 97:3. For pedestrians, directional splits that were considered included 100:0, 90:10, 80:20, 70:30, 60:40, and 50:50. Default values for average speed and standard deviation are given for bicycles and pedestrians; $12.8 \mathrm{mph}$ with a standard deviation of $3.4 \mathrm{mph}$ and $3.4 \mathrm{mph}$ with a standard deviation of $0.6 \mathrm{mph}$ respectively. The segments evaluated are the same as the ones used in the other shared off-street path methods; 4, 5 and 10, shown in Figure 21. 
Table 32: Variables Used for HCM 2010 BLOS for off-street paths

\begin{tabular}{c|lc}
\hline Variable & $\begin{array}{c}\text { Default or } \\
\text { collected } \\
\text { data? }\end{array}$ & Values used \\
\hline $\begin{array}{c}\text { Hourly volumes by } \\
\text { direction per user }\end{array}$ & Collected & Peak volumes used \\
\hline $\begin{array}{c}\text { Average speed for each } \\
\text { mode }\end{array}$ & Default & $\begin{array}{c}12.8 \text { mph for bicycles } \\
\text { with SD of } 3.4\end{array}$ \\
& & $\begin{array}{c}3.4 \text { mph for pedestrians } \\
\text { with a SD of } 0.06\end{array}$ \\
Proportion of path users \\
presented by each mode
\end{tabular}

For each of the three segments, 4, 5 and 10, a table of scores, with varying pedestrian splits is given in Table 33. For each model, the bicycle directional split was 99:1 and paired with each of the pedestrian splits given in Table 32. Segment 4 received a score of $\mathrm{E}$ and segments 5 and 10 received a score of D. See Table 33. 
Table 33: BLOS Results for Segments 4, 5 and 10 Using HCM BLOS for Shared Off-Street Paths

\begin{tabular}{ccccccc}
\hline \multirow{2}{*}{ Segment } & \multicolumn{2}{c}{ Bicycle } & \multicolumn{2}{c}{ Pedestrian Directional } & & \\
\cline { 2 - 5 } & Directional Split & \multicolumn{2}{c}{ Split } & HCM & \multirow{2}{*}{ BLOS } \\
& $\begin{array}{c}\% \\
\text { Opposing }\end{array}$ & $\begin{array}{c}\% \\
\text { Subject }\end{array}$ & $\begin{array}{c}\% \\
\text { Opposing }\end{array}$ & $\begin{array}{c}\% \\
\text { Subject }\end{array}$ & & \\
\hline \multirow{2}{*}{$\mathbf{3}$} & 0.01 & 0.99 & 0.50 & 0.50 & 2.12 & $\mathrm{E}$ \\
& 0.01 & 0.99 & 0.60 & 0.40 & 2.13 & $\mathrm{E}$ \\
\hline \multirow{2}{*}{$\mathbf{5}$} & 0.01 & 0.99 & 0.50 & 0.50 & 2.59 & $\mathrm{D}$ \\
& 0.01 & 0.99 & 0.60 & 0.40 & 2.61 & $\mathrm{D}$ \\
\hline \multirow{2}{*}{$\mathbf{1 0}$} & 0.01 & 0.99 & 0.50 & 0.50 & 2.60 & $\mathrm{D}$ \\
& 0.01 & 0.99 & 0.60 & 0.40 & 2.58 & $\mathrm{D}$ \\
\hline
\end{tabular}

\subsubsection{Sensitivity Analysis}

Variables tested in the sensitivity model include bicycle and pedestrian volumes, length of segment, path width, center line, bicycle and pedestrian mean and standard deviation of speed, directional split for both bicycles and pedestrians, peak hour factor, and the mode share split between bicycles and pedestrians. The results are illustrated in Figure 29 through Figure 32. Each figure includes the thresholds of BLOS. Percent changes in bicycle and pedestrian volumes are plotted in Figure 29. The base data received a BLOS score of E. Bicycle volumes are more sensitive than pedestrian volumes in this BLOS method. A 50\% increase or decrease in bicycle volumes changes the BLOS grade one value, with higher volumes receiving poorer BLOS grades. 


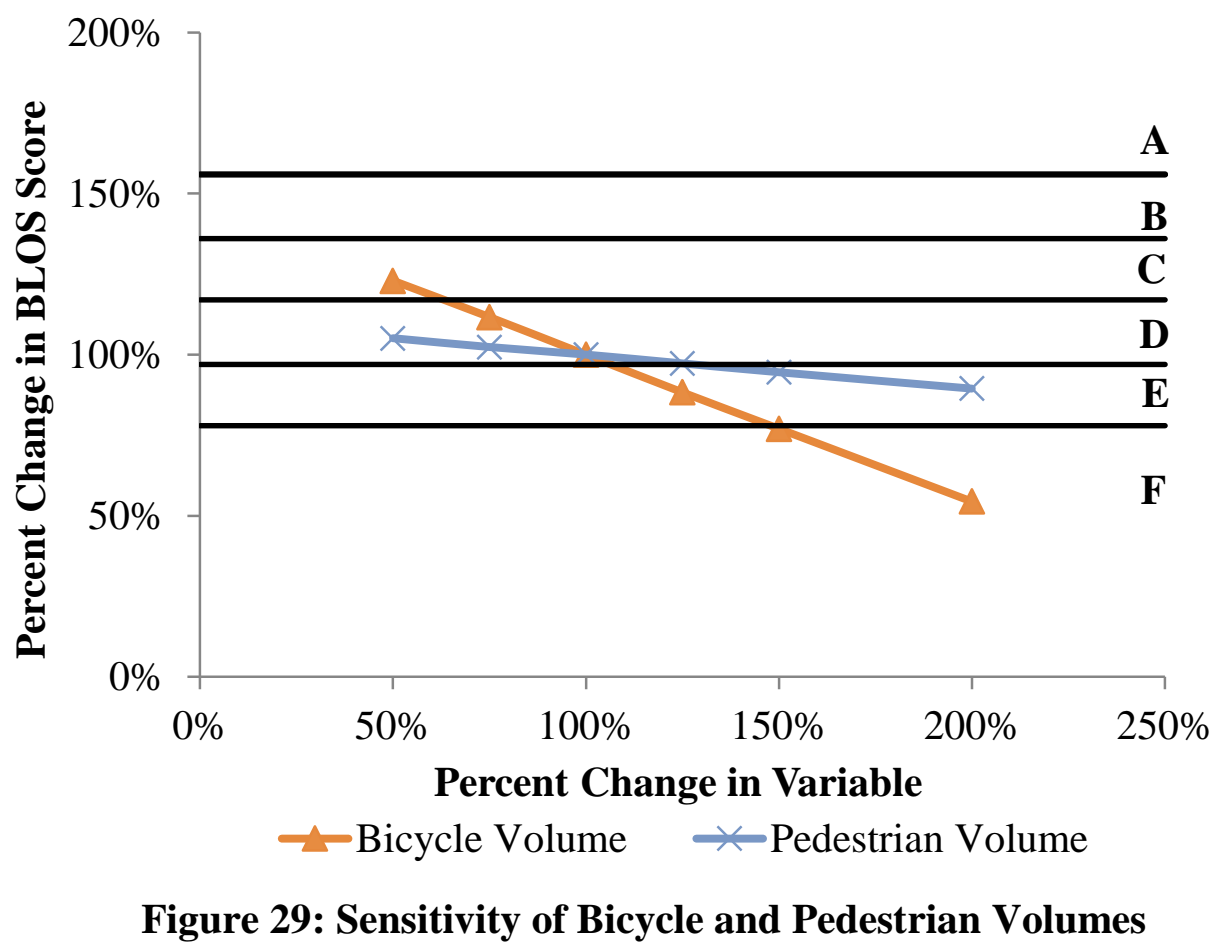

All geometric variables were plotted in Figure 30. The length of the segment has no direct impact of the BLOS score. The center line is a binary value of zero for no center line and a value of one for the presence of a center line. This plot illustrates that the addition of a center line will decrease the BLOS grade by one half. Path width is a sensitive variable in the model. This makes sense because path width has a large impact on the ability for users to maneuver around others when passing or meeting another. 


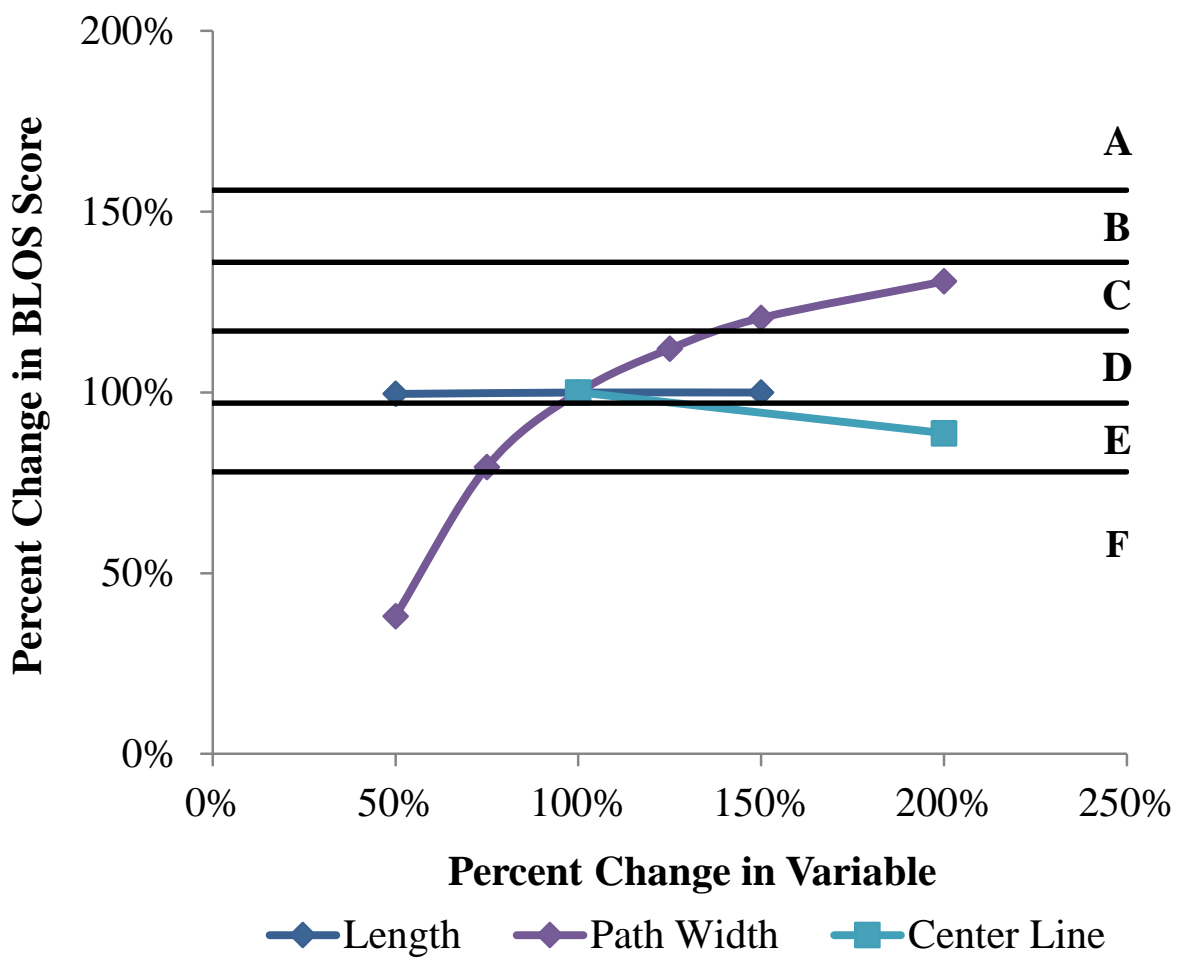

Figure 30: Sensitivity of Geometric Variables

The sensitivity of the method to percent change in the mean and the standard deviation for speed of bicycles and pedestrians are illustrated in Figure 31. The standard deviation of bicycle speed is a linear function with a negative slope that illustrates that if there is a larger variation of bicycle speeds, this will decrease the BLOS. The model is more sensitive to mean speed for bicycles is more sensitive at lower speeds and less sensitive at higher speeds; lower speeds contribute to lower BLOS scores. The model is also more sensitive to standard deviation of pedestrians at lower speeds and less at higher speeds. The mean speeds of pedestrians have a negative affect at lower speeds on the model. 


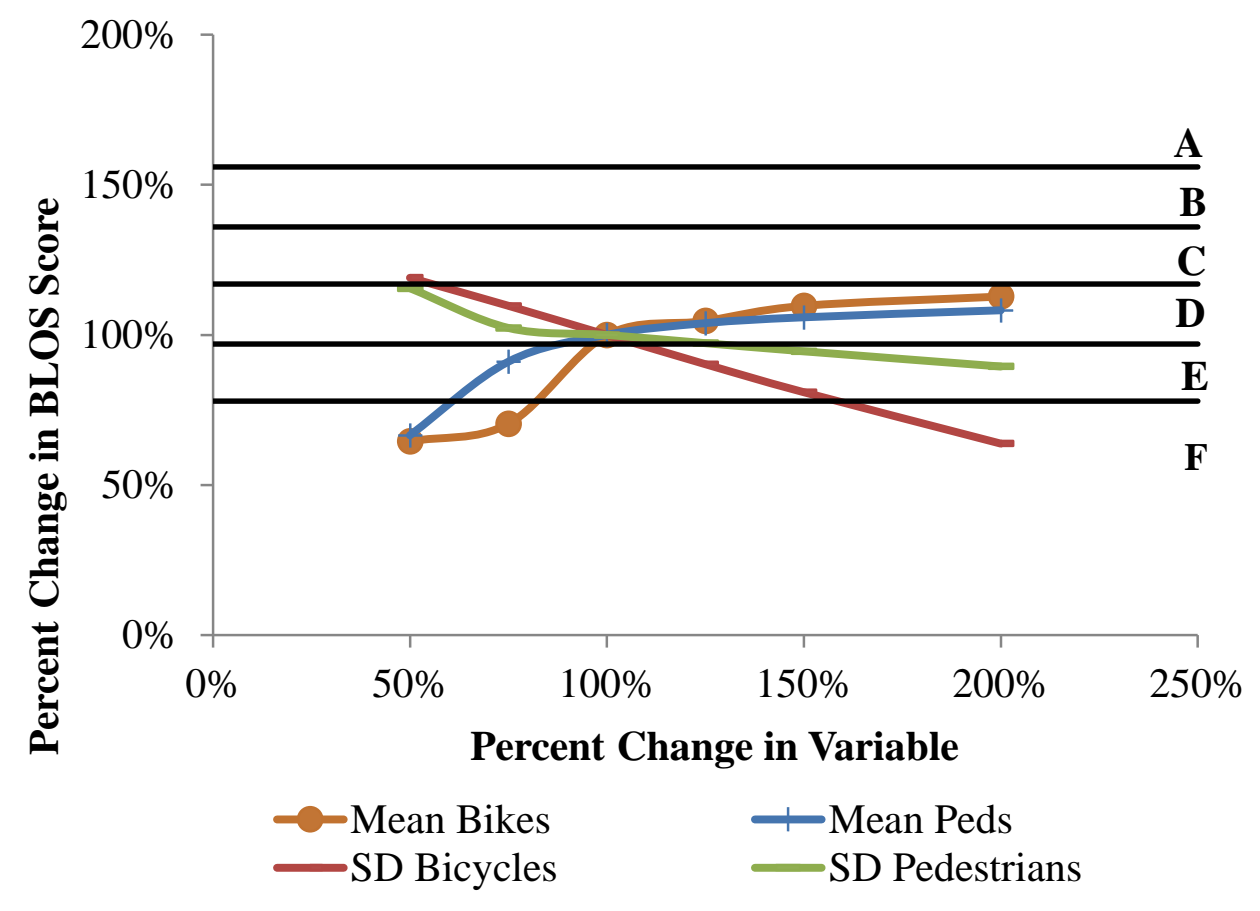

Figure 31: Sensitivity of Standard Deviation and Mean Speeds of Bicycles and Pedestrians

The remainder of the variables and their percent changes in BLOS scores versus change in the variable values is plotted in Figure 32. Changes in the percentage of bicycles traveling in the subject direction were modeled. With all other variables held constant including bicycle volumes, the directional volume was modeled at different percentages. The bicycle directional percentages in the subject: opposing directions were modeled at 99:1, 50:50 and 74:26 splits. These could not be modeled at change over $100 \%$. The same was done for pedestrians directions however the subject splits were modeled at 50:50, 75:25, 63:37, 37:63, 25:75 and 0:100. The wider range of directional splits for pedestrians was possible because the base value was 50\%; for 
bicycles it was 99\%. Pedestrian directional variation is not sensitive in this model. Bicycle directional variation is sensitive. This plot illustrates that BLOS score improves with a 50:50 directional split. This result is suspicious. The peak hour factor was also and modeled and shows that there is a minimal sensitivity for higher values in and more sensitivity for lower peak hour factors changes. The final variable that was modeled was the percent bicycles. This variable represents a change in bicycle mode share versus pedestrians. The base values for mode share were $90 \%$ for bicycles and $10 \%$ for pedestrians. The other two ratios that were modeled were $45 \%$ bicycles: $55 \%$ pedestrians and $67 \%$ bicycles: $33 \%$ pedestrians. The plot illustrates that a mode share of $55 \%$ for pedestrians and $45 \%$ for bicycles had a lower BLOS score than a $10 \%$ pedestrian and $90 \%$ bicycle mode split. This variable is relatively sensitive. 


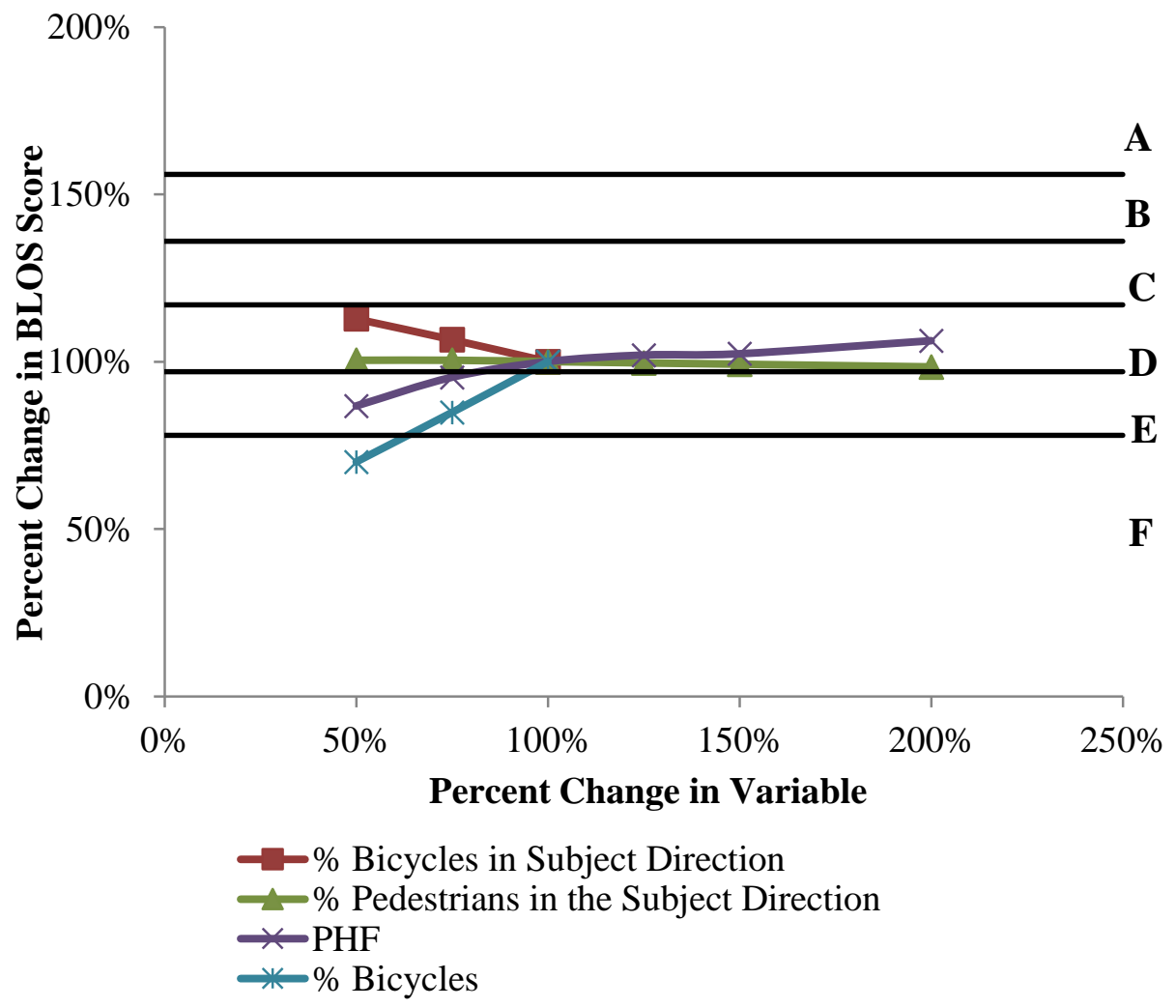

Figure 32: Sensitivity of Peak Hour Factor, Percent Bicycles and Pedestrians in Subject Direction, and the Percentage of Bicycles to Pedestrians

A summary of the BLOS scores for each method on each off-street method is given in Table 34. All methods gave a BLOS score of F except for the HCM 2010 method. 
Table 34: Summary of BLOS Scores for Off-Street Segments

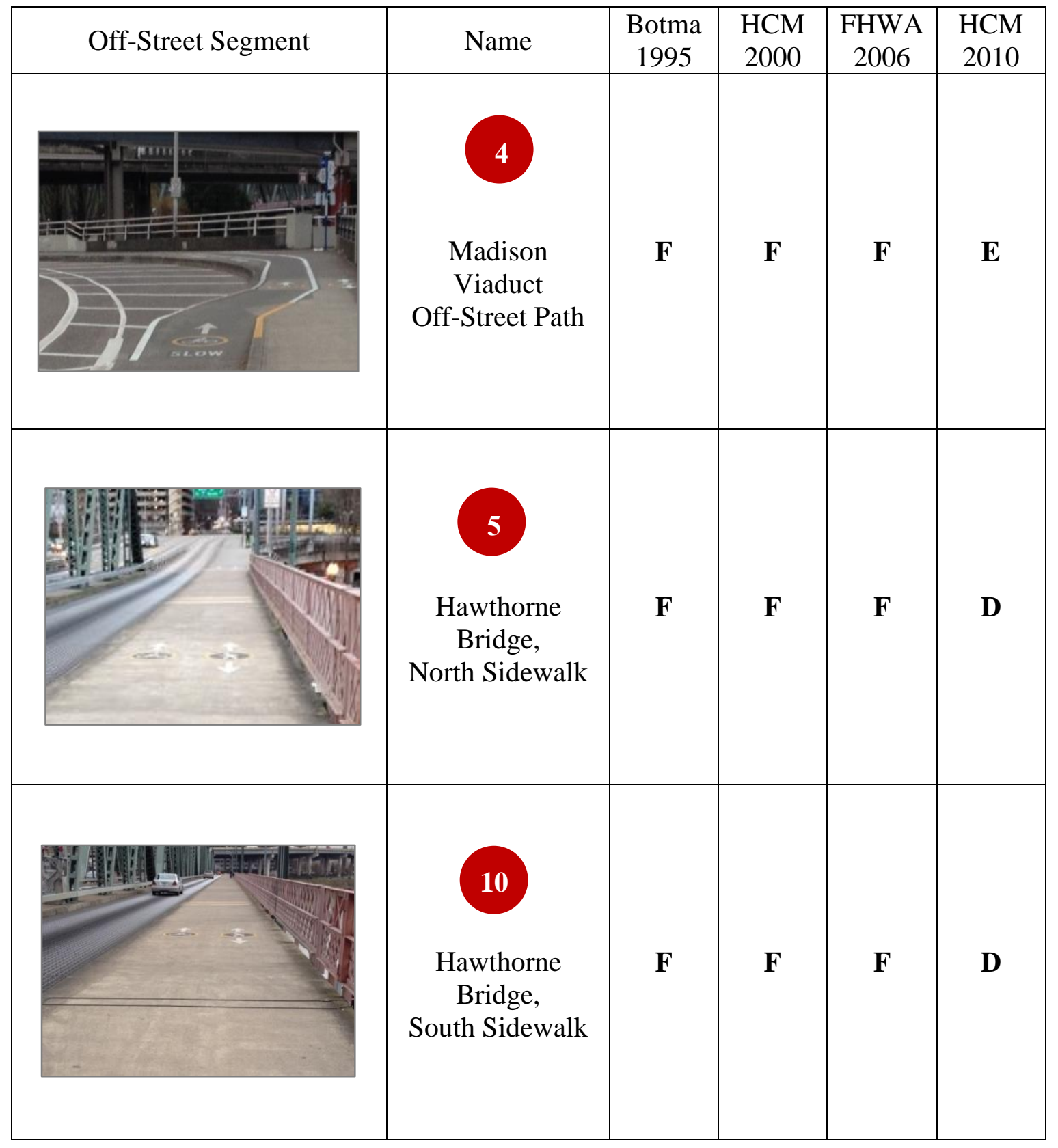




\subsection{Signalized intersections}

\subsubsection{HCM 2000 Signalized Intersections}

This was the only BLOS method found for intersections that uses bicycle volumes as an input. This method uses the measurement of control delay, in seconds per bicycle, to determine the BLOS score. First the capacity of the bicycle lane is estimated. It is recommended that at saturation flow rate of 2000 bicycles/hour be used. 


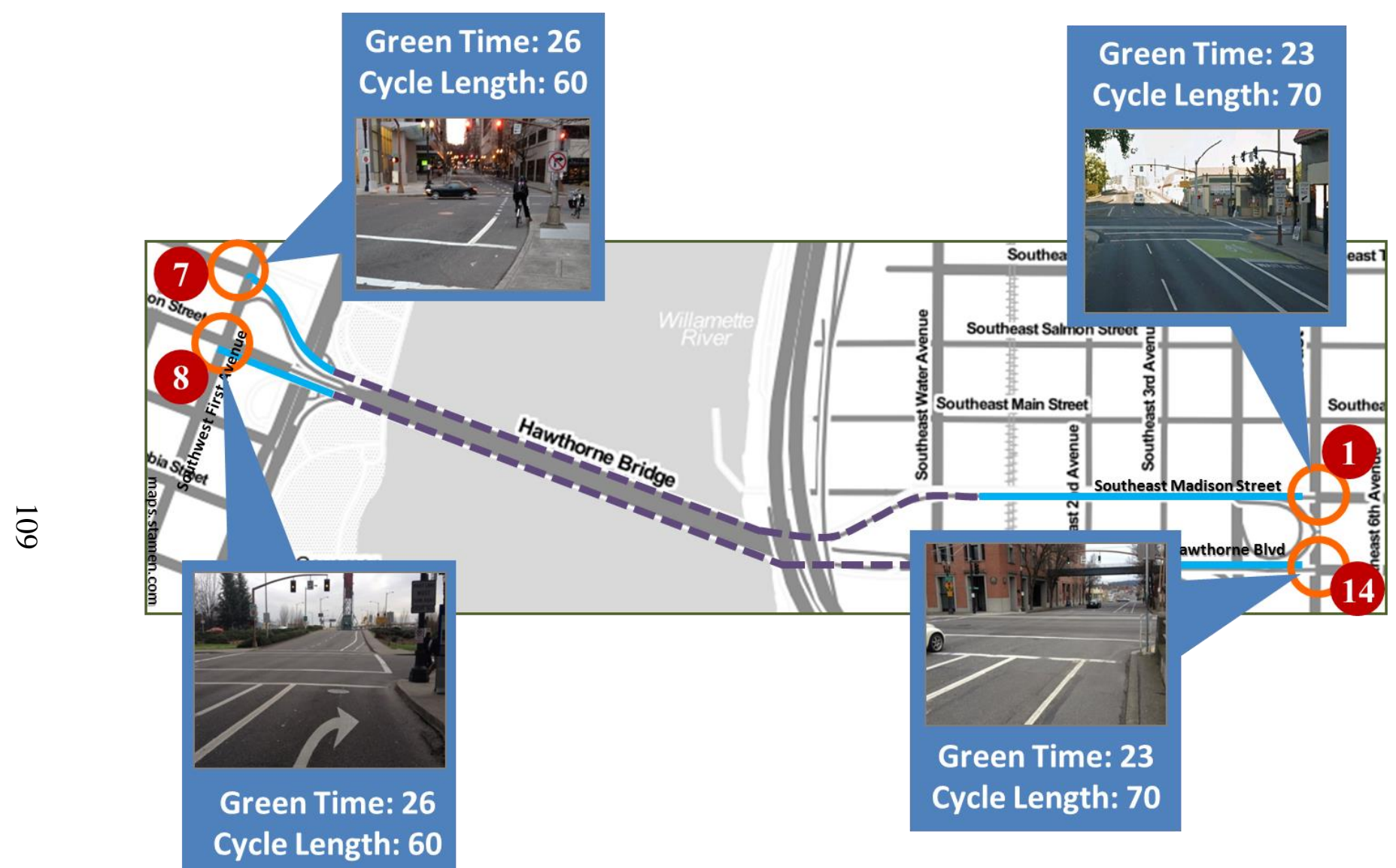

Figure 33: Signalized Intersection 
This method was tested on the four intersections in the study area; elements $1,7,8$, and 14. The results are given in Table 35. Intersections 1 and 14 are on the east end of the study area and received a BLOS grade of C. Intersections 7 and 8 are on the west, downtown end of the study area and received a BLOS grade B. 
Table 35: Summary of Intersection BLOS Variables and Results

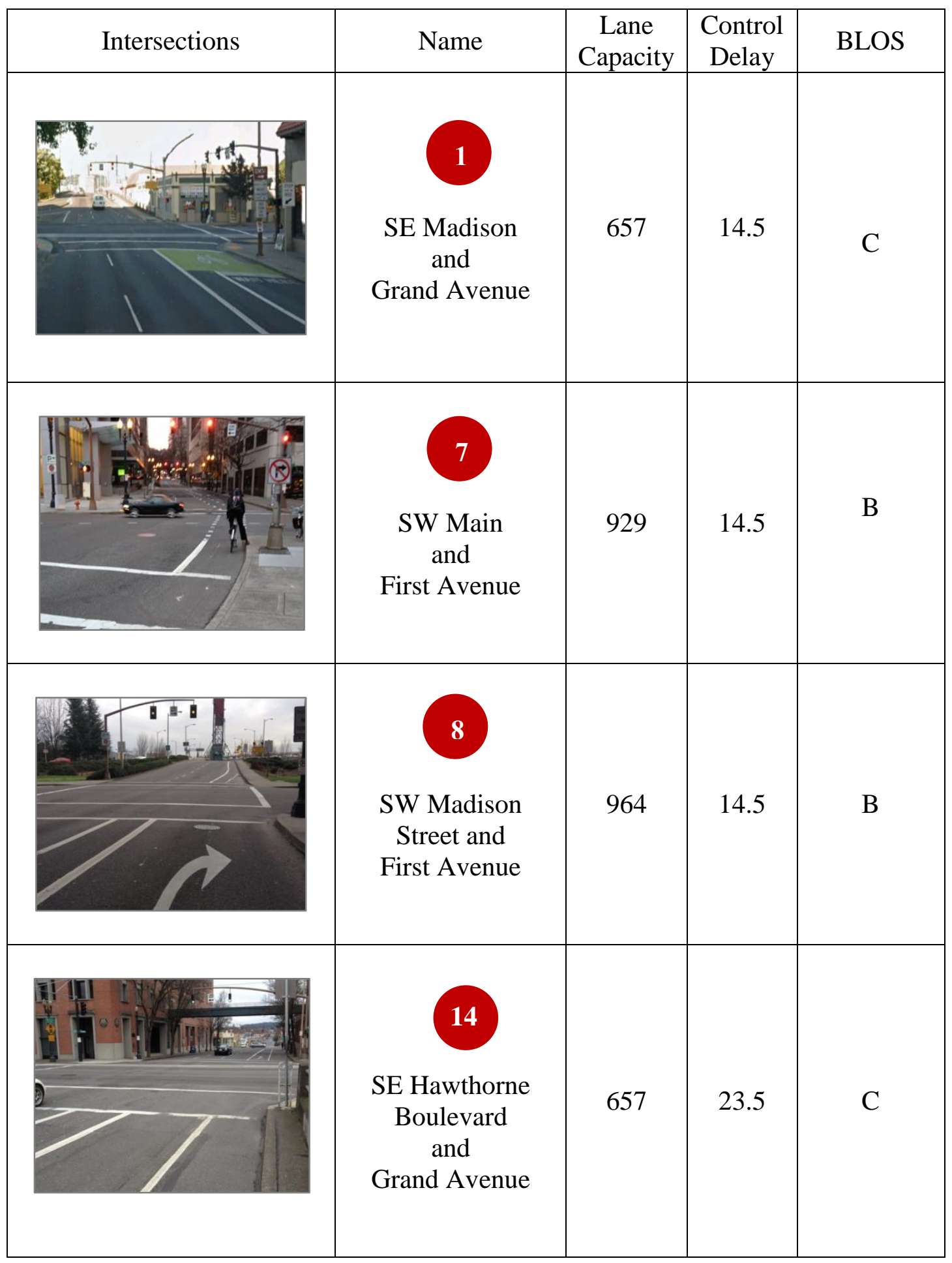




\subsubsection{Sensitivity Analysis}

Sensitivity analysis and BLOS on variables is illustrated in Figure 34 and Figure 35.

Figure 34 illustrates that saturation flow rate is not sensitive. More importantly, bicycle volume is not sensitive for higher volumes and is only slightly sensitive for lower volumes. The sensitivity of this intersection BLOS is greater compared to any of the segment models.

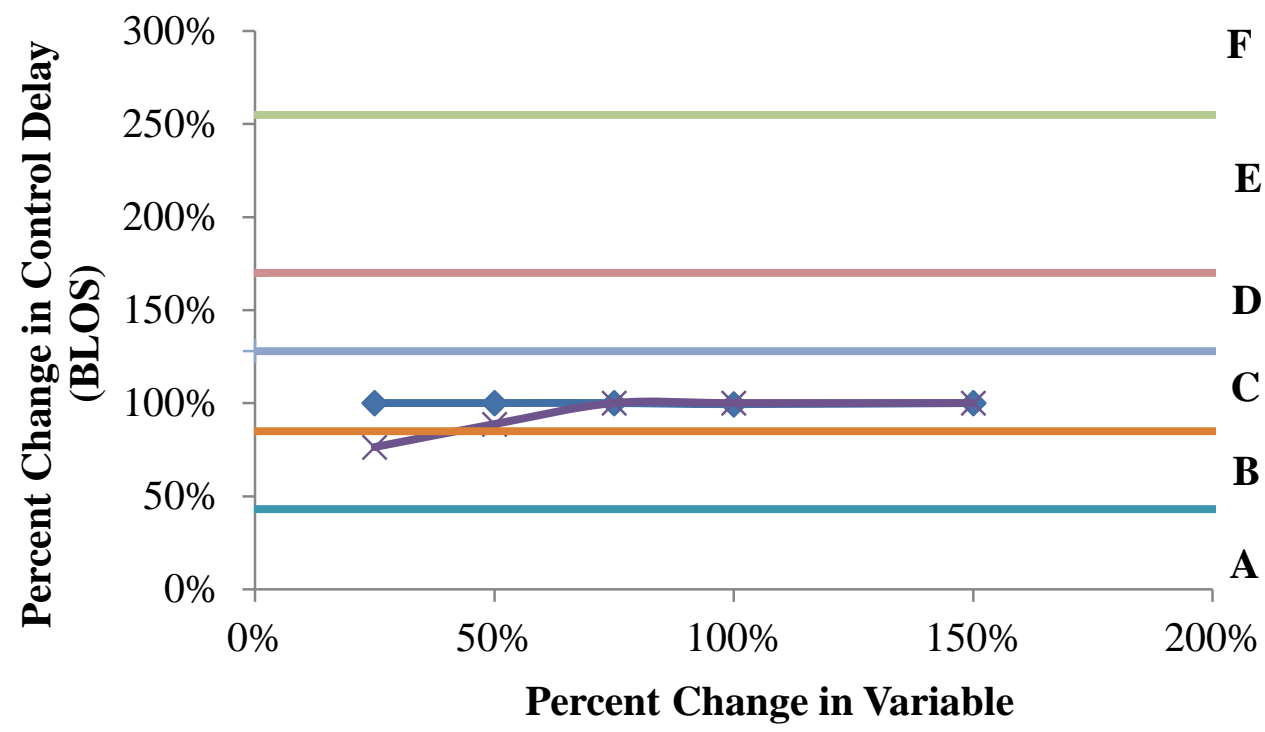

$\sim$ Saturation Flow Rate $\quad *$ Bicycle Volume

Figure 34: Sensitivity Analysis and BLOS Thresholds for Saturation Flow Rate and Bicycle Volume for Controlled Intersections

Figure 35 illustrates the sensitivity of the effective green time and the cycle length. As effective green time increases, the BLOS improves. As the cycle length increases, BLOS decreases. 


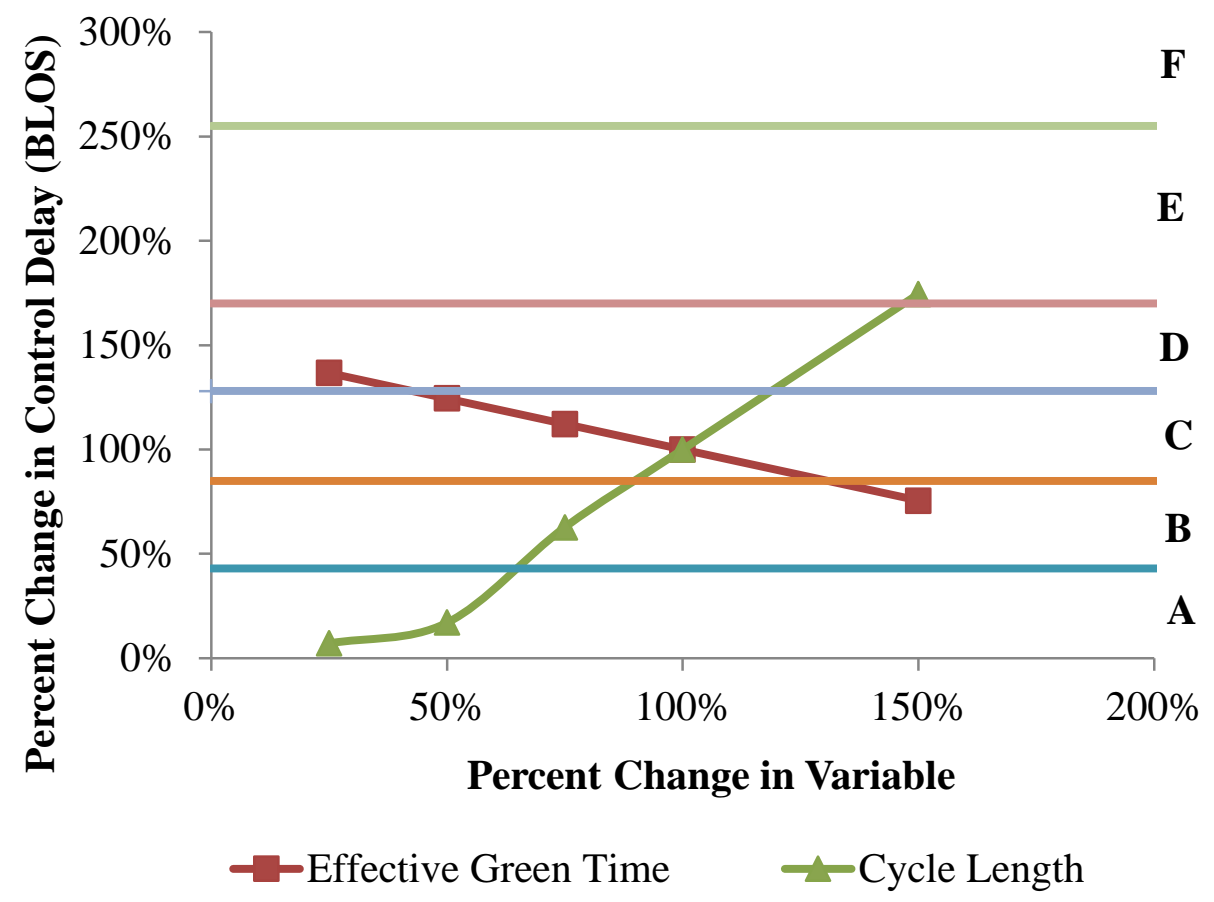

Figure 35: Sensitivity Analysis and BLOS Thresholds for Effective Green Time and Cycle Length . 
A summary of the BLOS grades for each segment is given in Table 36 . The shaded score boxes designate the locations that did not meet the general requirements of the method. For example, for LOS Bicycle Paths, segments 2, 6, 12 and 13 did not meet the path width requirement for the methods. Another example is segments 4, 5 and 10 did not have a 50:50 directional split. Less than 50, 18 out of 40 possible segment/ method combinations met the general requirements of the methods. Note that the conflict points 4 and 11 did not meet any of the requirements. The methods that were most applicable were the HCM 2010 paths method and the method for signalized intersections. However, bicycle volumes have very low sensitivity in the intersection model. A summary of the strengths and weaknesses of each of the methods is given in Table 37. Table 37 also gives a summary of the most significant variables in each BLOS model. 
Table 36: Summary of BLOS Methods and Scores for Each Segment/ Element Using Base Values

\begin{tabular}{|c|c|c|c|c|c|c|c|c|c|c|c|c|c|c|c|}
\hline Facility & Method & 1 & 2 & 3 & 4 & 5 & 6 & 7 & 8 & 9 & 10 & 11 & 12 & 13 & 14 \\
\hline \multirow{3}{*}{$\begin{array}{l}\text { On-Street } \\
\text { Facilities }\end{array}$} & Botma 1995 & & $\mathrm{E}$ & $\mathrm{E}$ & & & $\mathrm{E}$ & & & $\mathrm{E}$ & & E & E & $\mathrm{E}$ & \\
\hline & $\begin{array}{l}\text { Botma } 1995 \text { with } \\
\text { HCM Defaults }\end{array}$ & & $\mathrm{F}$ & $\mathrm{F}$ & & & $\mathrm{F}$ & & & $\mathrm{F}$ & & $\mathrm{F}$ & $\mathrm{F}$ & $\mathrm{F}$ & \\
\hline & HCM 2000 & & $\mathrm{~F}$ & $\mathrm{~F}$ & & & $\mathrm{~F}$ & & & $\mathrm{~F}$ & & $\mathrm{~F}$ & $\mathrm{~F}$ & $\mathrm{~F}$ & \\
\hline \multirow{5}{*}{$\begin{array}{l}\text { Off-Street } \\
\text { Facilities }\end{array}$} & Botma 1995 & & & & $\mathrm{~F}$ & $\mathrm{~F}$ & & & & & $\mathrm{~F}$ & & & & \\
\hline & $\begin{array}{l}\text { Botma } 1995 \text { with } \\
\text { HCM Defaults }\end{array}$ & & & & $\mathrm{F}$ & $\mathrm{F}$ & & & & & $\mathrm{F}$ & & & & \\
\hline & HCM 2000 & & & & $\mathrm{~F}$ & $\mathrm{~F}$ & & & & & $\mathrm{~F}$ & & & & \\
\hline & FHWA 2006 & & & & $\mathrm{~F}$ & $\mathrm{~F}$ & & & & & $\mathrm{~F}$ & & & & \\
\hline & HCM 2010 Paths & & & & $\mathrm{E}$ & $\mathrm{D}$ & & & & & $\mathrm{D}$ & & & & \\
\hline Intersections & HCM 2000 & C & & & & & & B & B & & & & & & $\mathrm{C}$ \\
\hline
\end{tabular}


Table 37: Summary of BLOS Methods that Include Bicycle Volumes as an Input

\begin{tabular}{|c|c|c|c|}
\hline Method & $\begin{array}{l}\text { Most } \\
\text { Sensitive } \\
\text { Variables }\end{array}$ & Strengths & Weaknesses \\
\hline
\end{tabular}




\begin{tabular}{|c|c|c|c|}
\hline Method & $\begin{array}{l}\text { Most } \\
\text { Sensitive } \\
\text { Variables } \\
\end{array}$ & Strengths & Weaknesses \\
\hline $\begin{array}{l}\text { HCM } 2000 \\
\text { Shared Off- } \\
\text { Street Paths }\end{array}$ & $\begin{array}{l}\text { Bicycle } \\
\text { volume } \\
\text { Directional } \\
\text { split for } \\
\text { bicycles }\end{array}$ & $\begin{array}{l}\text { Simple Equations } \\
\text { Accounts for directional } \\
\text { splits for bicycles and } \\
\text { pedestrians } \\
\text { BLOS thresholds for } \\
\text { both } 2 \text { and } 3 \text { lane paths }\end{array}$ & $\begin{array}{l}\text { Bicycle and pedestrian traffic volumes must be very low to } \\
\text { achieve a BLOS score of } \mathrm{E} \text { or better } \\
\text { BLOS threshold may be hard to achieve } \\
\text { Only meant for shared paths separated from motor vehicles }\end{array}$ \\
\hline $\begin{array}{l}\text { FHWA } \\
\text { Shared Use } \\
\text { Path Analysis } \\
\text { Tool }\end{array}$ & $\begin{array}{l}\text { Total volume } \\
\text { Path width } \\
\text { Percent } \\
\text { bicycles } \\
\text { versus } \\
\text { pedestrians }\end{array}$ & $\begin{array}{l}\text { Easy to use workbook/ } \\
\text { spreadsheet } \\
\text { Accounts for mode split } \\
\text { between bicycles, } \\
\text { pedestrians, runners, } \\
\text { inline skaters, and child } \\
\text { bicyclists. } \\
\text { Accounts for lane } \\
\text { markings on path and } \\
\text { path width }\end{array}$ & $\begin{array}{l}\text { Assumes a 50:50 directional split for all modes. } \\
\text { Only meant for shared paths separated from motor vehicles }\end{array}$ \\
\hline
\end{tabular}




\begin{tabular}{|c|c|c|c|}
\hline Method & $\begin{array}{l}\text { Most } \\
\text { Sensitive } \\
\text { Variables } \\
\end{array}$ & Strengths & Weaknesses \\
\hline $\begin{array}{l}\text { HCM } 2010 \\
\text { BLOS for } \\
\text { Shared Paths }\end{array}$ & $\begin{array}{l}\text { Path Width } \\
\text { Bicycle } \\
\text { Volumes }\end{array}$ & $\begin{array}{l}\text { Able to account for } \\
\text { mode share split among } \\
\text { many different modes. } \\
\text { Actual directional and } \\
\text { mode share split can be } \\
\text { modeled. } \\
\text { Some geometric } \\
\text { variables are included in } \\
\text { the model } \\
\text { Considered most } \\
\text { reliable method for } \\
\text { calculating BLOS for } \\
\text { shared paths }\end{array}$ & $\begin{array}{l}\text { Complex calculations; Difficult and time-consuming to } \\
\text { calculate } \\
\text { Only meant for shared paths separated from motor vehicles }\end{array}$ \\
\hline $\begin{array}{l}\text { HCM } 2000 \\
\text { Signalized } \\
\text { Intersections }\end{array}$ & Cycle length & Simple to Calculate & $\begin{array}{l}\text { According to the Latest HCM method not based on enough } \\
\text { evidence, research } \\
\text { Saturation flow rate and bicycle volumes are not sensitive }\end{array}$ \\
\hline
\end{tabular}




\subsection{INTERCEPT SURVEY}

In order to get a sense of how the BLOS scores compare with the expectations and perceptions of the users of the study area, an intercept survey was conducted. First, a preliminary pilot intercept survey was conducted. One month later, the actual intercept survey was administered.

Both surveys took place on the northwest side of the Hawthorne Bridge, near the Eco Counter Totem on Segment 6 . The survey was administered during a monthly event, Breakfast on the Bridges. Breakfast on the Bridges is a volunteer event held on the last Friday of each month from 7AM to 9AM. The purpose of the event is to reward people for commuting by bike. Coffee, fruit, and doughnuts are served. Respondents were approached to take the survey while stopping for coffee and snacks.

The pilot survey was administered on Friday, January 31, 2014 from 8AM to 9AM. The weather was wet but not raining, cloudy and approximately 45 degrees. Fifteen surveys were completed. The bicycle count on the bridge from 8AM to 9AM was 528. A copy of the Pilot survey is available in Appendix C. Respondents were asked to take the pilot survey and to give their feedback about the pilot survey. 
This initial pilot survey had fewer segments than the final number of segments used in the final survey. The area of study was only split into six segments; three in each direction; before the bridge, after the bridge, and on the bridge. The final study had 14 different segments/ elements. Respondent were asked their level of satisfaction in each of the segments.

Some useful information was gleaned from the pilot survey. The survey asked respondents, on a scale of 1-6 what their satisfaction biking in each of the areas (segments) was. These values were converted into a pseudo-BLOS score. Where a score of 1 was a BLOS F and a 6 was a BLOS A. All segments received an average pseudoBLOS grade between a C and a D-. However, the question only asked for overall satisfaction, not about bicycle capacity satisfaction.

Another question asked if they thought bicycle congestion was a problem in any of the segments. One of the respondents commented that he didn't think that bicycle congestion was a problem but that he welcomed bicycle congestion. The segment that had the most complaints about bicycle congestion was the north side of the Hawthorne Bridge. However, this is the segment that the respondents had just biked on before taking the survey. Four of the six segments they were asked about had not been biked on at the time of the survey; the memory of their previous experiences on the route would not be the same as for the two segment that they had just biked on. 
An improved and simplified final survey was administered at the next Breakfast on the Bridges on February 28. The weather was cloudy and dry. The temperature was 42 degrees. The bicycle traffic volume was 580 for the 8 AM to 9 AM hour. See final version of the survey in Appendix C. The goal was to collect 30 responses. However, only 16 surveys were completed.

Respondents were asked their route onto the bridge, demographic information, and what areas in the study area would they like to see improved. The purpose of this intercept survey was to see if capacity was affecting their bicycling experience. The main question asked' On the Hawthorne Bridge today, which best describes your riding experience?" They had six choices, A through F, and with each letter, a statement that describes each level of service:
A. Free flow, the path is all yours!
B. You can keep your speed but you must maneuver around bicycles and pedestrians a little
C. You have to change your speed a little to maneuver around bicycles and pedestrians
D. You have to change your speed to maneuver around other bicycles and pedestrians a lot!
E. Biking is difficult. It is hard to move around other bicycles and pedestrians
F. Forced to dismount your bike because there are too many obstacles on the route 
$67 \%$ of respondents came from SE Grand and Madison. 20\% came from the Esplanade ramp. 33\% were heading to SW First and Main. 27\% were heading to Waterfront Park, and $13 \%$ were going to Naito Parkway via the Waterfront Park trail.

\section{Table 38: LOS Grades from Intercept Survey}

\begin{tabular}{c|c}
\hline LOS Grade & \% of Respondents \\
\hline A & $20 \%$ \\
B & $47 \%$ \\
C & $27 \%$ \\
D & \\
E & \\
F & \\
\hline
\end{tabular}

Table 39: Segments that Respondents Would Like to See Improved

\begin{tabular}{c|cl}
\hline Segment & \% of respondents & Issues \\
\hline 4 & 20 & $\begin{array}{l}\text { Merging bicycles and pedestrians at ramp } \\
\text { from Esplanade Path } \\
\text { Weaving around pedestrians } \\
6\end{array}$ \\
& 20 & $\begin{array}{l}\text { Merging with vehicles } \\
\text { Bike lane drop } \\
\text { Narrowing bike } \\
\text { Merging with vehicles }\end{array}$ \\
\hline
\end{tabular}

Most respondents rode this route at least 4 times per week and considered themselves to be strong and fearless riders. $47 \%$ described their riding experience that morning to be a BLOS B, 27\% a BLOS of C, and 20\% a BLOS of A. There was not a BLOS score less 
than C. When applying the HCM 2010 method for bicycle paths for this hour of traffic with a volume of 580 bicycles per hour, the BLOS score was a C.

When asked what areas they would like to see improved, the segment/element that received the most responses was Element 7 at the intersection of SW first and Main. However, the area of improvement was right outside the study area. A bike lane drop is located in a highly congested area just west of the SW First and Main intersection. The next two elements that received requests for improvement were elements 4 and 6.4 is the conflict point at the esplanade ramp and 6 is the segment onto Main Street. There are no existing BLOS measures for measuring off-street path intersections such as the conflict point at the Esplanade ramp. Segment 6 concerns for bicyclists have to do with both bicycle congestion and merging left with high motor vehicle volumes and short left merging distance. There are also no measurements for merging with motor vehicle traffic.

This survey had many weaknesses. First, there were only 16 responses, which is a poor sample and not statistically sound. Second, most of the respondents are experienced commuters; therefore, it was not possible to understand what an acceptable level of congestion is. Third, although the respondents were asked questions about all of the segments in the corridor, but the segments that they had just rode on had a larger effect on their answers. 
One of the major issues with the survey is that not all respondents were familiar with the entire route. Some respondents used the shared path routes from or to the Esplanade and /or used the Waterfront park ramps. They were not familiar with the facilities on the viaducts.

Nevertheless, some interesting information was gleaned from the survey. First, from the pilot survey, overall the segment received an average psudo-BLOS grade of D. However this was not specific to traffic congestion. Second, in the main intercept survey, almost half of respondents gave the corridor a BLOS grade of B. Third, One respondent thought that bicycle traffic congestion is a good thing. 


\subsection{DISCUSSION}

The main purpose of this thesis was to summarize the state of BLOS for capacity methods and how applicable the methods are on bicycle facilities with high bicycle traffic flows. The focus of this research was to find methods that incorporate bicycle volumes to calculate BLOS capacity and traffic flow and to apply them to existing bike facilities that have periods of high bicycle traffic volumes.

The methods that most closely resembled BLOS capacity measures were methods that calculate the delay caused by passings and meetings of cyclists and other users on path segments separated from motor vehicle traffic. The method is called hindrance and was developed by Botma in the Netherlands in 1995. The hindrance method was intended for bicycle and bicycle and pedestrian paths separated from motor vehicles. Except for the one method found for intersections, all other methods found for were built on Botma's hindrance method.

Only one method was found that calculated BLOS using bicycle volumes for on-street bicycle facilities. This method, recommended by the FHWA, is a simplified version of the hindrance method in one direction applied to on-street one-way bike lanes. However, the method was not included in the HCM 2010 because of lack research and evidence that the method was applicable to on-street bike lanes (HCM 2010). Therefore, there is currently no method recommended for determining BLOS for capacity for on-street bike lanes. In this study, a bicycle volume of 975 yielded a LOS score of F. However, with a 
smaller standard of deviation in bicycle speeds of $0.9 \mathrm{mph}$ and a higher mean speed of $12.8 \mathrm{mph}$ the method yielded a score of $\mathrm{C}$.

It was recommended that the Botma hindrance method only be applied to bike paths that have a two lane width path between 1.5 and 2 meters wide. With these criteria, half of the one-way bike lanes did not meet the requirements of the method. Another weakness is that method, in terms of a determining BLOS for bike lanes, is that the road geometry and facilities were different for each segment. However, these were not considered in the oneway bike paths method.

For the one-way bicycle path methods, the sensitivity relationships for bicycle volumes and bicycle standard deviation were positive and linear; as bicycle volumes or bicycle standard deviation increased, the value of the frequency of passings and increased by the same percentage. For higher values of bicycle mean speed, the relationship was negative and linear. As mean speed decreased, the less sensitivity and effect it had on the overall frequency score. For a bicycle volume of 975 with a standard deviation of $1.9 \mathrm{mph}$, the BLOS was an E.

Another limit of the one-way path method is that it was only developed for a two lane path. It would not be possible to calculate the BLOS for one, three, or larger configurations with existing BLOS methods for bicycle paths. For evaluating capacity on a bike lane, lane width may be an important variable for relieving bicycle congestion. However, no such methods have been researched or developed. Additionally, each 
segment will have its own unique mean speed base on road slope and constraints. Mean bicycle speed can be measured but it is not data that is commonly collected for bicycles. This method may be adequate for on-street bike lanes but there are many gaps in the methods that need to be addressed.

Most of the methods for BLOS capacity are for off- street shared paths. Three of the segments/elements were used to evaluate this method; the Hawthorne Bridge sidewalk segments of 5 and 10 and the shared sidewalk of Segment 4. However, these methods are intended for recreational paths, not the constrained shared sidewalks located on that are used in this study. All methods for off-street paths are based on Botma's LOS method for off-street shared paths. This method assumes a directional split of 50:50 for all modes. The bicycle mode split on the Hawthorne Bridge is close to 100:0. Directional split is important because meetings and passings have different hindrance times and are the main criteria for BLOS in these methods. When directional splits for pedestrians were measured for this project, it was found that two-thirds of pedestrians walk in same direction as bicycles and vehicles but the other third travel in the opposite direction. During one peak hour count, $80 \%$ of pedestrians walked in the same direction as bicyclists, not $50 \%$ as the methods assume. Therefore, the segments did not meet the requirements of the methods. The thresholds for BLOS are unattainable with the conditions the study area. This was observed in the analysis. Those methods that assumed a directional mode share of 50:50 and had path width requirements yielded BLOS scores of $\mathrm{F}$. 
The HCM 2000 developed a version of the Botma method that allows for assigned directional split for all modes and can be used for two or three lane paths. However, all shared sidewalks in the study area received a BLOS grade of F. The sensitivity test for the HCM 2000 method revealed that bicycle volumes had the greatest sensitivity. This method was also not included in the 2010 version of the HCM for not enough evidence or research to conclude that this is an appropriate method. For our study area, realistic values of volumes did not garner BLOS scores higher than an F.

An FHWA worksheet was developed to calculate BLOS for shared paths. This worksheet is also based on Botma's work. This method uses the 50:50 directional split constraint but it includes bicycles, pedestrians, runners, inline skaters, and child cyclists; clearly this method is designed for recreational shared paths. Because of the directional path constraint, this method was also not applicable to our study area on the Hawthorne Bridge. When applying the variables for this method, it yielded a BLOS score of F. Again, volumes were the most sensitive variable.

The latest method in the HCM 2010 for off street paths allows for an unlimited number of user types and directional splits. The main drawback of this method is that it difficult and time consuming to calculate. The method requires a cumulative distribution calculation based on the length of the path and must be calculated separately for each mode interaction. This could probably be remedied with the development of a workbook or program that will calculate the cumulative probability functions within the method. The BLOS values for the Hawthorne Bridge were a D and Segment 3 received an E score. 
These values seem more reasonable compared to the three other methods. The variables that are most sensitive were bicycle volume, path width, standard deviation of bicycle speeds and lower mean speeds. The HCM 2010 method for paths may not be designed for high volume shared sidewalks in constrained areas, like a bridge, but it may be a good foundation to develop a better off-street shared path model for BLOS capacity measures.

In the case of intersections, one method uses bicycle volumes. However, the model was not sensitive to bicycle volumes. Capacity, or saturation flow rate, is a variable in this method. A default value of 2000 bicycles per hour is used. However there has not been much research or agreement on what constitutes the capacity for bicycles in the US. This method was also dropped from the HCM 2010 for inadequate research and validation. It was the only method found that utilized bicycle volumes to calculate BLOS capacity at intersections.

A summary of the intercept survey found that respondents were concerned most about segments 7: the intersection of SW $1^{\text {st }}$ and Main, Segment 6: the transition from the Hawthorne Bridge to SW Main Street, and conflict area 4: the Esplanade Ramp. All of these facilities were fresh in the minds of the cyclists. They were all located nearest the survey location. However, each of these segments/elements has legitimate safety and comfort issues that need to be addressed. Another issue with the survey is that the respondents were seasoned riders. The expectations of these riders may be different than those that rarely or never ride; those that we will need to attract if we are to increase bicycle mode share to $30 \%$ of trips. 
It must also be noted that methods have only been found for off-street bicycle only paths, off-street shared paths, and intersections. No methods exist for the growing variety of bicycle facilities such as bicycle boulevards, cycle tracks and bike boxes.

A bicycle projection estimation for the Hawthorne Bridge was carried out. To address this objective, population, household survey data, and bicycle counts for the Portland Metro area were used to develop an estimated 2030 bicycle traffic projection for Portland, and in particular for the Hawthorne Bridge. If estimated 2030 bicycle mode share goals are reached, Hawthorne Bridge bicycle volumes would increase by $230 \%$ with an estimated peak hour volume between 2,200 and 5,300 bicycles per hour. These values are higher than estimations of bicycle capacity saturation rates of between 2,000 and 3,500 per hour and confirm that capacity measures should be developed. Note that bicycle volumes below capacity will also cause delay. One of the tradeoffs for those that choose to use a bicycle over motor vehicle use is that, although the travel time tends to be slower on a bicycle, delay during the trip is low due to lower traffic volumes. If we want to encourage more people to cycle and keep the current cyclists choosing to cycle, than it would be wise for transportation agencies avoid bicycle delay. A measurement such as BLOS for capacity will help transportation officials mitigate and plan for future mitigation of bicycle traffic.

In summary, it was found that a bicycle capacity method will become a useful tool as bicycle mode share and bicycle volumes increase to meet future climate change and transportation planning goals. However, the existing models for BLOS capacity are not 
appropriate for bicycle facilities with periods of high bicycle traffic flows and will have to be developed. 


\subsection{CONCLUSION}

This study has revealed gaps in existing BLOS capacity measures and found that the existing BLOS models are not applicable to most bicycle facilities with high bicycle traffic flow such as on-street bike lanes and intersections. For many types of emerging bicycle facilities, such as bicycle boulevards and cycle tracks, no bicycle capacity or traffic flow measures have been developed. It has also been demonstrated that bicycle mode share is projected to increase drastically in the next 20 years due to aggressive planning goals as a strategy to curb climate change and traffic congestion. Yet, there have been no plans to develop a system to mitigate bicycle capacity and traffic flow.

Level of service measures are commonly used to measure all modes of traffic. It is recommended to use the current BLOS framework metrics for measuring bicycle congestion so that the integration of bicycles into overall multi-modal traffic evaluation is seamless. It is also recommended that BLOS for bicycle facilities with high bicycle flow be addressed through research and the development of a new BLOS methodology.

Initial research is needed in the areas of bicycle flow and capacity. Capacity guidelines for the urban, American context need to be developed. As previously discussed, An A level of capacity in China is an F level of service for Germany.. It is time to develop new guidelines that describe acceptable levels of bicycle capacity in the US.

In addition, it is recommended that variables that are statistically significant for a BLOS capacity measure for the urban context be investigated including geometric variables, 
bicycle speed and standard deviation for different facilities. Also, pedestrian, transit, and motor vehicle variables should be tested for significance in affecting bicycle capacity.

This study has also revealed that the best methods are those which can accommodate varying differentials of facilities and different levels of available data. Research is ripe for developing workbooks and programs that can more easily determine BLOS capacity and allow users to refine or customize the accuracy of the results. New default values also need to be researched and established.

The motivation for this study was to investigate what bicycle levels of service measures exist and if they are necessary. This study brings to light the necessity of BLOS Capacity measures in areas where bicycle mode share are increasing. BLOS Capacity measures will be a useful tool for transportation engineers and planners to mitigate future bicycle traffic congestion and to forecast possible bicycle capacity problems in the same way that they use these measures to mitigate motor vehicle traffic. If transportation agencies want to meet the future planning goals for emissions and traffic congestion then they should not ignore bicycle capacity issues. There are already many obstacles to attracting new bicycle riders. Bicycle traffic congestion and delay will not only discourage potential riders but decrease existing bicycle ridership. BLOS capacity and traffic flow measures will be a necessary tools for transportation planning in the near future. 


\section{REFERENCES}

AASHTO. Draft AASHTO Guide for the Planning, Design, and Operation of Bicycle Facilities. American Association of State Highway and Transportation Officals 2010.

Allen, D., Rouphail, D., Hummer, J., and Milazzo, J. Operational Analysis of Uninterrupted Bicycle Facilities. In Transportation Research Record: Journal of the Transportation Research Board, No.1636, TRB, National Research Council, Washington D.C., 1998, pp. 29-36.

Asadi-Shekari, Z., M. Moeinaddini, and M.Z.Shah. Non-Motorized Level of Service: Addressing Challenges in Pedestrian and Bicycle Level of Service. Transport Reviews, Vol.33 (2), 2013, pp.166-94.

Botma, H. Method to Determine Level of Service for Bicycle Paths and PedestrianBicycle Paths.In Transportation Research Record: Journal of the Transportation Research Board, No.1502, TRB, National Research Council, Washington D.C., 1995, pp. 38-44.

Callister, D., and M. Lowry. Tools and Strategies for Wide-Scale Bicycle Level-ofService Analysis. Journal of Urban Planning and Development, Vol 139 (4), 2013, pp. 250-57.

Carter, P., M. Núñez, S. Peters, J. Campbell, F. Martin, L. Raykin, and R. Milam. Complete Enough for Complete Streets? Testing the Sensitivity of HCM 2010 Multimodal Level of Service under Conditions of Change. Presented at the $92^{\text {nd }}$ Annual Meeting of the Transportation Research Board, Washington, D.C., 2013.

City of Portland and Multnomah County. Climate Action Plan 2009. Portland: City of Portland and Multnomah County. 2012.

Dowling, R. G., D. Reinke, A. Flannery, P. Ryus, M. Vandehey, T. Petritsch, B. Landis, N. Rouphail, and J. Bonneson. 2014. NCHRP Report 616: Multimodal Level of Service Analysis for Urban Streets. Transportation Research Board, Washington D.C., 2008

Elias, Aaron. 2010. Key Factors Affecting Multimodal Level Of Service. Dowling Associates, Oakland, 2010

FHWA. 1998. The Bicycle Compatibility Index: A Level of Service Concept, Implementation Manual. FHWA. http://safety.fhwa.dot.gov/tools/docs/bci.pdf. Accessed March 17, 2014.

Fong, Winnie. 2013. "The (D)evolution of Bicycling and Bikeshare in China and Beijing." Bikeshare. November 19, 2013.http://bikeshare.com/2013/11/can-bikeshare-make-beijing-part-of-the-kingdom-of-bicycles-again/.Accessed Feb. 10, 2014

Geller, Rodger . What does the Oregon Household Activity Survey Tell Us About the Path Ahead for Active Transportation in the City of Portland? City of Portland, Portland. 2013 
Fruin, John. "Designing for pedestrians." Public Transportation United States (1992). Hummer, J., N. Rouphail, J.L. Toole, R.S. Patten, R. J. Schneider, J.S. Green, R.G. Hughes, and S.J. Fain Fain. Evaluation and Safety, Design, and Operation of Shared-Use Paths, Final Report. Final Report FHWA-HRT-05-137. Federal Highway Administration., U.S Department of Transportation, Washington D.C. 2006.

Jensen, Søren. Pedestrian and Bicyclist Level of Service on Roadway Segments. In Transportation Research Record: Journal of the Transportation Research Board No. 2031 TRB, National Research Council, Washington D.C, 2007, pp. 43-51.

Jensen, Søren. Pedestrian and Bicycle Level of Service at Intersections, Roundabouts, and Other Crossings. Presented at the $91^{\text {nd }}$ Annual Meeting of the Transportation Research Board, Washington, D.C., 2012.

Kang, L., Y. Xiong, and F. L. Mannering. Statistical Analysis of Pedestrian Perceptions of Sidewalk Level of Service in the Presence of Bicycles. In Transportation Research Part A: Policy and Practice No. 53 (July), TRB, National Research Council, Washington D.C, 2013, pp.10-21.

Landis, B., V. Vattikuti, and M. Brannick. Real-Time Human Perceptions: Toward a Bicycle Level of Service. In Transportation Research Record: Journal of the Transportation Research Board. No.1578 (-1) TRB, National Research Council, Washington D.C 1997, pp.119-26.

Li, Z., W.Wang, P. Liu, and D. R. Ragland. 2012. "Physical Environments Influencing Bicyclists' Perception of Comfort on Separated and on-Street Bicycle Facilities." In Transportation Research Part D: Transport and Environment No. 17 (3) TRB, National Research Council, Washington D.C, 2012, pp. 256-61.

Lowry, M., D. Callister, M. Gresham, and B. Moore. Using Bicycle Level of Service to Assess Community-Wide Bikeability. Presented at the $91^{\text {nd }}$ Annual Meeting of the Transportation Research Board, Washington, D.C., 2012.

Metro. 20 and 50 Year Regional Population and Employment Range Forecasts. Portland: Metro. 2009

Parks, J., A. Tanaka, P. Ryus, C. Monsere, N. McNeil, and M. Goodno. Assessment of Three Alternative Bicycle Infrastructure Quality-of-Service Metrics. In Transportation Research Record: Journal of the Transportation Research Board No.2387 (-1), 2013, pp.56-65.

Patten, R.S., R.J. Schneider, J.L. Toole, J.E. Hummer, and N.M. Rouphail. Shared-Use Path Level of Service Calculator- A User's Guide. FHWA-HRT_05-138. FHWA, U.S Department of Transportation, 2006.

PBOT. "Portland Bicycle Plan for 2030. Strategic Implementation Plan". Portland Bureau of Transportation. Portland, 2010.

Petritsch, T., B. Landis, H. Huang, P. McLeod, D. Lamb, W. Farah, and M. Guttenplan. Bicycle Level of Service for Arterials. In Transportation Research Record: Journal of the Transportation Research Board . No. 2031 (-1): 2007, pp. 34-42. 
Portland Bureau of Transportation. 2012. "2011 Bicycle Counts Report”. Portland: Portland Bureau of Transportation.

Schweppe, E. Legacy of a Landmark: ISTEA After 10 Years. Public Roads, December. 2001.https://www.fhwa.dot.gov/publications/publicroads/01novdec/legacy.cfm. Accessed May 14, 2014

State of Florida Department of Transportation. 2013 Ouality/ Level of Service Handbook. State of Florida Department of Transportation. 2013.

http://www.dot.state.fl.us/planning/systems/programs/sm/los/pdfs/2013\%20QLO S\%20Handbook.pdf. Accessed March 22, 2014

TRB. 2000. Highway Capacity Manual, HCM 2000. Transportation Research Board. http://sjnavarro.files.wordpress.com/2008/08/highway_capacital_manual.pdf.

TRB. Highway Capacity Manual HCM 2010. 3 vols. Transportation Research Board, Washington D.C. 2010 


\section{APPENDIX A: 2030 BICYCLE VOLUME ESTIMATES}

In order to meet the goals of the Portland 2030 Plan, bicycle mode share needs to increase to 25\% (PBOT 2010). Bicycle mode share in the City of Portland is currently $6.2 \%$. The Portland metro area is projected to grow at a rate of $1.37-1.7 \%$ annually by 2030.This means that the current population of the Portland Metro Area will grow from 603,000 to between $826,110-1,025,100$ by 2030 (Metro 2009).

Mode share is the percent of daily trips using a particular traffic mode type. Daily trips are estimated by multiplying the number of households in an area by the average number of daily trips, which is currently estimated at 9.21 household trips per day. The number of households in Portland in 2011 was estimated to be 269,781 . The projected number of households in in Portland in 2035 is 402,000. Using a growth rate model, the estimated household population would be 369,947 in 2030, illustrated in Figure a.

One objective of this research was to determine if BLOS capacity measures are needed today or in the future. To address this objective, population, household survey data, and existing bicycle counts for the Portland Metro area were used to develop a 2030 bicycle traffic projection for Portland, and in particular for the Hawthorne Bridge. If projected bicycle mode share goals are reached, Hawthorne Bridge bicycle volumes would increase by $230 \%$ with an estimated peak hour volume between 2,200 and 5,300 bicycles per hour. These values are higher than estimations of bicycle capacity saturation rates of between 2,000 and 3,500 per hour (Allen et al. 1998). Using this example of a high bicycle traffic corridor, it is reasonable to assume that in the future there will be 
additional locations that will experience similar traffic congestion and confirm that capacity measures should be developed.

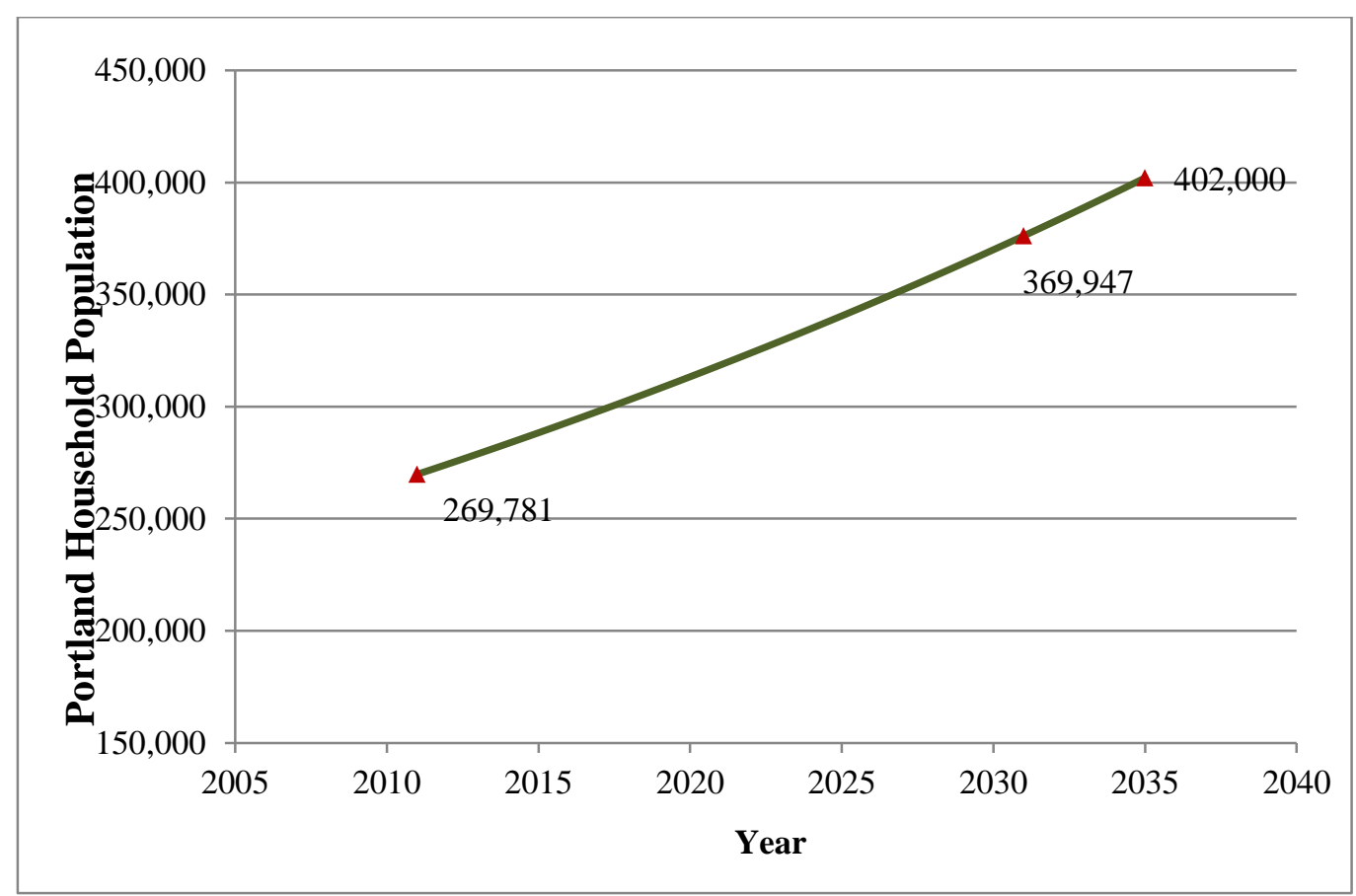

Figure a. Projected Growth of Portland Households

If the estimated 2030 households are multiplied by the current average daily trips per household of 9.2, daily trips in 2030 Portland are equal to 3,403,512 trips per day. If Portland reaches its goal of a $25 \%$ bicycle mode share, then there will be an estimated 850,878 bicycle trips per day. Using the same method with an estimated 2012 household population of 274,302 , the number of trips in 2012 that constitute $6.2 \%$ of daily trips is $156,462$. 
The 2012 Average Annual Daily Traffic (AADT) for bicycles on the Hawthorne Bridge was 4,364 (collected from PBOT EcoCounter Totem Site). The AADT was calculated from averaging all the daily volumes of the year. Dividing the 2012 bicycle AADT of 4,364 on the Hawthorne Bridge by the $6.2 \%$ bicycle mode daily trips of 156,462 , an estimated $2.8 \%$ of bicycle trips are taken on the Hawthorne Bridge. Assuming that only the household population and mode share of bicycles increases to $25 \%$ in 2030 , all else equal, the number of daily trips on the Hawthorne Bridge could be 369,947 households* 9.2 HH trips per day* 0.25 bike mode share* 0.028 on Hawthorne Bridge.

$$
=23,824 \text { AADT }
$$

If the peak hour in 2030 is distributed the same as in 2010, then the estimated peak hour volume would be 4,176 .

Table a. Current and Projected Bicycle Volume Estimations

\begin{tabular}{c|cc}
\hline Year & $\mathbf{2 0 1 2}$ & $\mathbf{2 0 3 0}$ \\
\hline Estimated Households & 275,000 & 370,000 \\
$\begin{array}{c}\text { Number of Daily Trips } \\
\text { (Households *9.2 Daily Trips) }\end{array}$ & $2,500,000$ & $3,400,000$ \\
Bicycle Mode Share & $6.2 \%$ & $25 \%$ \\
Number of Bike Trips & 156,000 & 850,000 \\
$\begin{array}{c}\text { Hawthorne Bridge AADT, } \\
\text { based on a 2.8\% of Bike Trips }\end{array}$ & 4,300 & 24,000 \\
Peak Hour Volume & & 4000 \\
\hline
\end{tabular}




\begin{tabular}{c|cc}
\hline Volume Estimation with & $(1,833)$ & 10,062 \\
58\% Diverted to Tilikum Bridge & & 2,234 \\
$\begin{array}{c}\text { Estimated Peak Hour Volume after } \\
\text { Tillikum Bridge Opening }\end{array}$ & $(407)$ & \\
\hline
\end{tabular}

Portland is building a bicycle, pedestrian, and transit only bridge that will be completed in 2016. The Tilikum Bridge is located less than one quarter mile south of the Hawthorne Bridge. Bicyclists who use the Hawthorne Bridge today may be diverted to the Tilikum Bridge.

The following is a very rough estimate of possible bicycle volumes in the future. A bicycle count in the vicinity of the Tilikum Bridge, on a popular commute and recreational trail, the Springwater Corridor, would be a good estimate of bicycle traffic that could be diverted by the Tilikum Bridge. In 2008, the bicycle AADT on the Springwater Corridor was 2543 (Portland Bureau of Transportation 2012). See Figure b. This is $58 \%$ of the bicycle traffic on the Hawthorne Bridge. Even if the Tilikum Bridge takes 58\% of the Hawthorne Bridge traffic, which is an overestimation of the actual traffic that will be diverted, the AADT on the Hawthrone bridge would be about 10,000 bicyclists; A 230\% increase from current bicycle volume. If the same daily percentage of bicycle travel during the peak hour in 2030 is the same as today with the diversion of $58 \%$ of the bicycle traffic to the Tilikum Bridge, then the estimated average peak traffic volume would be 2,234 bicycles per hour. Bicycle capacity estimates for a one lane bicycle path are between 2,000 and 3,500 bicycles per hour (Allen et. al 1998). Note that even though the Hawthorne Bridge is ten feet wide, it is a 140 
shared facility with pedestrians. During peak hours bicycle travel is often limited to one lane due to pedestrian use of the bridge.

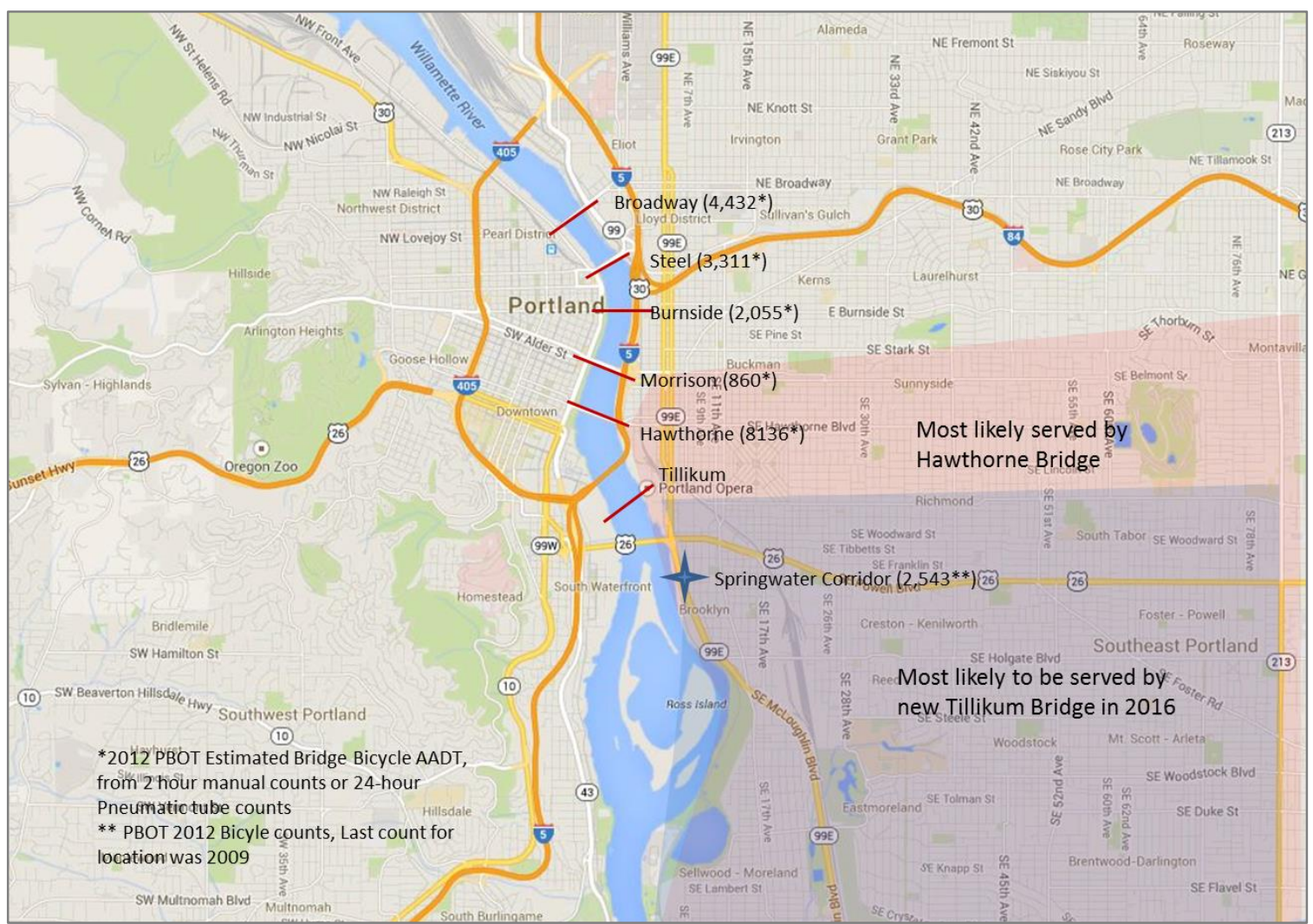

Figure b. Bridge Bicycle Counts and Projected Bridge Use. Image from Google Maps 


\section{APPENDIX B. PILOT SURVEY}

P Portland State

Please answer the following questions

about your biking satisfaction in these areas around the Hawthorne Bridge

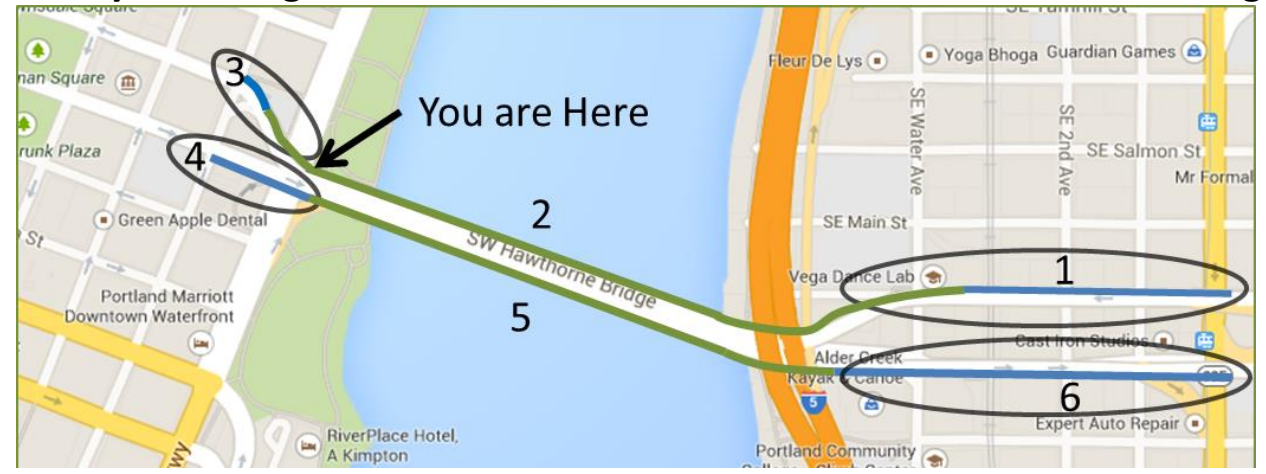

My satisfaction biking in these areas (Circle answer):

Location

Terrible!

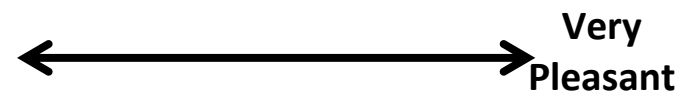

\begin{tabular}{|lllllll}
\hline $\mathbf{1}=$ Grand Ave to Bridge & 1 & 2 & 3 & 4 & 5 & 6 \\
\hline $\mathbf{2}=$ North side of Bridge & 1 & 2 & 3 & 4 & 5 & 6 \\
\hline $\mathbf{3}=$ Bridge to SW 1st Ave & 1 & 2 & 3 & 4 & 5 & 6 \\
\hline $\mathbf{4}=$ SW 1st to Bridge & 1 & 2 & 3 & 4 & 5 & 6 \\
\hline $\mathbf{5}=$ South Side of Bridge & 1 & 2 & 3 & 4 & 5 & 6 \\
\hline $\mathbf{6}=$ Bridge to Grand Ave & 1 & 2 & 3 & 4 & 5 & 6
\end{tabular}

Do you think bicycle congestion is a problem in any of these areas? YES NO If yes, which areas?
Gender
M
$\mathbf{F}$
TG

$\begin{array}{llllll}\text { Age } & \text { under } 18 & 18-35 & 36-50 & 50-65 & \text { Over } 65\end{array}$

Thank you for your feedback! Other comments welcome on back 


\section{APPENDIX C: INTERCEPT SURVEY}

1. Which way did you get here? (circle answer)

1. SE, Grand and Madison (bike box)

2. Spring water Corridor from the south

3. Esplanade from the North

4. Other, How?

2. Which way are you going now?

1. Waterfront Park, North

2. Waterfront Park, South

3. Naito Parkway

4. $1^{\text {st }}$ and Main

5. Other, how?

3. How often do you take this route?

\begin{tabular}{|l|l|l|}
\hline Per week? & Per day? & Per month? \\
\hline & & \\
& & \\
\hline
\end{tabular}

4. As a cyclist, do you consider yourself to be:

1. Very confident! I can ride on any street

2. Confident, I am comfortable riding if there is a bike lane

3. I am only comfortable riding on off-street paths or streets with low traffic volumes

5. On your route approaching and on/off the Hawthorne Bridge, what areas would you like to see improved the most? See map, write down number(s) or describe.

6. On the Hawthorne Bridge today, which best describes your riding experience?

A. Great! I can ride at the speed I want!

B. I can keep my desired speed but must maneuver around bicycles and pedestrians a little or let other faster riders pass me

C. I have to reduce my desired speed a little to maneuver around bicycles and pedestrians or to let other faster riders pass me

D. I have to reduce my desired speed a lot to maneuver around other bicycles and pedestrians or to let other faster riders pass me!

E. Biking is difficult. It is hard to maneuver around other bicycles/pedestrians or faster riders that want to pass me

F. I am forced to stop or nearly stop because there are too many bicycles/pedestrians on the bridge

7. What age range do you belong to?

\begin{tabular}{|l|c|c|c|c|}
\hline Under 18 & $18-35$ & $36-50$ & $51-65$ & Over 65 \\
\hline
\end{tabular}

8. What is your gender?

\begin{tabular}{|l|l|l|}
\hline $\mathrm{M}$ & $\mathrm{F}$ & Other \\
\hline
\end{tabular}

